Aimée Maria Valente da Silva

Estudos sobre a recuperação do titânio contido no rejeito da concentração de magnetita

Dissertação de Mestrado

Dissertação apresentada ao Programa de Pósgraduação em Engenharia de Materiais e de Processos Químicos e Metalúrgicos da PUC-Rio como requisito parcial para obtenção do grau de Mestre em Engenharia de Materiais e de Processos Químicos e Metalúrgicos.

Orientador: Prof. Eduardo de Albuquerque Brocchi Co-orientador: Prof. Ivan Guillermo Solórzano Naranjo 


\section{Estudos sobre a recuperação do titânio contido no rejeito da concentração de magnetita}

Dissertação apresentada como requisito parcial para obtenção do grau de Mestre pelo Programa de Pós-graduação em Engenharia de Materiais e de Processos Químicos e Metalúrgicos da PUC-Rio. Aprovada pela Comissão Examinadora abaixo assinada.

Prof. Eduardo de Albuquerque Brocchi Orientador Departamento de Engenharia Química e de Materiais - PUC-Rio

Prof. Ivan Guillermo Solórzano Naranjo Co-orientador Departamento de Engenharia Química e de Materiais - PUC-Rio

Prof. Fernando Antonio Freitas Lins Centro de Tecnologia Mineral - CETEM

Prof. Rodrigo Fernandes M De Souza Departamento de Engenharia Química e de Materiais - PUC-Rio

Prof. Marcio da Silveira Carvalho Coordenador(a) Setorial do Centro Técnico Científico - PUC-Rio 
Todos os direitos reservados. É proibida a reprodução total ou parcial do trabalho sem autorização da universidade, do autor e do orientador.

\section{Aimée Maria Valente da Silva}

Graduou-se em Engenharia Química pela Universidade do Estado do Amazonas (Manaus - AM, Brasil).

Ficha Catalográfica

Silva, Aimée Maria Valente da

Estudos sobre a recuperação do titânio contido no rejeito da concentração de magnetita / Aimée Maria Valente da Silva ; orientador: Eduardo de Albuquerque Brocchi ; co-orientador: Ivan Guillermo Solórzano Naranjo. $-2018$.

112 f. : il. color. ; $30 \mathrm{~cm}$

Dissertação (mestrado)-Pontifícia Universidade Católica do Rio de Janeiro, Departamento de Engenharia Química e de Materiais, 2018.

Inclui bibliografia

1. Engenharia Química e de Materiais - Teses. 2. Titânio. 3. Dióxido de titânio. 4. Solubilização seletiva. I. Brocchi, Eduardo de Albuquerque. II. Solórzano, Guillermo. III. Pontifícia Universidade Católica do Rio de Janeiro. Departamento de Engenharia Química e de Materiais. IV. Título. 


\section{Agradecimentos}

Aos meus pais, Alexandra Valente e Severino Barroso, que sempre me deram apoio e incentivo incondicionais em todos os momentos da minha vida, me proporcionando boa educação e formação de caráter e que, por muitas vezes, se privaram de muitas coisas para que eu pudesse cumprir meus deveres, e que, também, nunca me deixaram faltar nada, me proporciondo o privilégio de me dedicar exclusivamente aos estudos.

Ao CNPq e à Pontifícia Universidade Católica do Rio de Janeiro (PUCRio), ao Centro Brasileiro de Pesquisas Físicas (CBPF) e ao Centro de Tecnologia Mineral (CETEM) por todo o tipo concedido para a realização deste trabalho.

Aos meus queridos orientadores, Eduardo Brocchi e Guillermo Solórzano, que tanto participaram da elaboração deste trabalho, contribuindo para meu crescimento como aluna e pesquisadora. Ao técnico do laboratório da Casa XXI Henrique Meira e à pós-doutoranda Natasha Suguihiro que sempre me auxiliaram com muito conhecimento e boa vontade para que eu pudesse realizar meus experimentos e aos Professores Rogério Navarro e Rodrigo Souza, os quais me ampararam ao longo do trabalho. Ao Paul Juarez, aluno de doutorado, que me ajudou muito em diversas análises.

Às amigas que fiz ao longo desses anos, em especial à Maria Isabel, e as antigas que me acompanharam até o Rio. Quem tem amigos tem tudo.

Ao Artur Serpa por todo suporte, amizade e paciência em me ajudar nos estudos e a encontrar tantos livros e artigos online e pela companhia em tantas noites no laboratório.

Aos membros da banca, Prof. Rodrigo de Souza e Dr. Fernando Lins por terem aceitado o convite e pelas contribuições para a melhora deste trabalho.

A todos aqueles que, direta ou indiretamente, participaram desta etapa da minha vida de desenvolvimento pessoal. 


\section{Resumo}

Valente da Silva, Aimée Maria; de Albuquerque Brocchi, Eduardo; Solórzano Naranjo, Ivan Guillermo. Estudos sobre a recuperação do titânio contido no rejeito da concentração de magnetita. Rio de Janeiro, 2018. 112p. Dissertação de Mestrado - Departamento de Engenharia Química e de Materiais, Pontifícia Universidade Católica do Rio de Janeiro.

O Brasil é um dos produtores mundiais de materiais contendo vanádio, exportando cerca de 10 t/ano, na forma de seu óxido mais comum, $\mathrm{V}_{2} \mathrm{O}_{5}$, o qual ocorre associado à magnetita. $\mathrm{O}$ seu processo de produção industrial tem como primeira etapa a concentração deste mineral, onde é gerado uma grande quantidade de rejeito, o qual se estima conter entre 5\%-15\% de titânio e cerca de $30 \%$ de ferro. Materiais com estas características podem viabilizar uma fonte para a recuperação do titânio por processos químicos que viabilizem a separação seletiva dos seus constituintes. Desta forma, inicialmente foi realizada a caracterização de um rejeito mineral por métodos convencionais: distribuição granulométrica; DR-X; FR-X; Microscopia Eletrônica de Varredura e ICP-OES. Em seguida, foi conduzida uma avaliação termodinâmica de possíveis reações com diferentes agentes químicos em condições de variação de temperatura. As reações ocorreram em um forno do tipo mufla, utilizando barquetes cerâmicos. Após a reação e eventual fusão, a amostra era imergida água destilada aquecida, em seguida filtrada e seca, e o material sólido filtrado era então submetido a $\mathrm{HCl}$ $5 \%$ aquecido, em seguida filtrado e seco. A caracterização dos produtos foi feita de maneira semelhante ao do material inicial. O resultado da distribuição granulométrica determinou tamanho médio de partícula de $96 \mu \mathrm{m}$. A análise quantitativa de DR-X indicou 25 \% de óxidos de titânio e o restante de minerais complexos como Tremolita e Clinocloro llb-2. A análise do FRX inicial apontou presenças de $\mathrm{Na}_{2} \mathrm{O}, \mathrm{MgO}, \mathrm{Al}_{2} \mathrm{O}_{3}, \mathrm{SiO}_{2}, \mathrm{SO}_{3}, \mathrm{~K}_{2} \mathrm{O}, \mathrm{CaO}, \mathrm{MnO}, 11,3 \%$ de $\mathrm{TiO}_{2}$, e $25,8 \%$ de $\mathrm{Fe}_{2} \mathrm{O}_{3}$. A análise termodinâmica indicou a potencial formação de produtos solúveis em água contendo $\mathrm{Al}$ e $\mathrm{Si}$ enquanto o Ti se agrega a um composto insolúvel. O Fe pode ser solubilizado na etapa seguinte com $\mathrm{HCl}$, onde as solubilizações foram, nitidamente, maiores. Observou-se a formação de um produto cristalino, prevalecendo a forma $\mathrm{CaTiO}_{3}$, com o desaparecimento 
das fases originais, em um dos ensaios. Os resultados também indicaram que as perdas de massa foram crescentes nas etapas de solubilização com o aumento da temperatura e da relação mássica, implementadas na ustulação sólido-sólido, contudo foram gerados produtos complexos que dificultaram a concentração do teor Ti. Em linhas gerais, o processo selecionado indicou a viabilidade de solubilizações seletivas, as quais geram um produto final com maior teor de titânio que o inicial e razoável recuperação deste metal, se fazendo necessário otimização do processo.

\section{Palavras-chave}

Titânio; Dióxido de Titânio; Solubilização Seletiva. 


\section{Abstract}

Valente da Silva, Aimée Maria; de Albuquerque Brocchi, Eduardo (Advisor); Solórzano Naranjo, Ivan Guillermo (Co-Advisor). Studies on titanium recovery from tailing of the magnetite concentration. Rio de Janeiro, 2018. 112p. Dissertação de Mestrado - Departamento de Engenharia Química e de Materiais, Pontifícia Universidade Católica do Rio de Janeiro.

Brazil is one of the world producers of materials containing vanadium, exporting about 10 ton/year, in the form of its most common oxide, $\mathrm{V}_{2} \mathrm{O}_{5}$, which occurs in association with magnetite. Its industrial production process has as its first step the concentration of this mineral, where a large amount of tailings is generated, which composition is estimated between 5\%-15\% titanium and about $30 \%$ iron. Materials with these characteristics can provide a source for the recovery of titanium by chemical processes that enable the selective separation of its constituents. In this way, the characterization of a mineral tail was initially performed by conventional methods: granulometric distribution; DR-X; FR-X; Scanning Electron Microscopy and ICP-OES. Then, a thermodynamic evaluation of possible reactions with different chemical agents under conditions of temperature variation was carried out. The reactions occurred in a muffle furnace, using ceramic caskets. After reaction and eventual melting, the sample was immersed heated distilled water, then filtered and dried, and the filtered solid material was then subjected to heated $5 \% \mathrm{HCl}$, then filtered and dried. The characterization of the products was done in a similar way to the starting material. The result of the particle size distribution determined a mean particle size of $96 \mu \mathrm{m}$. Quantitative analysis of DR-X indicated $25 \%$ of titanium oxides and the rest of complex minerals such as Tremolita and Clinochlore IIb-2. Initial FRX analysis showed $\mathrm{Na}_{2} \mathrm{O}, \mathrm{MgO}, \mathrm{Al}_{2} \mathrm{O}_{3}, \mathrm{SiO}_{2}, \mathrm{SO}_{3}, \mathrm{~K}_{2} \mathrm{O}, \mathrm{CaO}, \mathrm{MnO}, 11.3 \%$ $\mathrm{TiO} 2$ and $25.8 \% \quad \mathrm{Fe}_{2} \mathrm{O}_{3}$ presentations. Thermodynamic analysis indicated the potential formation of water-soluble products containing $\mathrm{Al}$ and $\mathrm{Si}$ while $\mathrm{Ti}$ is added to an insoluble compound. Fe can be solubilized in the next step with $\mathrm{HCl}$, where the solubilizations were markedly larger. It was observed the formation of a crystalline product, prevailing the $\mathrm{CaTiO}_{3}$ form, with the disappearance of the original phases, in one of the tests. The results also 
indicated that mass losses were increased in the solubilization steps with the increase in temperature and mass ratio, implemented in solid-solid roasting, however complex products were generated which hindered the concentration of $\mathrm{Ti}$ content. The selected process indicated the feasibility of selective solubilizations, which generate a final product with higher titanium content and reasonable recovery of this metal, making process optimization necessary.

\section{Keywords}

Titanium; Titanium dioxide; Selective Solubilizations. 


\section{Sumário}

1 Introdução 17

2 Aspectos Gerais 20

2.1. O Vanádio 20

2.1.1. Aplicações 20

2.1.2. Reservas 21

2.1.3. Obtenção do $\mathrm{V}_{2} \mathrm{O}_{5}$

2.2. O Titânio 24

2.2.1. Aplicações 25

$\begin{array}{ll}\text { 2.2.2. Reservas } & 26\end{array}$

$\begin{array}{ll}\text { 2.2.2.1. Os minerais de titânio } & 27\end{array}$

2.2.3. Obtenção do titânio 29

2.3. Beneficiamento de Minérios 30

3 Metodologia experimental $\quad 34$

3.1. Matéria-prima $\quad 34$

3.2. Preparação da matéria-prima 34

3.2.1. Quarteamento 34

3.2.2. Secagem 35

3.3. Caracterização da matéria-prima 36

3.3.1. Distribuição granulométrica 36

3.3.2. Difração de Raios-X - DR-X 37

3.3.3. Fluorescência de Raios-X - FRX 37

3.3.4. Microscopia Eletrônica de Varredura - MEV 38

3.3.5. Espectroscopia de emissão atômica com plasma acoplado indutivamente - ICP-AES 38

3.4. Avaliação do comportamento termodinâmico 38

3.5. Ensaios Experimentais $\quad 39$

3.5.1. Determinação do tempo residência apropriado 39

3.5.2. Reação de fusão com reagente alcalino 40 
3.5.4. Lixiviação em $\mathrm{HCl}$

3.6. Caracterização dos produtos intermediários e final 43

3.7. Ensaios experimentais avulsos $\quad 44$

3.7.1. Teste de solubilização $\quad 44$

3.7.2. Análise de perda de massa ao longo do tempo 44

3.7.3. Ensaio sobre a influência da concentração da solução ácida 45

4 Resultados e discussões $\quad 47$

4.1. Caracterização do material como recebido $\quad 47$

4.1.1. Análise granulométrica 47

4.1.2. Difração de Raios-X (DR - X) 55

4.1.3. Fluorescência de Raios $-\mathrm{X}(\mathrm{FR}-\mathrm{X})$

4.1.4. ICP - AES 58

4.1.5. Microscopia eletrônica de varredura - MEV $\quad 59$

4.1.5.1. EDS de partículas selecionadas $\quad 62$

4.2. Análise do sistema reacional 64

4.3. Determinação do tempo reacional 71

4.4. Ensaios de reação de fusão com reagente alcalino 72

$\begin{array}{ll}\text { 4.4.1. } \mathrm{MEV} & 81\end{array}$

$\begin{array}{ll}\text { 4.4.2. EDS } & 94\end{array}$

4.4.3. DR-X e FR-X 97

4.5. Análise de perda de massa ao longo do tempo 98

4.6. Ensaio sobre a influência da concentração da solução ácida 101

4.7. Obtenção de um composto rico em Ti 102

5 Conclusões 107

6 Sugestões de trabalhos futuros 109

$\begin{array}{ll}7 \text { Referências bibliográficas } & 110\end{array}$ 


\section{Lista de figuras}

Figura 1 - Principais aplicações do Vanádio. $\quad 21$

Figura 2 - Principais aplicações do vanádio em ligas de aço. 21

Figura 3 - Localização da mina de vanádio no Brasil. 23

Figura 4 - Fluxograma do processo de produção do $\mathrm{V}_{2} \mathrm{O}_{5}$. 24

Figura 5 - Principais aplicações do $\mathrm{TiO}_{2}$. 26

Figura 6 - Esquematização das estruturas cristalinas do a) rutilo e b) $\begin{array}{ll}\text { anatásio. } & 29\end{array}$

Figura 7 - Fluxograma genérico do processo de beneficiamento mineral. 32

Figura 8 - Esquema de quarteamento. 35

Figura 9 - Esquema de secagem na estufa. 35

Figura 10 - Esquema de peneiras. 36

Figura 11 - Fluxograma de processo. 39

Figura 12 - Representação genérica de um forno do tipo mufla. 41

Figura 13 - Esquematização de 'banho-maria'. 42

Figura 14 - Esquema filtração à vácuo. $\quad 42$

Figura 15 - Distribuição granulométrica. 48

Figura 16 - Imagem dos particulados retidos na peneira de 80 mesh. 49

Figura 17 - Espectro das partículas retidas na peneira de 80 mesh. 49

Figura 18 - Imagem dos particulados retidos na peneira de 120 mesh. 49

Figura 19 - Espectro das partículas retidas na peneira de 120 mesh. 50

Figura 20 - Imagem dos particulados retidos na peneira de 170 mesh. $\quad 50$

Figura 21 - Espectro das partículas retidas na peneira de 170 mesh. 50

Figura 22 - Imagem dos particulados retidos na peneira de 250 mesh. 51

Figura 23 - Espectro das partículas retidas na peneira de 250 mesh. 51

Figura 24 - Imagem dos particulados retidos na peneira de 450 mesh. 52

Figura 25 - Espectro das partículas retidas na peneira de 450 mesh. 52

Figura 26 - Imagem dos particulados retidos na peneira de 635 mesh. $\quad 52$

Figura 27 - Espectro das partículas retidas na peneira de 635 mesh. 53

Figura 28 - Distribuição elementar na série de Tyler. 53

Figura 29 - Imagem da matéria-prima gerada por SE com aumento de 
5000x.

Figura 30 - Espectro de elementos gerados por análise de EDS. 54

Figura 31 - Imagem da MP gerada por SE com aumento de 2500x 55

Figura 32 - Espectro de elementos gerados por análise de EDS 55

Figura 33 - Difratograma qualitativo da kaersutita. 56

Figura 34 - Difração de raios-x da amostra como recebida. 56

Figura 35 - Vista geral da amostra como recebida por elétrons retroespalhados. 59

Figura 36 - Espectro geral da amostra como recebida. 60

Figura 37 - Imagem por elétrons retroespalhados de uma partícula contendo mais de uma fase.

Figura 38 - Imagem por elétrons retroespalhados de uma partícula contendo mais de uma fase e apresentando efeito de carregamento. 61

Figura 39 - Identificação da partícula 1 analisada por EDS. 62

Figura 40 - Espectro de partícula 1 específica. 62

Figura 41 - Identificação da partícula 2 analisada por EDS. 63

Figura 42 - Espectro de partícula 2 específica.

Figura 43 - Simulação da reação do $\mathrm{SiO}_{2}$ com carbonato de Na. 65

Figura 44 - Simulação da reação do $\mathrm{SiO}_{2}$ com fosfato de Na. 66

Figura 45 - Simulação da reação do $\mathrm{SiO}_{2}$ com sulfato de Na. 66

Figura 46 - Energia livre de Gibbs para a reação de decomposição do $\mathrm{Na}_{2} \mathrm{CO}_{3} . \quad 68$

Figura 47 - Considerações termodinâmicas. $\quad 69$

Figura 48 - Energia livre de Gibbs das considerações termodinâmicas ao $\begin{array}{ll}\text { longo da variação de temperatura. } & 70\end{array}$

Figura 49 - Perda de massa ao longo do tempo. 71

Figura 50 - Aspecto físico das amostras após reação e solubilização em água.

Figura 51 - Perda de massa ao final da reação na mufla. $\quad 74$

Figura 52 - Imagens das amostras após reação na mufla. (a) amostra do ensaio 8. (b) amostra do ensaio 9. 74

Figura 53 - Imagem da amostra, do ensaio 3, após reação na mufla. 75

Figura 54 - Perda de massa ao final da solubilização em água. 76 
Figura 55 - Perda de massa ao final da solubilização em $\mathrm{HCl}$.

Figura 56 - Solução exemplo resultante da solubilização em ácido.

Figura 57 - Perda de massa ao longo das etapas do processo na condição de massa de $50 \%(-)$.

Figura 58 - Perda de massa ao longo das etapas do processo na condição de massa de $50 \%(+)$.

Figura 59 - Perda de massa ao longo das etapas do processo condição estequiométrica de massa.

Figura 60 - Perda de massa ao longo das etapas do processo na condição de $800{ }^{\circ} \mathrm{C}$

Figura 61 - Perda de massa ao longo das etapas do processo condição de $850{ }^{\circ} \mathrm{C}$.

Figura 62 - Perda de massa ao longo das etapas do processo na condição de $900{ }^{\circ} \mathrm{C}$.

Figura 63 - Amostra do ensaio 1 , a $800{ }^{\circ} \mathrm{C}$ e $50 \%$ (-) de reagente.

Figura 64 - Área selecionada para análise de EDS, de uma amostra rica em Ti.

Figura 65 - Espectro da área selecionada, de uma amostra rica em Ti.

Figura 66 - Área selecionada para análise de EDS, de uma amostra rica em Fe.

Figura 67 - Espectro da área selecionada, de uma amostra rica em Fe.

Figura 68 - Amostra do ensaio 2 , a $800{ }^{\circ} \mathrm{C}$ e quantidade estequiométrica de reagente.

Figura 69 - Amostra do ensaio 3, a $800{ }^{\circ} \mathrm{C}$ e $50 \%(+)$ de reagente.

Figura 70 - Área selecionada para análise de EDS, de uma amostra rica em Fe.

Figura 71 - Espectro da área selecionada, de uma amostra rica em Fe.

Figura 72 - Área selecionada para análise de EDS, da amostra 3.

Figura 73 - Espectro da área selecionada, da amostra 3.

Figura 74 - Amostra do ensaio 4 , a $850{ }^{\circ} \mathrm{C}$ e $50 \%$ (-) de reagente.

Figura 75 - Área selecionada para análise de EDS, da amostra 4.

Figura 76 - Espectro da área selecionada, da amostra 4.

Figura 77 - Amostra do ensaio 5 , a $850{ }^{\circ} \mathrm{C}$ e quantidade estequiométrica de 
$\begin{array}{ll}\text { reagente. } & 90\end{array}$

Figura 78 - Amostra do ensaio 6, a $850{ }^{\circ} \mathrm{C}$ e $50 \%$ (+) de reagente. 91

Figura 79 - Amostra do ensaio 7, a $900{ }^{\circ} \mathrm{C}$ e $50 \%$ (-) de reagente. 92

Figura 80 - Amostra do ensaio 8 , a $900{ }^{\circ} \mathrm{C}$ e quantidade estequiométrica de reagente. 93

Figura 81 - EDS da imagem do quadrante inferior esquerdo da figura 75. 93

Figura 82 - Amostra do ensaio 9, a $900{ }^{\circ} \mathrm{C}$ e $50 \%$ (+) de reagente. 94

Figura 83 - Quantificação (\%) vs elemento das amostras de relação molar

$50 \%(-)$.

Figura 84 - Quantificação (\%) vs elemento das amostras de relação molar $\begin{array}{ll}\text { estequiométrica. } & 96\end{array}$

Figura 85 - Quantificação (\%) vs elemento das amostras de relação molar $50 \%(+) . \quad 96$

Figura 86 - Perda de massa na mufla ao longo do tempo. 99

Figura 87 - Perda na solubilização em água, em diferentes tempos e temperaturas de reação na mufla.

Figura 88 - Perda na solubilização ácida em diferentes tempos e temperaturas de reação na mufla.

Figura 89 - Influência da concentração de ácido e da adição da etapa de solubilização em água, na comparação da perda de massa.

Figura 90 - Perda de massa ao longo das etapas do processo de teste.

Figura 91 - Análise DR-X do teste de solubilização.

Figura 92 - Diferença de composição entre a amostra como recebida e a final, por análise de EDS. 


\section{Lista de tabelas}

$\begin{array}{lr}\text { Tabela } 1 \text { - Minerais contendo Titânio } & 28\end{array}$

Tabela 2 - Matriz de ensaios de determinação de tempo reacional. 40

Tabela 3 - Matriz de ensaios com tempo de 90 min. 41

Tabela 4 - Matriz de ensaios com relação mássica fixa e tempo variado. 45

Tabela 5 - Matriz de ensaios comparativos. 46

Tabela 6 - Distribuição granulométrica ao longo de uma série de peneiras de Tyler. $\quad 47$

Tabela 7 - Fases prováveis segundo análise de dr-x. 56

Tabela 8 - Ajuste composicional fornecido pelo Topas. 57

Tabela 9 - Dados composicionais fornecidos pelo FR-X. 57

Tabela 10 - Dados composicionais fornecidos pelo ICP. 58

Tabela 11 - Composição elementar da amostra como recebida, em massa, fornecido pelo EDS, considerando o valor total e o valor desconsiderando o oxigênio presente. 60

Tabela 12 - Espectro de partícula 1 específica. 63

Tabela 13 - Espectro de partícula 2 específica. 64

Tabela 14 - Interação dos reagentes com os óxidos contidos na amostra. 67

Tabela 15 - Pressão de vapor da decomposição do $\mathrm{Na}_{2} \mathrm{CO}_{3}$. 68

Tabela 16 - Resultados dos ensaios de tempo reacional.

Tabela 17 - Resultado das perdas de massa ao longo das etapas do processo. $\quad 72$

Tabela 18 - Composição das áreas das partículas, ${ }^{1}$ rica em $\mathrm{Ti}^{\mathrm{e}}{ }^{2}$ rica em $\mathrm{Fe}$, respectivamente. 84

Tabela 19 - Composição das áreas das partículas, ${ }^{1}$ complexa e ${ }^{2}$ rica em Si,

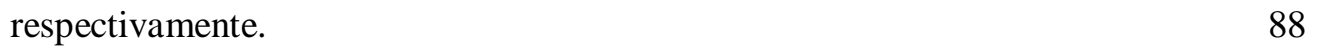

Tabela 20 - Composição das áreas das partículas, da Figura 77 e do quadrante inferior ${ }^{1}$ esquerdo e ${ }^{2}$ direito da ${ }^{3}$ Figura 72, respectivamente. 91

Tabela 21 - Sugestão das fases que compões as amostras 1, 2 e 3.

Tabela 22 - Sugestão das fases que compões as amostras 4 a 9.

Tabela 23 - Quantificação do teor de Fe e Ti por análise química em amostras selecionadas, respectivamente amostras 6,5 e $8, v s$ material como recebido. 98

Tabela 24 - Comparação composicional dos resultados de DR-X do teste de solubilização. 104

Tabela 25 - Condições do ensaio e teor de Fe e Ti na amostra final e no material como recebido. 
"You shoot me down, but I won't fall. I am Titanium".

- David Guetta. 


\section{1 \\ Introdução}

Praticamente todos os setores de bens de consumo são dependentes de matérias-primas minerais. Com o desenvolvimento e crescimentos das sociedades ao redor do mundo a demanda por esses insumos também cresceu, pela necessidade de matéria-prima para atender as crescentes necessidades dessas sociedades.

Pelos últimos 40 anos, esse crescimento da economia global resultou em rápido aumento na demanda por metais e óxidos metálicos para aplicações em alta tecnologia, como por exemplo o óxido de titânio $\left(\mathrm{TiO}_{2}\right)$, que é muito utilizado principalmente como pigmento branco nas mais diversas áreas, e sua versão metálica é também muito utilizada na fabricação de ligas para indústria aeroespacial e na área médica (Parirenyatwa et al. 2016).

Por conta disso, o consumo de minerais contendo esse óxido, tais como rutilo, anatásio e ilmetina, aumentou de forma que os diversos depósitos de rutilo pelo mundo foram se tornando escassos. Como consequência desse esgotamento de fontes ricas em $\mathrm{TiO}_{2}$, da consequente geração de resíduos gerados e da energia requerida para o tratamento desses minérios ao longo dos anos, é grande o interesse por pesquisas que possam utilizar materiais alternativos para atender a demanda de consumo.

Não somente para o minério citado acima, mas em geral o aumento nos níveis de consumo desses insumos minerais gera como consequência o aumento de resíduos, provenientes de seus processos de extração e beneficiamento/refino. Ao longo dos últimos anos nota-se uma crescente preocupação, principalmente pelo aspecto ambiental, com a geração de resíduos provenientes de processos industriais, voltando a atenção para a necessidade de redução desses resíduos, se tornando um assunto que chama cada vez mais visado, promovendo a busca por produtos que sejam sustentáveis e/ou zero-perdas. Dentro desse assunto, a utilização de resíduos de processos industriais como matéria-prima tem 
despertado interesse, sendo grande parte desses insumos industriais de origem mineral, metálica ou não (Alkan et al., 2017).

Os processos de aproveitamento desses rejeitos é uma área de muito interesse, por ser pouco explorada, podendo ser estudados adaptações de métodos clássicos ou mesmo implementação de novas rotas de processo.

$\mathrm{O}$ ideal então é que, para todas as atividades de extrações e processamentos minérios, o produto lavrado seja integralmente aproveitado, isto é que todos os minerais contidos tenham finalidade de utilização. Infelizmente a realidade ainda está muito longe de atingir esse ideal utópico (Ministério de Minas e Energia, 2006). Os processos de produção de minerais têm muitas oportunidades de eficiência também, principalmente nas etapas químicas.

Nesse contexto, o Brasil é produtor mundial de vários minerais de interesse, e/ou produtos metálicos, sendo um dos responsáveis pela produção mundial de produtos contendo vanádio (Heider, 2015). O vanádio ocorre associado à magnetita titanífera e o produto final a ser exportado é o $\mathrm{V}_{2} \mathrm{O}_{5}$, que é matéria prima para a obtenção de seu componente metálico e é de grande interesse na indústria de ligas, ferrosas ou não, por conta de suas propriedades físicas.

Em geral, a concentração inicial de vanádio dentro de seus minerais é muito pequena, menos de $3 \%$, e para que seja produzido ao final um produto rico em $\mathrm{V}_{2} \mathrm{O}_{5}$ o minério inicial passa por muitos processos, gerando ao longo de todos eles rejeitos e gangas, sendo a quantidade de rejeitos totais gerados mais de $95 \%$ do total lavrado (Moskalyk e Alfantazi, 2003). O primeiro dos processos de produção desse óxido, após adequação do tamanho de partículas, é a concentração via separação magnética, de onde é proveniente um rejeito com teores de $\mathrm{Ti}$ e $\mathrm{Fe}$ com potencial para ser processado e eventual comercialização, uma vez que, como já citado, há crescente interesse em fontes alternativas de $\mathrm{Ti}$, assim como na redução de resíduos poluentes.

Rejeitos são inicialmente classificados de acordo com a NBR 10004 Classificação dos Resíduos Sólidos. Aqui se aplica um exemplo do tipo "resíduo não-inerte classe II A”. Essa classificação indica que o rejeito não é agressivo ao meio ambiente, todavia ainda seria de interesse e oportuna a sua utilização como insumo para um processo subsequente. Tais processos podem ser considerados mais simples por não incluírem, necessariamente, as medidas relacionadas com a contenção de riscos por manuseio de resíduos de maior periculosidade. 
Considerando os temas abordados, o presente trabalho busca avaliar possíveis vias de recuperação do $\mathrm{TiO}_{2}$ proveniente do rejeito de uma concentração de Magnetita, a qual é utilizado na produção industrial do $\mathrm{V}_{2} \mathrm{O}_{5}$.

Tal estudo aborda os seguintes aspectos:

- Caracterização estrutural e morfológica do resíduo da concentração de magnetita;

- Identificação da interação do resíduo com reagentes sólidos em altas temperaturas de modo a se avaliar a possibilidade uma eventual separação seletiva posterior;

○ Solubilização seletiva dos produtos provenientes da reação anterior para obtenção de um produto enriquecido de $\mathrm{TiO}_{2}$;

- Estabelecimento da relevância de variáveis operacionais sobre as conversões;

○ Determinação do efeito de variáveis selecionadas ao longo do tempo;

- Caracterização sequencialmente os produtos intermediários e finais obtidos ao longo das reações sólido-sólido/ solubilização seletiva. 


\section{2 \\ Aspectos Gerais}

2.1.

O Vanádio

O vanádio $(\mathrm{V})$ é o $17^{\circ}$ elemento de maior ocorrência na crosta terrestre (Mitchell, 2001), é um metal de transição prateado brilhante, maleável (podendo ser forjado ou laminado à temperatura ambiente) e resistente à corrosão (Habashi, 1997). Recebeu este nome em homenagem a deusa nórdica Vanadis (Freia), deusa da beleza e fertilidade, pela beleza das cores que seus compostos possuem. (Moskalyk e Alfanzati, 2003). Possui grande resistência ao ataque de ácidos concentrados, mas baixa resistência ao ataque por fusão alcalina, por isso é muito utilizado em ligas e aço (Midat.org).

É encontrado num grande número de minerais, incluindo vanadinita, fervanita e patronita, além de rochas de fosfatos, alguns minerais de ferro, como magnetita, e na forma de complexos orgânicos contidos em óleos crus (Periodic Table; Habashi, 1997; Taylor et al., 2006).

\subsection{1.} Aplicações

É um metal estratégico que tem várias aplicações, sendo sua principal aplicação a utilização em ligas para reforço de aços e titânio. A adição de pequenas quantidades, menos de $1 \%$, de vanádio ao aço o torna mais resistente a choques e vibração, mais forte e leve. Dentre as ligas, as de vanádio são as que apresentam maiores vantagens em relação a proporção resistência vs peso. Por conta dessas características, essas ligas são comumente utilizadas em materiais de ferramentas e quando associadas com titânio e alumínio são utilizadas em materiais de aviação e aeroespaciais (Largo Resources, 2018, Periodic Table, 2018). Outras aplicações de seus óxidos incluem fabricação de pigmentos para vidros e cerâmicas, como catalisador em produção de supercondutores magnéticos, em reatores nucleares (Moskalyk e Alfanzati, 2003, Periodic Table) e 
na composição de eletrodos (Zhu et al., 2013). As principais aplicações desse metal estão discriminadas nos gráficos das Figuras 1 e 2.

Figura 1 - Principais aplicações do Vanádio.

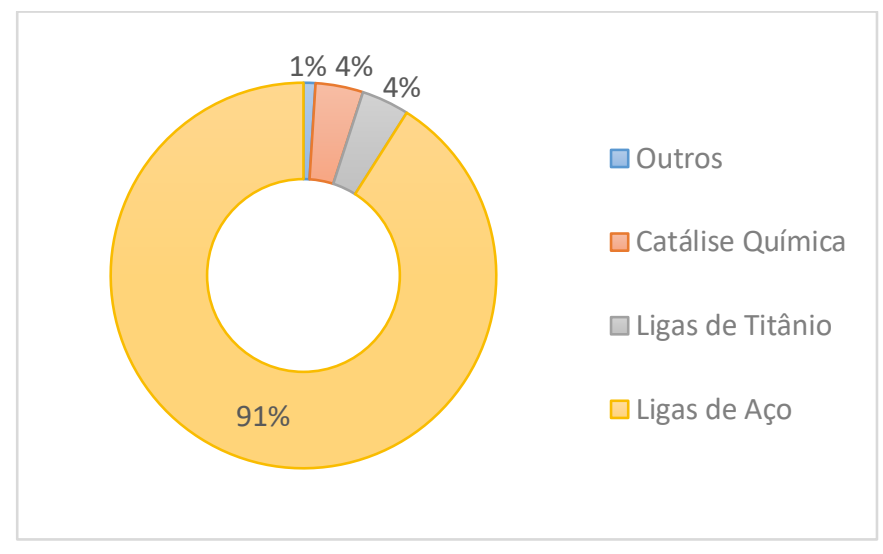

Fonte: Largo Resorces, 2018.

Figura 2 - Principais aplicações do vanádio em ligas de aço.

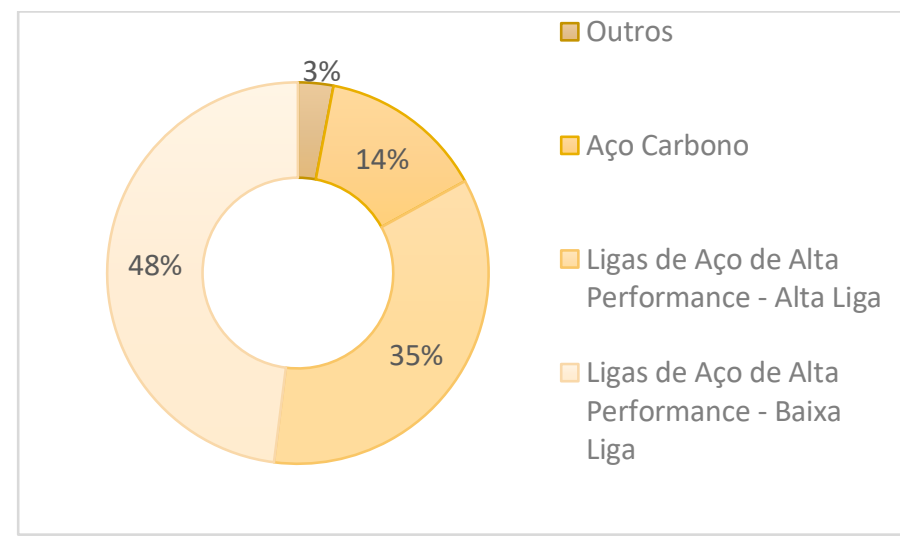

Fonte: Largo Resorces, 2018.

\subsection{2.}

\section{Reservas}

As reservas mundiais de $\mathrm{V}$ correspondem a 15.6 milhões de toneladas (Mt), em termos de metal contido, de acordo com o último levantamento feito em 2015 pela Agência Nacional de Mineração. As maiores reservas lavradas do mundo estão localizadas na China, Rússia e África do Sul, correspondendo a 5,1 Mt, 5,0 Mt e 3,5 Mt, respectivamente. (Sumário Mineral Brasileiro, 2016) Contudo, pelo fato de o vanádio ser tipicamente produzido como um coproduto ou subproduto, os indicadores das reservas mundiais não fornecem dados acurados sobre a verdadeira disponibilidade de suprimento desse metal. (Mineral Commodity Summaries, 2018). 
As reservas totais de vanádio no mundo, lavráveis e não lavráveis, excedem 63 Mt e maiores ocorrências do vanádio são em rochas de fosfato, magnetita titanífera e arenito uranífero. A composição desses depósitos costuma conter menos de $2 \%$ de vanádio (Mineral Commodity Summaries, 2018).

A produção das três maiores reservas abastece o mercado mundial com $88,9 \%$ do total produzido, enquanto que as reservas brasileiras representaram 1,12\% deste total (Sumário Mineral Brasileiro, 2016).

\subsection{3.}

\section{Obtenção do $\mathrm{V}_{2} \mathrm{O}_{5}$}

$\mathrm{Na}$ rota mais consagrada, o $\mathrm{V}_{2} \mathrm{O}_{5}$ é produzido por meio de digestão acompanhada de reações que possibilitem solubilizações e precipitações seletivas (Habashi, 1997).

Em maio de 2014 o Brasil passou a fazer parte do seleto grupo de países com expressiva produção de vanádio, na sua forma oxidada mais comum (o $\mathrm{V}_{2} \mathrm{O}_{5}$ ), após a abertura da mina Menchen Maracás (Heider, 2015). As reservas lavráveis brasileiras de vanádio (V), em metal contido, correspondem a 126 mil toneladas $(\mathrm{kt})$ de $\mathrm{V}_{2} \mathrm{O}_{5}$. A produção brasileira gira em torno de 9,0 kt de concentrado de vanádio, em metal contido, o que representa cerca de $10 \%$ da produção mundial (Sumário Mineral Brasileiro, 2016).

O Brasil é o único produtor relevante na América Latina, possuindo o depósito de maior alto teor no mundo, com teores de $1,0 \%$ a $1,5 \%$, e baixo custo de produção. O depósito brasileiro fica localizado no Estado da Bahia, conforme indicado na Figura 3, uma propriedade de 17.690 hectares (Heider, 2015). 
Figura 3 - Localização da mina de vanádio no Brasil.

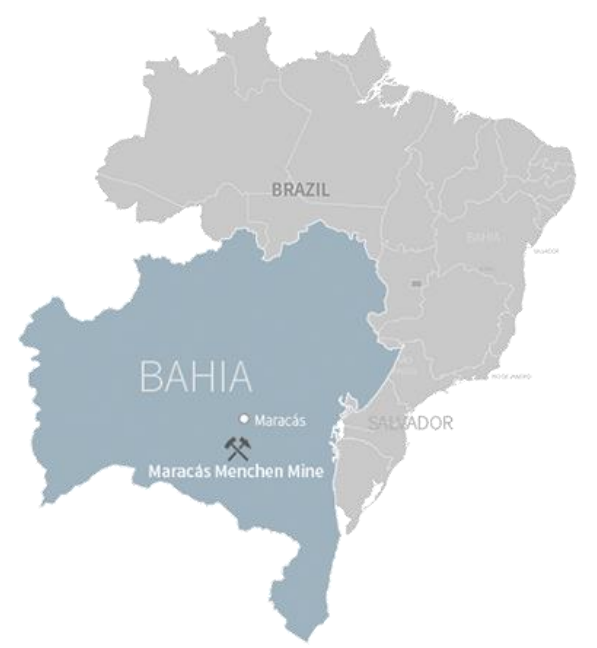

Fonte: Largo Resources, 2018.

A ocorrência do vanádio no Brasil está associada com o minério de magnetita titanífera, com baixos níveis de contaminantes, como sílica $\left(\mathrm{SiO}_{2}\right)$. As características únicas da reserva brasileira permitem que haja uma fácil extração e processamento do minério em seu produto comerciável rico em vanádio. Essas condições operacionais tem o custo consideravelmente reduzido, tornando o Brasil um competitivo produtor de vanádio).

O processo brasileiro, ilustrado no fluxograma da Figura 4, começa com etapas de tratamento físico, o material extraído é britado e moído e em seguida enviado para concentrar o vanádio por via de separação magnética. Após essas etapas, o material concentrado possui um teor significativamente elevado, por volta de $3 \%$ de $\mathrm{V}_{2} \mathrm{O}_{5}$, que segue para processos químicos até gerar o produto final com altíssima pureza de $\mathrm{V}_{2} \mathrm{O}_{5}$ (Largo Resources, 2018). 
Figura 4 - Fluxograma do processo de produção do $\mathrm{V}_{2} \mathrm{O}_{5}$.

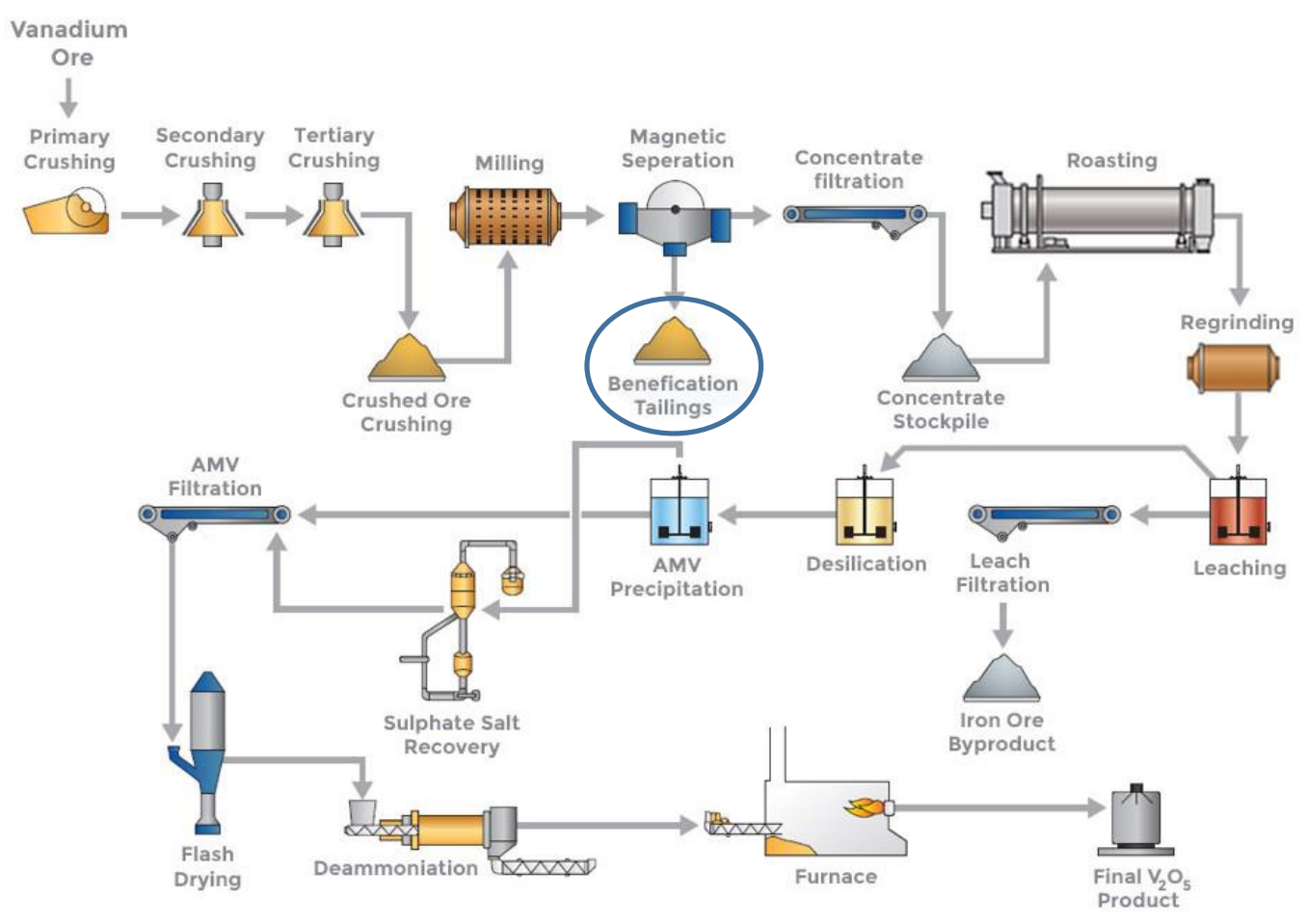

Fonte: Largo Resources, 2018.

Contudo, como já mencionado, o vanádio é uma fração muito pequena dentro de todo material mineral extraído da mina. Mais de $90 \%$ de todo material extraído é considerado rejeito e não possui finalidade atualmente, porém eles possuem altos teores de outros elementos, mostrando um grande potencial de gerar subprodutos ou coprodutos que possam ser comerciáveis.

Dentre os rejeitos gerados ao longo do processo de produção do pentóxido de vanádio, o gerado durante a etapa de beneficiamento de concentração por separação magnética apresenta altos teores de ferro e titânio.

\section{2.}

\section{O Titânio}

O titânio (Ti) é um metal de transição de cor branca metálica, brilhante, dúctil, resistente a corrosão (Habashi, 1997) e alto ponto de fusão (Hanson, 1986). Pode ser encontrado em meteoritos e em rochas lunares, mas na natureza ocorre apenas combinado, geralmente, com oxigênio e ferro (Baltaret al., 2008), estando entre os dez elementos mais abundantes na crosta terrestre, mais abundante que o cobre, por exemplo (Habashi, 1997; Zhang et al., 2011, Carvalho et al., 2017). Foi 
obtido pela primeira vez em 1922 pela redução do hexafluorotitanato de potássio, com sódio em atmosfera inerte (Habashi, 1997).

Apesar de ser um metal de baixa reatividade, quando em temperatura ambiente (Baltar et al., 2008), ele possui grande afinidade com oxigênio, nitrogênio e carbono, característica que torna bastante complexa a obtenção do metal puro (Habashi, 1997), contudo, possui boa resistência à grande parte dos ácidos orgânicos, além de resistir aos ácido clorídrico e sulfúrico diluídos. Seu estado de oxidação mais estável é na forma de titânio (IV) (Baltar et al., 2008).

A vantagem em utilizar o titânio se dá por suas propriedades excepcionais, como tenacidade, o alto ponto de fusão, uma resistência à corrosão que se equipara à da platina, resistência mecânica semelhante à do aço, estabilidade térmica, entre outras (Baltar, 2008). Por essas e outras razões, o titânio é o metal que representa um dos mais importantes desenvolvimentos na indústria dos não ferrosos (Hanson, 1986), tendo aplicações desde ligas de aço até corantes alimentares e material medicina (Baltar et al., 2008).

\subsection{1.}

\section{Aplicações}

O titânio metálico possui um ampla grama de aplicações que exigem do material, resistência a condições adversas. Embora as propriedades de biocompatibilidade (material médico ou odontológico) do titânio sejam conhecidas a mais de um século, a maior parcela onde é utilizado é na indústria, como ligas, sendo utilizado na indústria aeroespacial, civil, automobilística, petroleira, naval (Ezugwu e Wang, 1995; Habashi, 1997; Baltar, 2008; Carvalho et al., 2017). Na engenharia de materiais passou a ser utilizado em várias ligas e em formas forjadas, como folhas, placas, tiras, extrusões, entre outros (Ezugwu e Wang, 1995)

Embora o titânio metálico possua um razoável campo de aplicações, a sua maior demanda (em torno de $90 \%$ ) é para produção de sua forma oxidada, o $\mathrm{TiO}_{2}$ (Monteiro, 2016; Carvalho et al., 2017), conforme ilustrado na Figura 5. 
Figura 5 - Principais aplicações do $\mathrm{TiO}_{2}$.

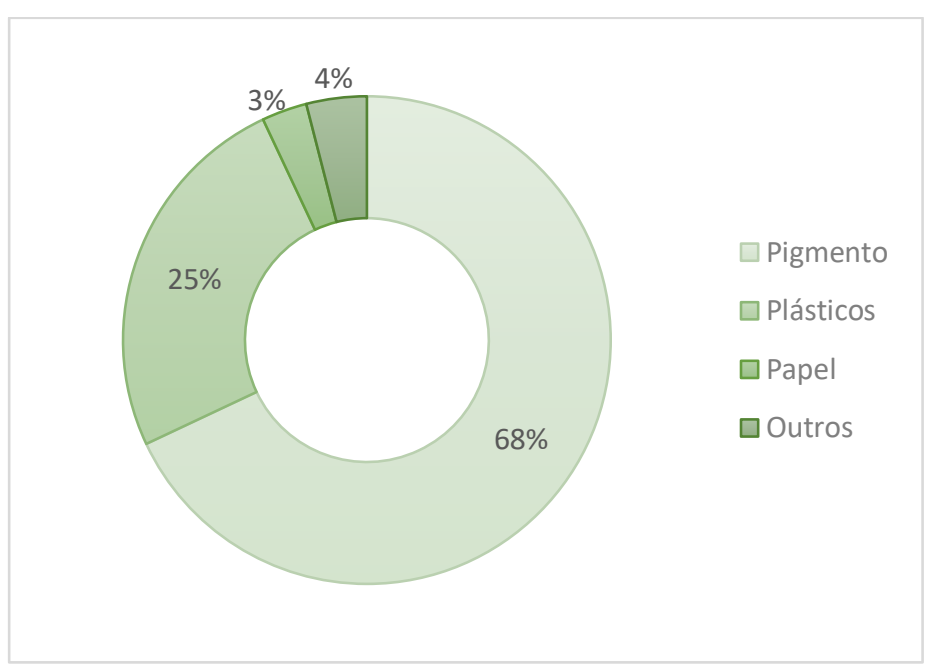

Fonte: Adaptado de Mineral Commodity Summaries, 2018.

O rutilo é produzido em larga escala e transformado em pigmento branco, catalisador, células fotovoltaicas, purificador de ar, dispositivos biomédicos e na produção de material cerâmico. Além dele, a ilmenita também é muito utilizada na fabricação do $\mathrm{TiO}_{2}$ como pigmento branco. Seu uso como pigmento é devido suas propriedades de espalhamento, grande estabilidade e baixa toxicidade, sendo utilizado em tintas, plásticos, protetor solar, cosméticos e até mesmo em alimentos (Habashi, 1997; Zaki, 2017).

\subsection{2.}

\section{Reservas}

Nos anos 50, era comum haver depósitos de titânio contendo até $30 \%$ de rutilo, contudo a partir dos anos 80 essa quantidade decaiu para menos de $1 \%$ (Zhang et al., 2011), e hoje cerca de $90 \%$ do minério de titânio consumido no mundo são portadores do mineral ilmenita (Sumario Mineral Brasileiro, 2016; Mineral Commodity Summaries, 2018). O interesse na exploração econômica de depósitos alternativos surgiu por conta desse decréscimo de minérios de rutilo tradicionalmente explotados (Monteiro, 2016; Sumario Mineral Brasileiro, 2016). As fontes de rutilo, anatásio e ilmenita juntas correspondem a mais de 2 bilhões de toneladas (Mineral Commodity Summaries, 2018), estando quase $60 \%$ dessas reservas localizadas em três países, China, Austrália e Índia, correspondendo respectivamente a $25 \%, 20 \%$ e $12 \%$ (Sumário Mineral Brasileiro, 2016).

As reservas lavráveis brasileiras de ilmenita e rutilo correspondem a menos de $0.3 \%$ das reservas mundiais, totalizaram cerca de $2 \mathrm{Mt}$, ainda assim o Brasil é 
o maior produtor da América Latina, produzindo, no ano de 2015, o correspondente a 1,3 \% da produção mundial de titânio (Sumário Mineral Brasileiro, 2016).

No Brasil, os principais três produtores estão localizados em Mataraca (PB), Santa Bárbara de Goiás (GO) e São Francisco de Itabapoana (RJ), sendo três as empresas que beneficiaram o titânio no Brasil: Indústrias Nucleares do Brasil S.A., Titânio Goiás Mineração, Indústria e Comércio Ltda. e Cristal Mineração do Brasil Ltda. Esta última pertencente a multinacional Cristal Global, que é a segunda maior produtora mundial de $\mathrm{TiO}_{2}$, sendo, aqui no Brasil, responsável por mais de $80 \%$ da produção nacional (Sumário Mineral Brasileiro, 2016).

\subsubsection{1.}

\section{Os minerais de titânio}

O titânio primário ocorre em rochas ígneas a partir de duas origens: quando formado a partir de componentes ácidos de magmas básicos, tem-se ilmenita $\left(\mathrm{FeTiO}_{3}\right)$ e perovskita $\left(\mathrm{CaTiO}_{3}\right)$; quando a partir de componentes básicos, tem-se os dióxidos de titânio.

Formas intermediárias podem ser encontradas, como por exemplo em silicatos. Nesses minérios o titânio está presente como um elemento básico (como em aluminosilicatos e minerais de zircônio), contudo pode ser encontrado em alguns minerais como um substituto do silício. Um exemplo dessas formas intermediárias é a titanita (ou esfeno), $\mathrm{CaTi}\left(\mathrm{SiO}_{4}\right) \mathrm{O}$, muito comum em rochas magmáticas. Todas essas formas também ocorrem em rochas metamórficas contendo titânio, mas as duas formas do dióxido de titânio, anatásio e brookita, ocorrem exclusivamente nesse tipo de rochas (Habashi, 1997; Parirenyatwa et al., 2016). Já os depósitos secundários incluem a abundante ilmenita, presente tanto em depósitos quanto em areias de praia (Habashi, 1997), sendo o leucoxênio um produto naturalmente alterado derivado da ilmenita (Zhang et al., 2011).

O titânio pode ocorrer em diversos minerais de maneira bem diferente do vanádio que ocorre em baixíssimos teores nos minérios. Os minerais de titânio podem conter teores altíssimos de $\mathrm{Ti}$, geralmente na forma de seu óxido $\mathrm{TiO}_{2}$. Dentre eles, conforme ilustrado na Tabela 1, alguns dos mais comuns são rutilo, ilmenita e leucoxênio. (Zhang et al., 2011, Parirenyatwa et al., 2016), que são os de processamento mais fácil. (Habashi, 1997) 
Tabela 1 - Minerais contendo Titânio

\begin{tabular}{llcc} 
Mineral & Composição & $\mathrm{TiO}_{2}(\%)$ & $\begin{array}{c}\text { Estrutura } \\
\text { Cristalina }\end{array}$ \\
\hline Rutilo & $\mathrm{TiO}_{2}$ & $\sim 95 \%$ & Tetragonal \\
Anatásio & $\mathrm{TiO}_{2}$ & $\sim 95 \%$ & Tetragonal \\
Brookita & $\mathrm{TiO}_{2}$ & $\sim 95 \%$ & Ortorrômbica \\
Ilmenita & $\mathrm{FeO} \mathrm{TiO}_{2}$ & $40-65 \%$ & Hexagonal \\
Leucoxênio & $\mathrm{Fe}_{2} \mathrm{O}_{3} \cdot \mathrm{nTiO}_{2}$ & $60-90 \%$ & Hexagonal \\
Arizonita & $\mathrm{Fe}_{2} \mathrm{O}_{3} \cdot \mathrm{nTiO}_{2} \cdot \mathrm{mH}_{2} \mathrm{O}$ & - & - \\
Perovskita & $\mathrm{CaTiO}_{3}$ & $40-60 \%$ & Ortorrômbica \\
Geikielite & $\mathrm{MgTiO}_{3}$ & - & - \\
Titanita ou Esfeno & $\mathrm{CaTiSiO}_{5}$ & $30-42 \%$ & - \\
Magnetita Titanífera & $\left(\mathrm{Fe} . \mathrm{Ti}_{2} \mathrm{O}_{3}\right.$ & $2-20 \%$ & - \\
\hline \multicolumn{4}{r}{ Fonte: Adaptado de Habashi, 1997; Zhang et al., 2011; Monteiro, 2016. }
\end{tabular}

A classificação dos minerais de Ti é feita de acordo com o tipo de óxido formado, e para os que dividem mesma composição a classificação se dá pela estrutura cristalina dos óxidos. Dentre os minerais mais comuns, tem-se o rutilo e anatásio que compartilham mesma composição e estrutura cristalina, divergindo em algumas propriedades por conta de distorções em suas células unitárias (Monteiro, 2016).

Como já mencionado, o dióxido de titânio ocorre na natureza em três formas: rutilo, anatásio e brookita (Habashi, 1997), onde a estrutura do rutilo e do anatásio estão ilustradas na Figura 6. O anatásio e a brookita são fases meta estáveis, com maior atividade catalítica, já o rutilo é uma fase estável termodinamicamente. Basicamente as outras duas fases tendem a se transformar de maneira exotérmica e irreversível em rutilo numa larga faixa de temperatura (Ziemniak e Opalka, 1993; Monteiro, 2016), ainda assim, a energia das outras redes é semelhante e podem ser estáveis por longos períodos de tempo (Habashi, 1997). 
Figura 6 - Esquematização das estruturas cristalinas do a) rutilo e b) anatásio.

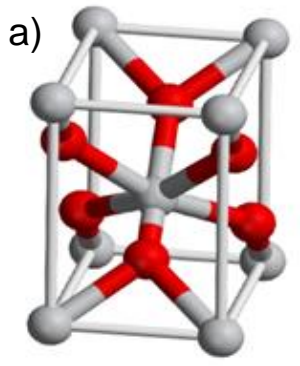

b)

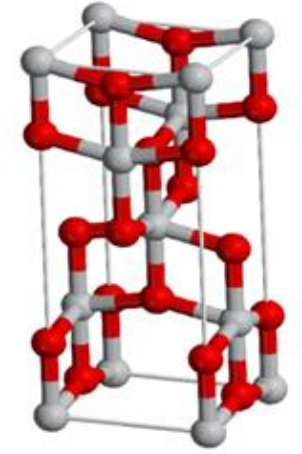

Fonte: Monteiro, 2016.

Nesses compostos o Ti está cercado por um octaedro irregular de $\mathrm{O}_{2}$, e o número de arestas comuns compartilhadas de maneira octaédrica similar aumenta de duas para o rutilo, três para a brookita e quatro para o anatásio, ou seja, o rutilo possui a maior densidade e estrutura mais compacta. Os átomos de $\mathrm{O}$ são cercados, cada um, por três átomos de Ti em arranjo trigonal (Ziemniak e Opalka, 1993, Habashi, 1997).

$\mathrm{O} \quad \mathrm{TiO}_{2}$ é um semicondutor sensível à luz, que absorve radiação eletromagnética na região próxima à do UV, também possui característica anfótera, possuindo baixo caráter básico ou ácido. As formas ácidas ou básicas são instáveis em água, formando compostos amorfos (Habashi, 1997).

Assim como o titânio metálico, o $\mathrm{TiO}_{2}$ é bastante estável e não é atacado pela maioria dos reagentes inorgânicos e orgânicos, mas pode ser dissolvido por fusões ácidas ou básicas e por ácido sulfúrico ou clorídrico concentrado. Na presença de carbono, pode reagir com o cloro e em altas temperaturas forma óxidos de menor valência ao contato com amônia, hidrogênio ou monóxido de carbono (Habashi, 1997).

\subsection{3.}

\section{Obtenção do titânio}

Existem duas rotas que viabilizam a produção do $\mathrm{TiO}_{2}$, são duas rotas conhecidas, a de cloretos e a de sulfatos. A primeira rota é baseada na obtenção do $\mathrm{TiCl}_{4}$ por cloração, e a sua subsequente oxidação, ao passo que a segunda rota utiliza uma digestão com solução de ácido sulfúrico, seguida por separações sucessivas.

Sendo essa última a via de obtenção utilizada no Brasil. 


\section{3.}

\section{Beneficiamento de Minérios}

São raras as exceções de minérios que podem ser utilizados e/ou comercializados da maneira como são encontrados na natureza, sendo necessário que haja uma ou mais etapas de tratamento (Brocchi, 2017). Esse tratamento ou beneficiamento, como também pode ser chamado, tem como intuito modificar o minério de origem para que ao final, tenha-se o minério de interesse, as modificações podem ser relativas a granulometria e concentração, mas não alterando a identidade química do minério (Luz e Lins, 2010; Brocchi, 2017), embora haja autores que consideram esse tratamento de maneira mais abrangente, contanto que a alteração química seja simples decomposição térmica (Luz e Lins, 2010).

Antes do beneficiamento mineral é necessário que o mineral seja analisado sob quatro perspectivas diferentes (Brocchi, 2017):

(i) Composição mineralógica - identificação dos minerais contidos;

(ii) Composição química - identificação dos elementos presentes em cada mineral;

(iii) Granulometria - identificação do tamanho dos grãos;

(iv) Grau de liberação - identificação de \% do mineral de interesse na forma partículas isoladas.

Isso porque os processos a serem aplicados num minério são diretamente dependentes de propriedades físicas, químicas, físico-químicas, morfológicas e superficiais dos cristais e partículas minerais puras e do tipo do depósito. A origem geológica do minério, naturalmente, tem influência na granulometria de liberação e na composição mineralógica da ganga (Ciminelli, 2008; Baltar et al., 2008).

Em geral o beneficiamento consiste em primeiro, liberar o(s) minerais(s) de interesse por meio de processos físicos de fragmentação (britagem/moagem) até que as partículas tenham um tamanho adequado, que não deve ser muito pequeno para não dificultar o processo de segregação, além de que os processos de fragmentação tem alto custo (consumo de energia, meio moedor, revestimento etc), e por isso devem passar por estes processos apenas a quantidade mínima necessária. Em seguida as partículas são classificadas por tamanho (peneiras, 
ciclones, etc) e direcionadas para a concentração, sendo as partículas muito finas retidas em barragens para até que existam equipamentos capazes de separá-las (Luz e Lins, 2010; Brocchi, 2017).

A concentração pode ser por separação gravimétrica, separação magnética ou até mesmo por flotação e é, em geral, uma etapa importante para que o minério possa ser utilizado na metalurgia extrativa. O mineral de interesse é separado da ganga e recebe a denominação de precursor, a partir do qual podem ser aplicados processos químicos para obtenção do elemento de interesse (Luz e Lins, 2010; Brocchi, 2017). Alguns minérios têm alto desempenho nessa etapa, como é o exemplo da scheelita, com teor inicial de $0,35 \%$ de $\mathrm{WO}_{3}$, chegando após a concentração gravítica ou flotação, até cerca de $70 \%$ de $\mathrm{WO}_{3}$. Outras vezes o minério não possui condições favoráveis para esta etapa, como é o caso das lateritas niquelíferas, nas quais o níquel está dentro da estrutura cristalina sem preferência, fazendo parte tanto da ganga quanto do concentrado e tornando o processo ineficaz. Em geral, o processo de concentração acontece por via úmida, o que faz necessário adição de uma etapa de remoção de água (espessamento e filtragem) e secagem (Luz e Lins, 2010).

A etapa de reações químicas é a que apresenta maiores desafios de rendimento, por meio deles são formados um segundo precursor, geralmente óxidos, cloretos, sulfetos ou solventes ricos do metal de interesse. Esse precursor pode ser comercializado desta forma, ou passar por outros processos químicos para redução e formação do metal de interesse e posteriormente por um refino para retirada de impurezas residuais (químico ou físico), podendo o produto final atingir purezas de mais de $98 \%$ (Brocchi, 2017).

O resumo das etapas de beneficiamento está ilustrado no fluxograma da Figura 7, as etapas são (Luz e Lins, 2010):

(i) fragmentação: britagem e moagem;

(ii) separação e classificação: peneiramento, ciclonagem e classificação em espiral;

(iii) concentração: gravítica, magnética, eletrostática, flotação etc.

(iv) desaguamento: espessamento e filtragem;

(v) secagem: secador rotativo, spray dryer, secador de leito fluidizado;

(vi) disposição de rejeito. 
Figura 7 - Fluxograma genérico do processo de beneficiamento mineral.

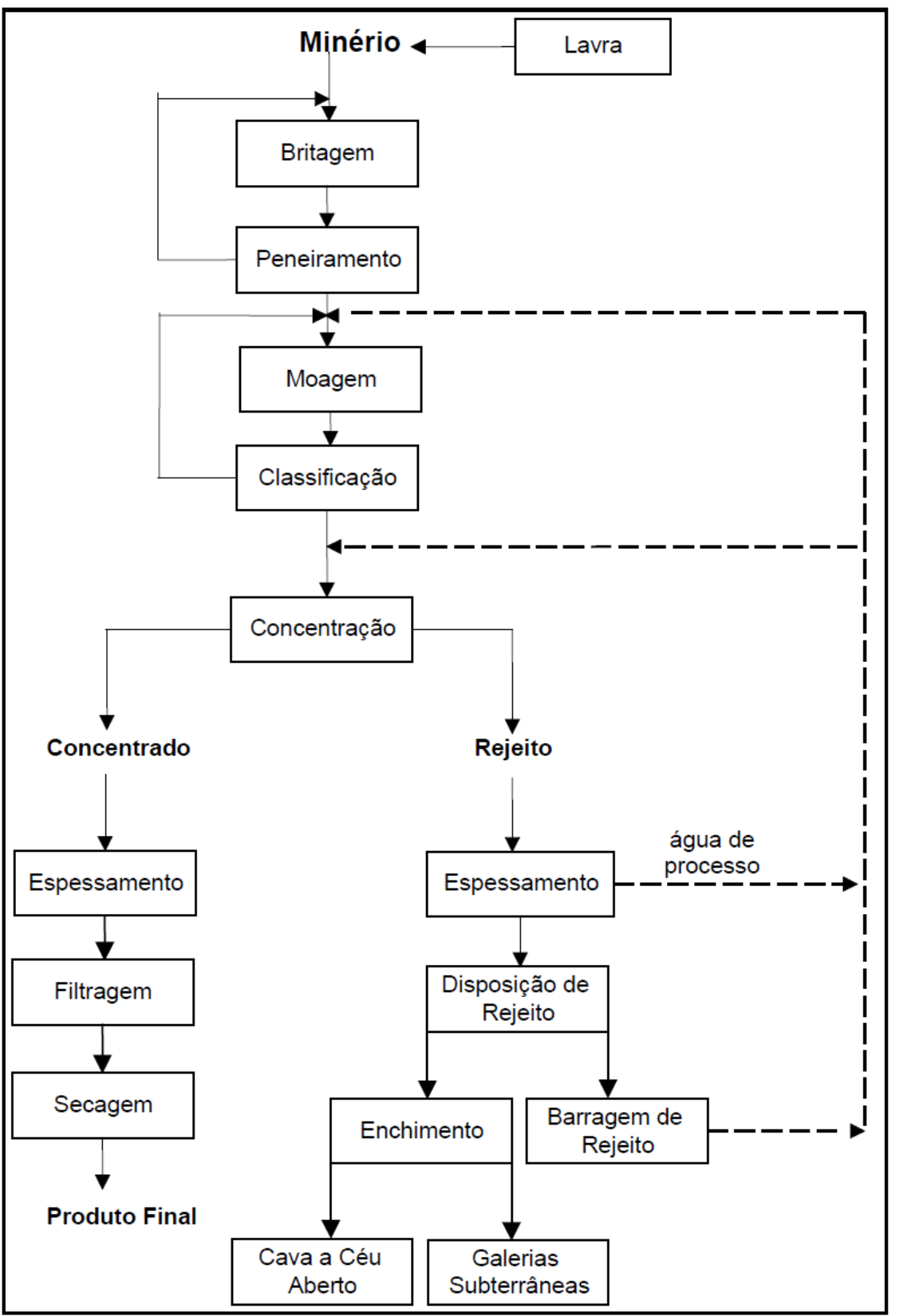

Fonte: Luz e Lins, 2010.

A demanda pode fazer com que a comercialização de um produto intermediário seja maior que a do metal puro, como é o caso do $\mathrm{TiO}_{2}$ em relação ao Ti. Muitas vezes também é vantajoso comercializar não apenas o produto final, mas recuperar as gangas e rejeitos ao longo do processo, gerando assim coprodutos/subprodutos, como é o caso do vanádio. No caso do Brasil, priorizar a recuperação do rejeito da concentração de magnetita, em decorrência da presença do titânio. 
A etapa da metalurgia extrativa viabiliza a obtenção desses produtos intermediários, finais e coprodutos/subprodutos utilizam métodos hidropirometalúrgicos. A diferença entre os métodos está na forma de conduzir as reações, pois enquanto nos processos pirometalúrgicos são utilizadas alta temperaturas, os processos hidrometalúrgico ocorrem em meio aquoso e baixas temperaturas. Existem também processos eletroquímicos, que normalmente, são utilizados para obtenção (exs: $\mathrm{Zn}$ e $\mathrm{Al}$ ) ou refino (exs: Cu e Sn) de metais.

O processamento industrial do titânio é feito tradicionalmente por duas rotas: ustulação com cloreto e com sulfato (Monteiro, 2016), a primeira por piro e a segunda por hidro (Habashi, 1997).

Dentro desse panorama, como já mencionado, o objetivo base desse trabalho é avaliar uma rota que viabilize a recuperação do titânio contido no rejeito da concentração de vanádio que acompanha a magnetita. Esse rejeito, embora já tenha sido caracterizado de forma genérica, nunca foi objeto de estudo desta natureza, consequentemente, não existem referencias que abordem as reações que possam viabilizar a separação desejada.

Todavia o objetivo em si, a recuperação de metais de interesse a partir de rejeitos minerais e resíduos industriais, é motivo de alguns estudos. Nesse contexto os trabalhos recentes, como Tathavadkar e Jha (2004) que estuda a fusão alcalina de minerais de rutilo e ilmenita com carbonato de sódio e posteriores solubilizações em água e ácido; como também Meng e colaboradores (2016), que também abordam a recuperação de titânio a partir de tionita (resíduo industrial abundante na China) por via conversão hidrotérmica com soda cáustica e posteriores separações com água e ácido; Alkan e colaboradores (2017) estudaram a recuperação de titânio a partir do resíduo do processo Bayer, que é a lama vermelha, por lixiviação com ácido clorídrico e/ou sulfúrico. Existem também trabalhos que estudam a digestão mais abrangente de minerais, como Chiweshe e Purcell (2017), que estudaram o efeito da fusão de um minério complexo com fosfato de sódio e subsequentes solubilizações em meios básicos para a separação de níquel e cobre.

O potencial para estudos dessa natureza é ainda muito grande. 


\section{3 \\ Metodologia experimental}

\section{1.}

Matéria-prima

A matéria-prima utilizada no presente trabalho se constituía de um pó fino, com coloração preta, sem odor característico e semelhante a um rejeito proveniente de uma etapa de concentração da magnetita por separação magnética. As amostras utilizadas nos ensaios, em geral de 1,0 gramas, foram geradas a partir de uma porção de aproximadamente 2,0 quilogramas.

\section{2.}

\section{Preparação da matéria-prima}

Considerando as condições iniciais do material como recebido, se fez necessário preparo prévio da amostra, como retirada de umidade, homogeneização. Os procedimentos foram realizados no laboratório de processos químicos do Departamento de Engenharia Química e de Materiais da PUC - Rio.

\subsection{1.}

\section{Quarteamento}

Sendo o material recebido um rejeito do minério de vanádio, sua composição elementar pode variar significativamente de acordo com a área selecionada da amostra. Com intuito de conferir a maior homogeneidade possível ao material, ele foi submetido ao processo de quarteado utilizando um quarteador tipo “Jones", ilustrado na Figura 8. 
Figura 8 - Esquema de quarteamento.

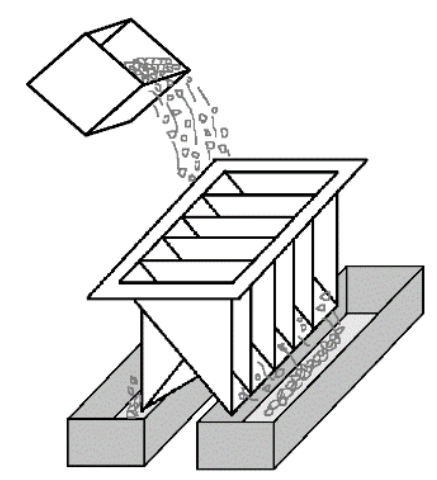

Fonte: Autor.

A amostra recebida foi despejada por inteiro no quarteador, e um dos recipientes de coleta foi escolhido para ser despejado novamente. Os recipientes foram escolhidos de maneira alternada, até que sobrasse uma massa de aproximadamente 200 gramas (g).

Esse procedimento foi realizado duas vezes, para garantir maior grau de mistura ao material.

\subsection{2.}

\section{Secagem}

Para retirada de umidade, tomando cuidado para que não ocorressem oxidações indesejadas no material ainda não caracterizado, a amostra previamente quarteada foi disposta em vidros de relógio dentro de uma estufa, conforme ilustrado na Figura 9, a $50{ }^{\circ} \mathrm{C}$ durante um período de $24 \mathrm{~h}$.

Figura 9 - Esquema de secagem na estufa.

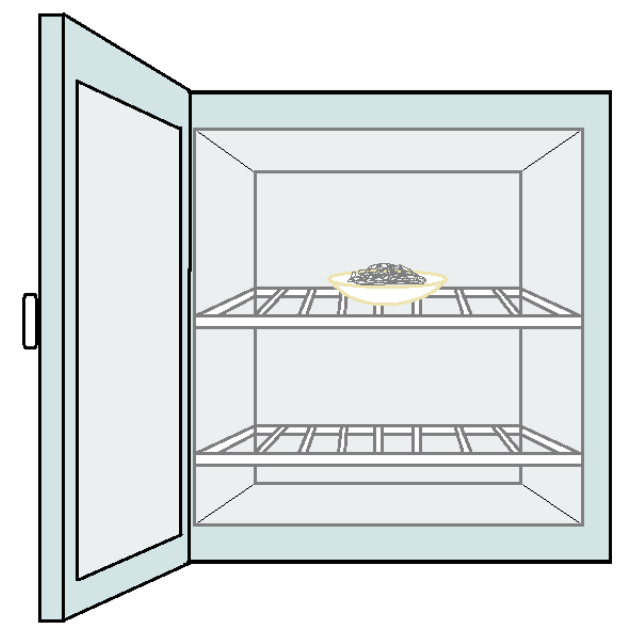

Fonte: Autor. 


\section{3.}

\section{Caracterização da matéria-prima}

Sendo a matéria-prima recebida uma mistura pouco conhecida, se fez necessário a caracterização detalhada do material afim de identificar os compostos e elementos fundamentais que o constituem, antes de determinar a abordagem a ser utilizada. Bem como suas características morfológicas, físicas, químicas e mineralógicas do material.

\subsection{1.}

\section{Distribuição granulométrica}

Para identificar o tamanho médio de partículas, montou-se uma série contendo seis peneiras (tipo Tyler), descritas na Figura 10, acopladas a um agitador, para a separação do material.

Foram pesados cerca de $200 \mathrm{~g}$ do material e adicionados a peneira do topo, que em seguida foram presas ao agitador e agitadas por $60 \mathrm{~min}$ seguidos. Decorrido o tempo, o material retido em cada peneira e no fundo foi pesado.

Figura 10 - Esquema de peneiras.

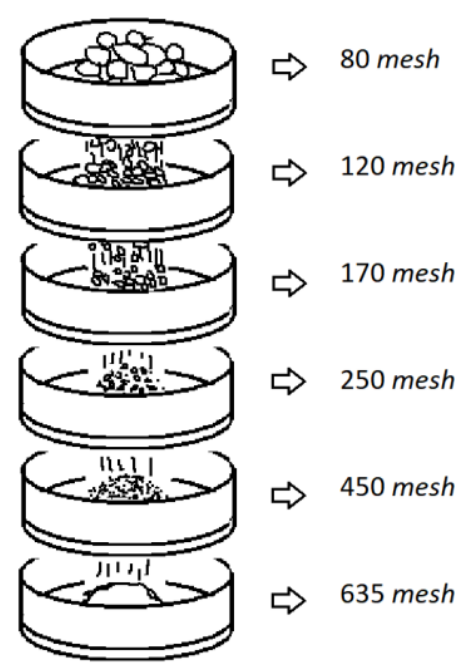

Fonte: Autor.

A fração mássica retida foi calculada dividindo a massa de material retido na peneira pela soma das massas de todas as peneiras. A equação 1 mostra como é calculada a fração mássica retida na peneira, usando como exemplo a de 80 mesh.

$$
\%_{i}=\left(\frac{M_{i}}{M_{t}}\right) \times 100
$$


$M_{i}$ : massa das partículas retidas na peneira de $i$ mesh, em g;

$M_{t}$ : massa total inicial, em $\mathrm{g}$;

O cálculo foi feito para todas as peneiras e para o fundo.

O material coletado em cada peneira foi separado para posterior análise em microscopia eletrônica de varredura - MEV, afim de identificar possíveis tendências nas concentrações de elementos.

\subsection{2.}

\section{Difração de Raios-X - DR-X}

Com intuito de identificar as possíveis estruturas cristalinas e fases presentes do material como recebido, foi realizada uma análise de Difração de Raios-X, utilizando um difratômetro da PANalytical, modelo X'pert Pro XPD, com radiação $\mathrm{CuK} \alpha$, varredura $2 \theta$ de 10 a $99^{\circ}$, com passo de $0,05^{\circ}$ e tempo de aquisição de 200 s por passo, no Laboratório de Difração de Raios - X do Centro Brasileiro de Pesquisas Físicas - CBPF.

A amostra como recebida apresentava tamanho de partícula suficientemente pequeno, não sendo assim necessário preparo prévio para analisar no $\mathrm{DR}-\mathrm{X}$.

Os dados foram analisados tanto no software Highscore da PANalytical, programa qualitativo que verifica as fases presentes na amostra, quanto no software Topas da Bruker, programa quantitativo, que determina as quantidades de cada fase contida na amostra, em termos de percentual em massa.

\subsection{3.}

\section{Fluorescência de Raios-X - FRX}

Com intuito de identificar a composição química do material como recebido, foi adotada a técnica de FR-X utilizando um espectrômetro por fluorescência de raios-x WDS-1, modelo AxiosMax (Panalytical), do laboratório de fluorescência de raios- $X$ do Centro de Tecnologia Mineral - CETEM.

A amostra foi preparada em prensa automática VANEOX (molde de $20 \mathrm{~mm}$, pressão $=20$ ton e tempo $=30 \mathrm{~s}$ ), utilizando como aglomerante ácido bórico $\left(\mathrm{H}_{3} \mathrm{BO}_{3}\right)$ na proporção de $1: 0,3$ - 0,6 g do ácido e 2,0 g da amostra seca à $100{ }^{\circ} \mathrm{C}$.

Os resultados semiquantitativos são expressos em \%, calculados como óxidos normalizados a $100 \%$. 


\subsection{4.}

\section{Microscopia Eletrônica de Varredura - MEV}

Para caracterizar a morfologia e homogeneidade das partículas da amostra foram utilizados alternadamente e de maneira complementar dois equipamentos: O Microscópio da Hitachi TM3000 e o da JEOL JSM-6510LV, ambos localizados na PUC-Rio. O primeiro utiliza detector de elétrons retroespalhados, possibilitando identificação das diferentes fases (previamente identificadas por DR-X) devido sua diferença de contraste e chega a aumentos com nitidez de até 10.000 x. O segundo utiliza detector de elétrons secundários, que possibilitam a identificação da morfologia dos grãos presentes na amostra.

Em paralelo foram analisados por Espectroscopia de Dispersão de Energia Característica de Raios-X, EDS. Esse detector está acoplado em ambos os equipamentos do MEV utilizados, por meio dele é possível identificar a composição elementar, em quantidades percentis estimadas, de cada partícula da amostra ou de uma área selecionada. O que permitiu uma correlação entre a identificação das fases e morfologia com as análises de DR-X.

\subsection{5.}

\section{Espectroscopia de emissão atômica com plasma acoplado indutivamente - ICP-AES}

Com intuito de identificar a composição química do material como recebido de forma mais abrangente que a feita por FR-X, a amostra foi enviada para fazer uma análise em ICP-AES, modelo ICAP 6500 DUO (axial-radial) da marca Thermo Scientific. Para a amostra foram utilizados os métodos de ensaio Multielemental com digestão multi-ácida e de ensaios específicos para arsênio e mercúrio.

Por ser uma análise muito sensível, capitando a presença de elementos com concentrações de até $1 \mathrm{ppm}$, para analisar o teor de titânio na amostra foi necessário fazer uma análise separada, também pelo método de digestão multiácida.

\section{4.}

\section{Avaliação do comportamento termodinâmico}

Após a identificação da composição elementar do material foram estipuladas, com o auxílio do software HSC Chemistry 6, as respectivas reações 
dos possíveis óxidos contidos na amostra com os reagentes propostos, com intuito de verificar a viabilidade das reações propostas e os possíveis produtos a serem gerados.

Os reagentes a serem considerados na análise foram o fosfato de sódio, carbonado de sódio e sulfato de sódio. Após a determinação do reagente mais promissor, foi determinado o balanço de massa do sistema, a partir da composição indicada pelas diferentes técnicas de caracterização, para determinar a quantidade mínima de reagente necessário.

Foram gerados gráficos de composição de equilíbrio para todas as reações, para verificar o comportamento teórico dos sistemas reacionais ao longo do aumento da temperatura.

\section{5.}

\section{Ensaios Experimentais}

Com o intuito de concentrar o óxido de titânio na amostra, foram realizados ensaios de fusão alcalina, em forno do tipo mufla, seguida de solubilização seletiva em água e depois $\mathrm{HCl}$, adaptando a metodologia de Tathavadkar e Jha (2004) e Lasheen (2008), o fluxograma descrito na Figura 11 mostra o processo adotado no presente trabalho. O roteiro dos ensaios está ilustrado a seguir e detalhado nos próximos tópicos.

Figura 11 - Esquema do Roteiro Experimental

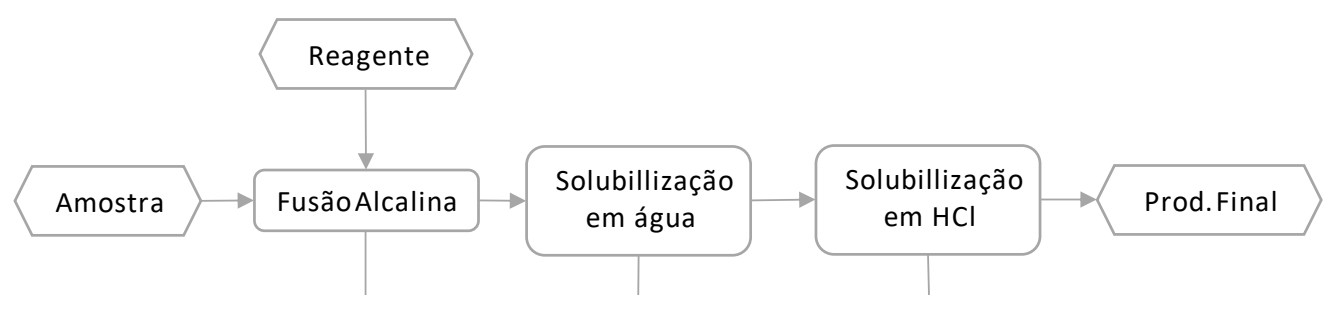

\subsection{1.}

\section{Determinação do tempo residência apropriado}

Para determinar experimentalmente o tempo ideal de reação na mufla foram realizados 5 experimentos variando apenas o tempo de reação dentro da mufla, com temperatura de $850{ }^{\circ} \mathrm{C}$ e relação mássica de $1: 1$, totalizando $2,0 \mathrm{~g}$. 
Os tempos de reação trabalhados estão dispostos na Tabela 2, cada tempo correspondendo a um ensaio independente.

Tabela 2 - Matriz de ensaios de determinação de tempo reacional.

\begin{tabular}{c|c}
\hline \multirow{2}{*}{ Ensaio } & Variáveis Reais \\
\cline { 2 - 2 } & Tempo (min) \\
\hline $\mathbf{1}$ & 15 \\
$\mathbf{2}$ & 30 \\
$\mathbf{3}$ & 60 \\
$\mathbf{4}$ & 90 \\
$\mathbf{5}$ & 120 \\
\hline
\end{tabular}

Antes da reação, as massas da barquete vazia, da amostra e de reagente eram anotadas separadamente. As massas da amostra e reagente eram misturadas por cerca de 30 segundos, a fim de garantir que houvesse contato total entre as duas partes. Em seguida a massa misturada era adicionada a barquete e pesada, considerando esse valor a massa 'inicial' da reação.

Decorrido o tempo, a massa final foi pesada, esperando que o cadinho chegasse a temperatura suportável pela mão. O material reagido em seguida foi imediatamente, imergido em $250 \mathrm{~mL}$ de água destilada a $70{ }^{\circ} \mathrm{C}$ por cerca de 30 min, agitado manualmente com auxílio de um bastão de vidro. A diferença de massa em cada etapa foi o determinante para selecionar a tempo de reação.

\subsection{2.}

\section{Reação de fusão com reagente alcalino}

Após a determinação do tempo reacional, que foi de 90 minutos (min), foram realizados 12 ensaios nas condições dispostas na Tabela 3, variando temperatura e a proporção entre as massas da amostra e do reagente, com tempo fixo de 90 minutos. 
Tabela 3 - Matriz de ensaios com tempo de $90 \mathrm{~min}$.

\begin{tabular}{c|cc}
\hline \multirow{2}{*}{ Ensaio } & \multicolumn{2}{|c}{ Variáveis Reais } \\
\cline { 2 - 3 } & T ( $\left.{ }^{\circ} \mathrm{C}\right)$ & Relação mássica $(\mathrm{g})$ \\
\hline $\mathbf{1}$ & 800 & $50 \%(-)$ \\
$\mathbf{2}$ & 800 & Esteq \\
$\mathbf{3}$ & 800 & $50 \%(+)$ \\
\hline $\mathbf{4}$ & 850 & $50 \%(-)$ \\
$\mathbf{5}$ & 850 & Esteq \\
$\mathbf{6}$ & 850 & $50 \%(+)$ \\
\hline $\mathbf{7}$ & 900 & $50 \%(-)$ \\
$\mathbf{8}$ & 900 & Esteq \\
$\mathbf{9}$ & 900 & $50 \%(+)$ \\
\hline $\mathbf{1 0}$ & 950 & $50 \%(-)$ \\
$\mathbf{1 1}$ & 950 & Esteq \\
$\mathbf{1 2}$ & 950 & $50 \%(+)$ \\
\hline
\end{tabular}

O valor definido como estequiométrico foi considerando a massa de reagente necessária para reagir completamente de acordo com as reações favoráveis indicadas pelo $H S C$, e $50 \%$ a mais e a menos desse valor encontrado.

As reações aconteceram em um forno do tipo mufla, ilustrado na Figura 12, utilizando cadinhos retos de cerâmica.

Figura 12 - Representação genérica de um forno do tipo mufla.

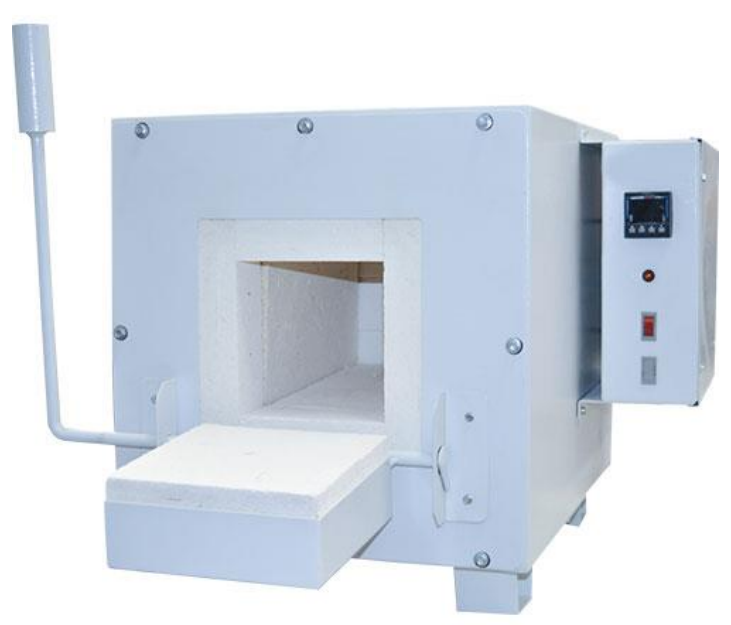

Fonte: Didática Sp. 
Para realizar o balanço de massa da reação, as massas iniciais e finais foram pesadas em balança analítica.

\subsection{3.}

\section{Lixiviação em $\mathrm{H}_{2} \mathrm{O}$}

O material reagido era imediatamente, após ser pesado, imergido em $250 \mathrm{~mL}$ de água destilada a $70{ }^{\circ} \mathrm{C}$ por cerca de $20 \mathrm{~min}$. $\mathrm{O}$ sistema foi aquecido em 'banho-maria' e agitado manualmente, com auxílio de um bastão de vidro, conforme ilustrado na Figura 13.

Figura 13 - Esquematização de 'banho-maria'.

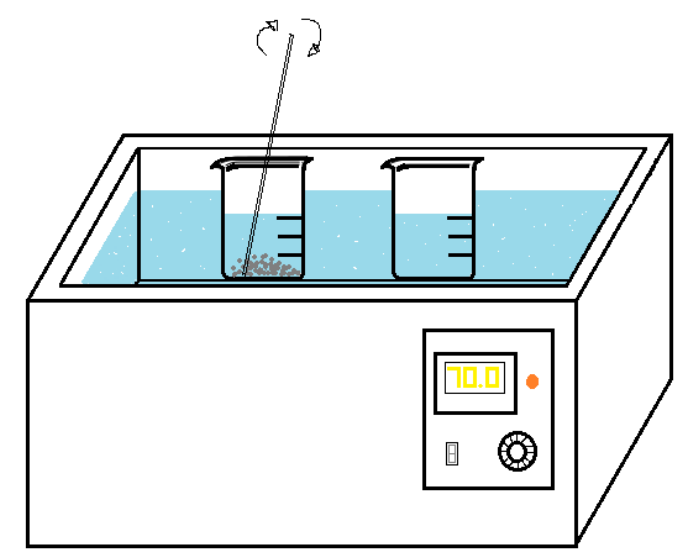

Fonte: Autor.

Decorrido o tempo a mistura era filtrada à vácuo, com auxílio de uma bomba a vácuo, papel de filtro qualitativo e funil, de acordo com a Figura 14. O material era então lavado mais 4 vezes em $250 \mathrm{~mL}$ água destilada aquecida. Ao final da lavagem, a última fração de água tinha o $\mathrm{pH}$ foi aferido.

Figura 14 - Esquema filtração à vácuo.

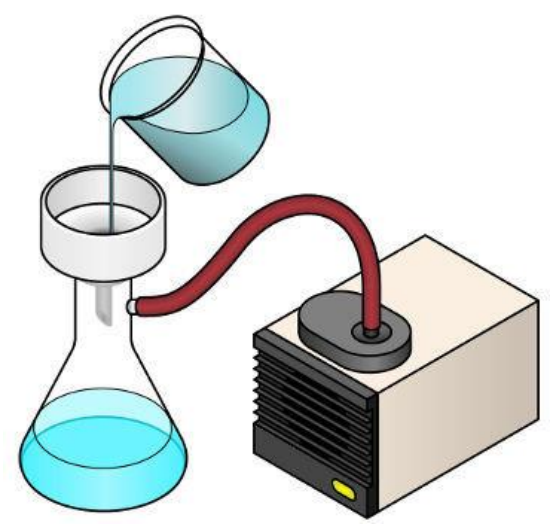

Fonte: Manual da Química. 
$\mathrm{O}$ resíduo filtrado era posto para secar à $50{ }^{\circ} \mathrm{C}$ por $24 \mathrm{~h}$ na estufa, e a massa final era pesada.

\subsection{4.}

\section{Lixiviação em HCl}

Em seguida o material seco e pesado era imergido em $50 \mathrm{~mL}$ de uma solução de $\mathrm{HCl} 5 \%$ a $70{ }^{\circ} \mathrm{C}$ por cerca de 20 minutos. O sistema foi aquecido em banho-maria e agitado manualmente, com auxílio de um bastão de vidro, conforme ilustrado na Figura 13.

Decorrido o tempo, o material foi filtrado seguindo exatamente o mesmo fluxo da lavagem em água do item 3.5.2.1.

$\mathrm{O}$ resíduo filtrado era posto para secar à $50{ }^{\circ} \mathrm{C}$ por $24 \mathrm{~h}$ em estufa, e a massa final pesada.

\section{6.}

\section{Caracterização dos produtos intermediários e final}

Os produtos intermediários e finais foram caracterizados de forma semelhante a caracterização do material como recebido, com alteração em alguns dos equipamentos utilizados.

No caso da difração de Raios-X - DR-X foi utilizado um difratômetro da Bruker AXS, modelo D8-Discover, com radiação $\mathrm{CuK} \alpha$, varredura $2 \theta$ de 10 a $90^{\circ}$, com passo de $0,02^{\circ}$ e tempo de aquisição de $200 \mathrm{~s}$ por passo, no Laboratório de Difração de Raios-X do Departamento de Engenharia Química e de Materiais da PUC-Rio. Esses dados foram analisados tanto no software Evaluation da Bruker, programa qualitativo que verifica as fases presentes na amostra, quanto no software Topas da Bruker.

No caso do Microscopia Eletrônica de Varredura - MEV foram utilizados alternadamente e de maneira complementar dois equipamentos da Hitachi TM3000 e o TM1000, ambos localizados na PUC-Rio. Ambos utilizam detector de elétrons retroespalhados. Em paralelo foram analisados utilizando detector EDS, no caso do Hitachi TM10000 só é possível fazer análise de área. 
3.7.

Ensaios experimentais avulsos

Alguns experimentos foram realizados de maneira independente, para analisar melhor determinados parâmetros. Estes ensaios levaram em consideração apenas a perda de massa entre as etapas.

\subsection{1.}

\section{Teste de solubilização}

Foi realizado em condições diferentes das do item 3.5.2 e para isso foi utilizado o ensaio 4 do item 3.5.1.

Foram aquecidos $50 \mathrm{~mL}$ de ácido clorídrico $5 \%$, à solução foi adicionada a massa da amostra previamente solubilizada em água e armazenada. A mistura ficou 20 min sob aquecimento e sendo agitada, conforme os ensaios do item 3.5.

Decorrido o tempo a amostra foi posta pra secar por $24 \mathrm{~h}$ e então analisada apenas em DR-X e MEV.

\subsection{2.}

Análise de perda de massa ao longo do tempo

A fim de estudar o comportamento de perda de massa ao longo do tempo em cada etapa do processo, foram feitos outros 16 ensaios em forno mufla, descritos na Tabela 4, com relação mássica constante, no ponto estequiométrico da reação com o reagente de carbonato de sódio e variando temperatura. 
Tabela 4 - Matriz de ensaios com relação mássica fixa e tempo variado.

\begin{tabular}{c|cc}
\hline \multirow{2}{*}{ Ensaio } & \multicolumn{2}{|c}{ Variáveis Reais } \\
\cline { 2 - 3 } & $\mathrm{T}\left({ }^{\circ} \mathrm{C}\right)$ & Tempo (min) \\
\hline $\mathbf{1}$ & 800 & 15 \\
$\mathbf{3}$ & 800 & 30 \\
$\mathbf{4}$ & 800 & 60 \\
\hline $\mathbf{5}$ & 800 & 120 \\
$\mathbf{6}$ & 825 & 15 \\
$\mathbf{7}$ & 825 & 30 \\
$\mathbf{8}$ & 825 & 60 \\
\hline $\mathbf{9}$ & 850 & 120 \\
$\mathbf{1 0}$ & 850 & 30 \\
$\mathbf{1 1}$ & 850 & 60 \\
$\mathbf{1 2}$ & 850 & 120 \\
\hline $\mathbf{1 3}$ & 900 & 15 \\
$\mathbf{1 4}$ & 900 & 30 \\
$\mathbf{1 5}$ & 900 & 60 \\
$\mathbf{1 6}$ & 900 & 120 \\
\hline & &
\end{tabular}

Após a reação no forno, as amostras reagidas foram solubilizadas e secas conforme os itens 3.5.3 e 3.5.4.

\subsection{3.}

\section{Ensaio sobre a influência da concentração da solução ácida}

Com intuito de verificar a influências de cada etapa de solubilização sobre a quantidade de massa removida da amostra, foram realizados três novos ensaios comparativos, alterando concentração da solução ácida e a quantidade de etapas.

As condições utilizadas para a reação conduzida no interior forno estão descritas a seguir na Tabela 5. O tempo de reação de todos os ensaios desse item foi o mesmo, de 90 minutos. 
Tabela 5 - Matriz de ensaios comparativos.

\begin{tabular}{c|cccc}
\hline \multirow{2}{*}{ Ensaio } & \multicolumn{4}{|c}{ Variáveis Reais } \\
\cline { 2 - 5 } & T $\left({ }^{\circ} \mathrm{C}\right)$ & Relação mássica $(\mathrm{g})$ & Etapas de solub. & Concentração (\%) \\
\hline $\mathbf{1}$ & 900 & Estequiométrica & 1 & $5 \%$ \\
$\mathbf{2}$ & 900 & Estequiométrica & 2 & $5 \%$ \\
$\mathbf{3}$ & 900 & Estequiométrica & 2 & $1 \%$ \\
\hline
\end{tabular}

O ensaio 1 seguiu as etapas 3.5.3 e 3.5.4 de solubilização e o ensaio 2 passou apenas pela etapa do item 3.5.4, as massas secas foram pesadas. 


\section{4 \\ Resultados e discussões}

\section{1.}

\section{Caracterização do material como recebido}

Para possibilitar a determinação de um método de processamento do material, visando concentrar titânio em teores de dióxido de titânio, o material, quarteado e seco, passou por métodos convencionais de caracterização, e seus resultados estão descritos nos subtópicos a seguir.

\subsection{1.}

\section{Análise granulométrica}

Por meio desta análise foi possível verificar a tendência do tamanho de partículas. Na Tabela 6, a seguir está descrito a abertura de cada peneira utilizada, bem como as massas retidas e acumuladas ao longo das peneiras. Nenhuma massa passou pela peneira 635, indicando que mesmo que algumas partículas tenham passado, não há quantidade significativa menores que $20 \mu \mathrm{m}$.

Tabela 6 - Distribuição granulométrica ao longo de uma série de peneiras de Tyler.

\begin{tabular}{ccccc} 
Peneira (mesh) & Abertura $(\boldsymbol{\mu m})$ & M. Retida $(\mathbf{g})$ & $\begin{array}{c}\% \\
\text { Retida }\end{array}$ & $\begin{array}{c}\% \\
\text { Acumulada }\end{array}$ \\
\hline 80 & 180 & 17.4654 & $11.54 \%$ & $11.54 \%$ \\
\hline 120 & 125 & 36.0833 & $23.85 \%$ & $35.39 \%$ \\
\hline 170 & 88 & 43.2771 & $28.60 \%$ & $63.99 \%$ \\
\hline 250 & 62 & 42.6018 & $28.15 \%$ & $92.14 \%$ \\
\hline 450 & 32 & 10.0585 & $6.65 \%$ & $98.79 \%$ \\
\hline 635 & 20 & 1.8357 & $1.21 \%$ & $100.00 \%$ \\
\hline
\end{tabular}

A partir desses dados foi possível traçar um gráfico ilustrando a distribuição de partículas, e traçar uma linha de tendência de dispersão, conforme apresentado na Figura 15. Considerando as \% de massa e o tamanho das aberturas calculou-se 
o tamanho médio de partícula, de acordo com a equação 2 abaixo, tendo o resultado de $96 \mu \mathrm{m}$.

$$
\frac{\sum\left(\text { abertura }_{i} * \% \text { retida }_{i}\right)}{\sum \% \text { retida }_{i}}
$$

Figura 15 - Distribuição granulométrica.

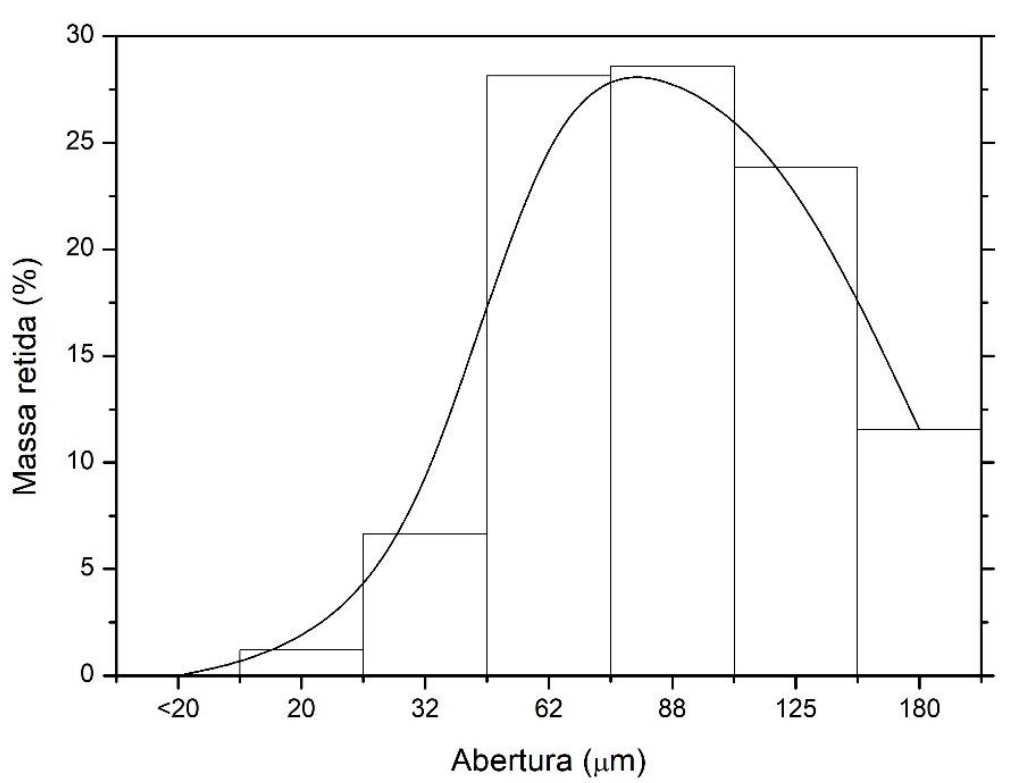

O material retido em cada peneira foi levado até o MEV TM 3000 a fim de avaliar a composição estimada por faixa de tamanho de partícula, com auxílio do detector EDS. A seguir, nas Figuras 16 até 27, pode-se observar o aspecto das partículas retidas em cada peneira e o espectro gerado por área em cada amostra.

Nas Figuras 16, 18, 20 e 22 podemos observar que ainda há resquícios de partículas muito menores do que a abertura da peneira correspondente. Isso sugere que as partículas possuem atratividade entre si, o que segundo Jena e colaboradores (1995) pode ser justificado pelo baixo caráter magnético dos compostos característicos desse tipo de amostra contendo ilmenita.

Nas Figuras 17, 19, 21 e 23 podemos observar os espectros de EDS correspondentes a cada imagem anterior, respectivamente, permitindo identificar o elenco de elementos contidos em cada fração. 
Figura 16 - Imagem dos particulados retidos na peneira de 80 mesh.

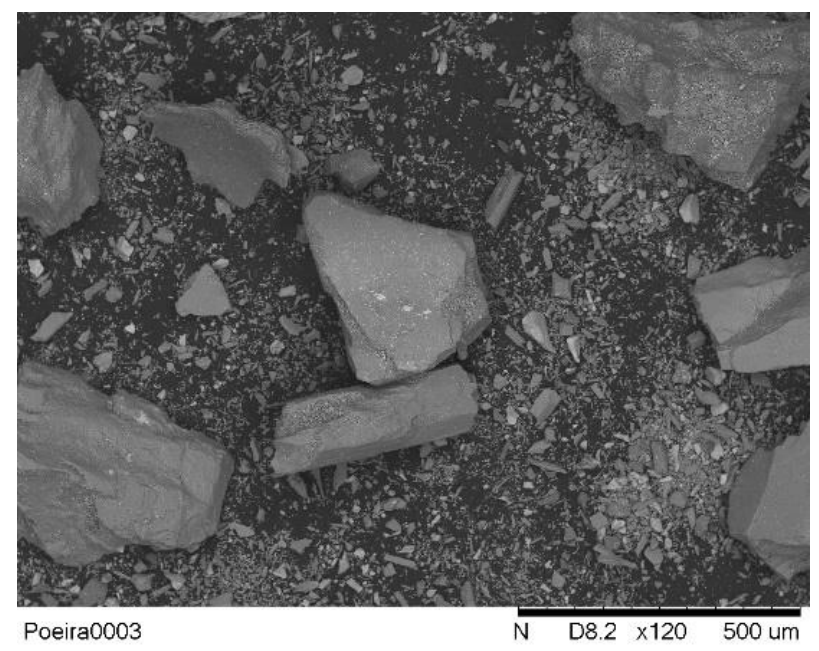

Figura 17 - Espectro das partículas retidas na peneira de 80 mesh.

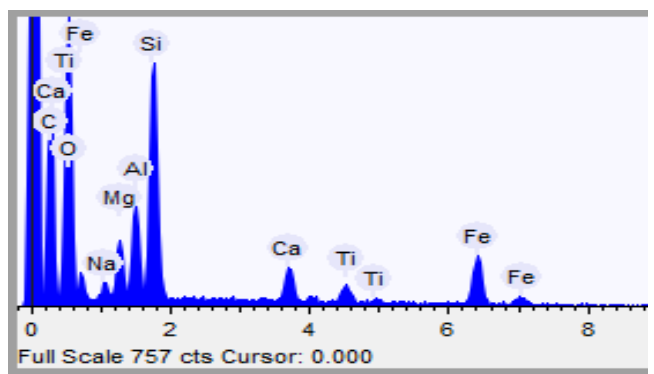

Figura 18 - Imagem das partículas dos retidos na peneira de 120 mesh.

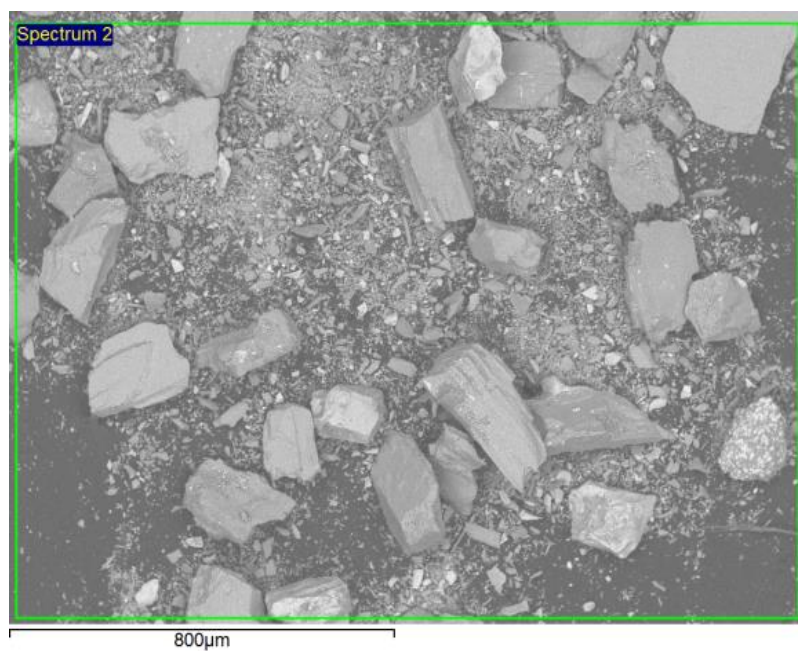


Figura 19 - Espectro das partículas retidas na peneira de 120 mesh.

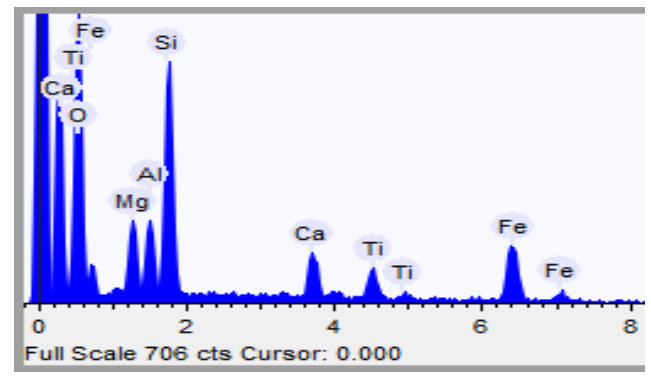

Figura 20 - Imagem dos particulados retidos na peneira de 170 mesh.

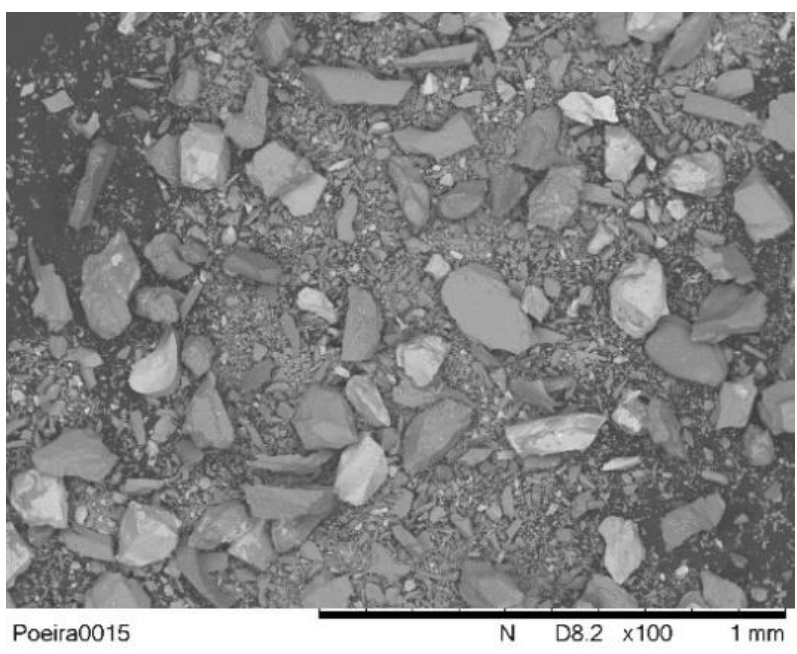

Figura 21 - Espectro das partículas retidas na peneira de 170 mesh.

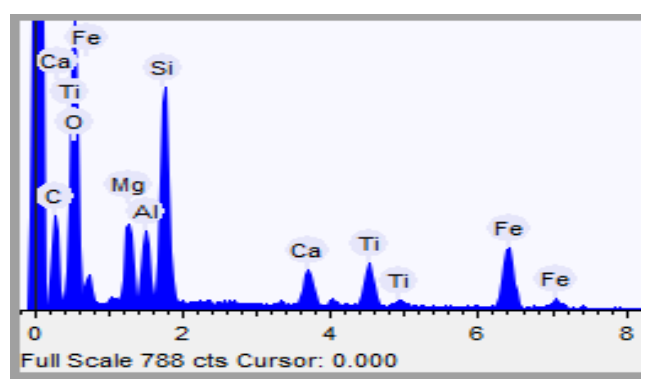


Figura 22 - Imagem dos particulados retidos na peneira de 250 mesh.

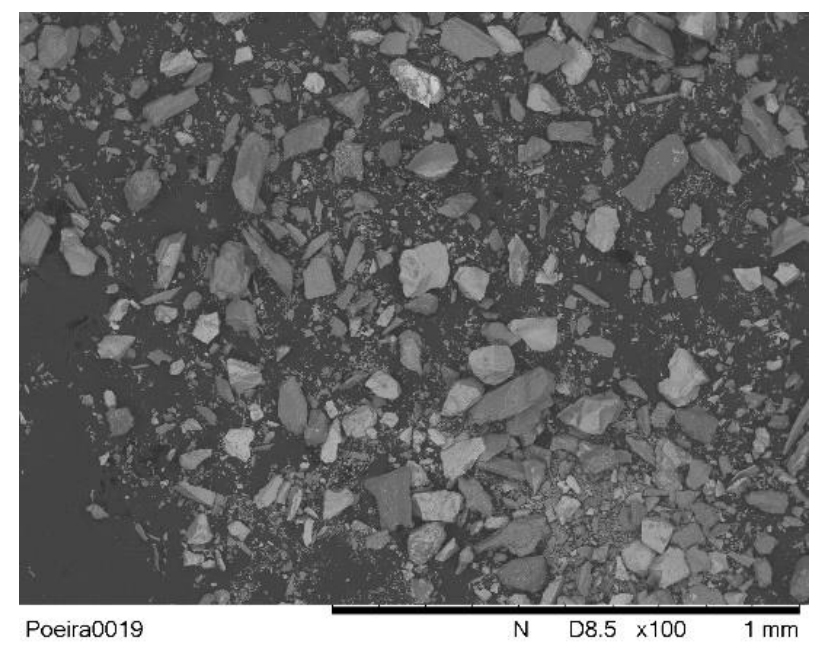

Figura 23 - Espectro das partículas retidas na peneira de 250 mesh.

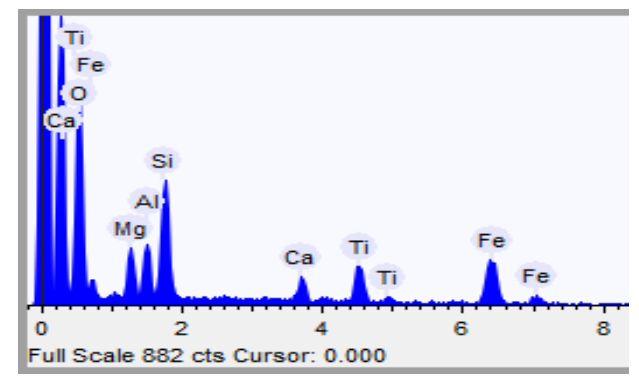

Apesar de ser a fração não magnético da concentração da magnetita, o separador magnético utilizado é de baixa intensidade, separando o conteúdo de alto caráter magnético deixando para trás um conteúdo que pode apresentar baixo caráter, corroborando com os resultados observados no microscópio.

Já nas frações mais finas, Figuras 24 e 26, pode-se observar maior homogeneidade no tamanho de partículas, sugerindo que essas partículas não apresentam caráter magnético. As Figuras 25 e 27 correspondem aos espectros de EDS de cada fração. 
Figura 24 - Imagem dos particulados retidos na peneira de 450 mesh.

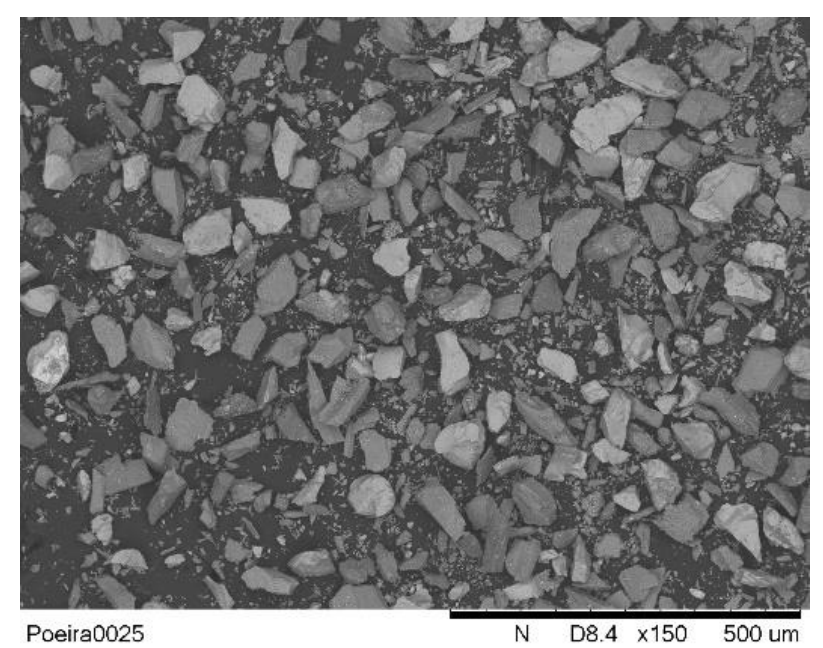

Figura 25 - Espectro das partículas retidas na peneira de 450 mesh.

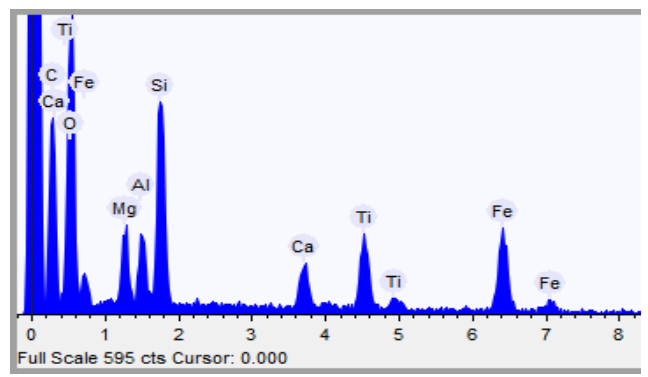

Figura 26 - Imagem dos particulados retidos na peneira de 635 mesh.

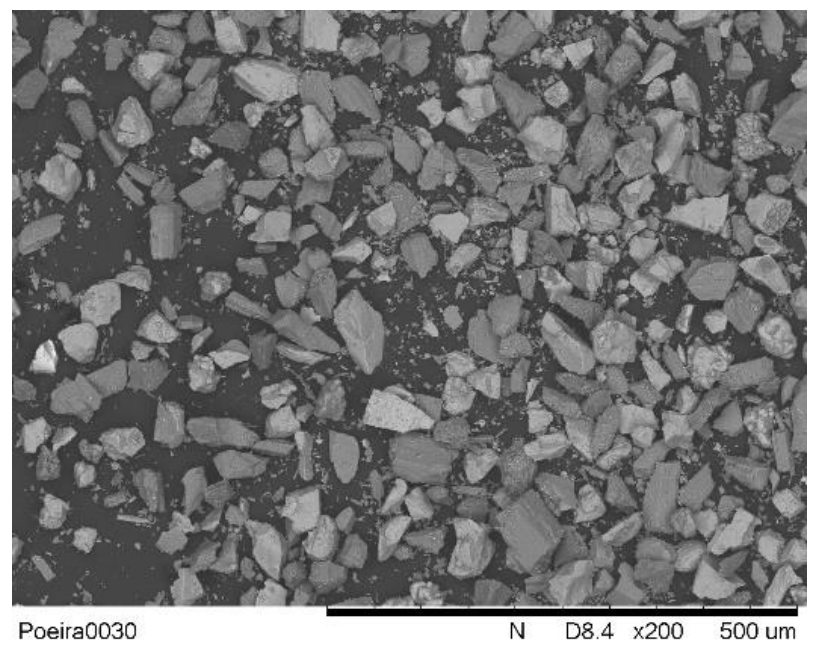


Figura 27 - Espectro das partículas retidas na peneira de 635 mesh.

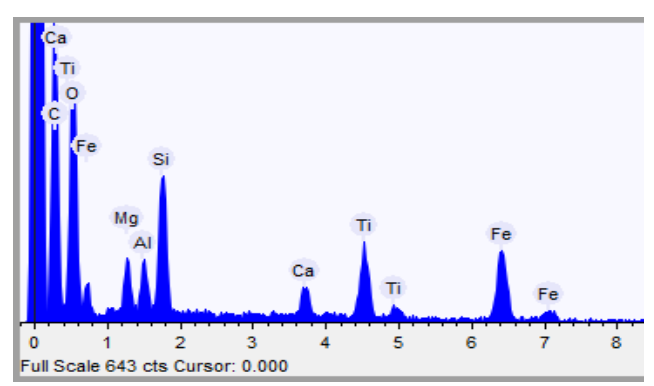

A partir dessa análise utilizando o EDS, foi possível fazer o gráfico, ilustrado na Figura 28, de distribuição dos elementos ao longo das peneiras. Vale ressaltar que, devido ao tipo de captura de raios-x poder ter interferência de outros sinais, os valores fornecidos pelo EDS não podem ser considerados precisos, podendo ter variações altas entre o identificado e o real (Goldstein, 2018).

Observando o gráfico nota-se que quanto menor o tamanho de partícula, maiores os teores de ferro e titânio, enquanto que $\mathrm{Si}, \mathrm{Al}, \mathrm{Mg}$ e $\mathrm{Ca}$ tendem a permanecer similares. As quantidades de oxigênio identificadas pelo detector eram muito maiores que as dos demais elementos e por conta disso foi removida do gráfico.

Figura 28 - Distribuição elementar na série de Tyler.

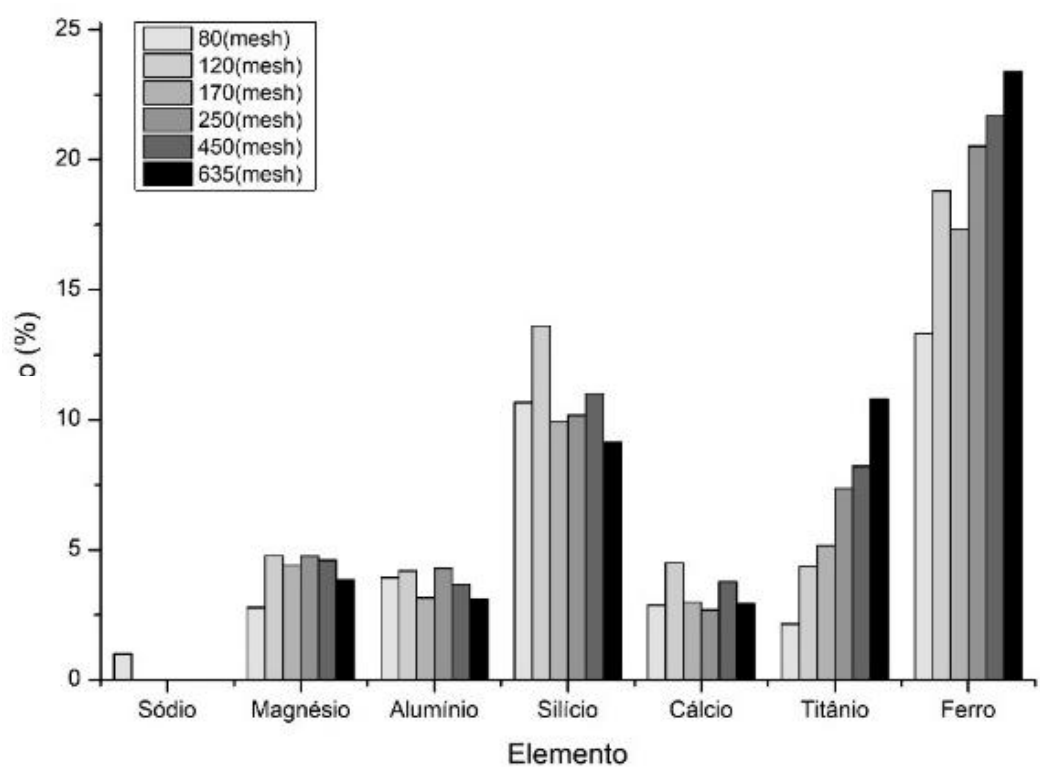

Em reações, sólido-sólido o tamanho de partícula pode interferir diretamente na eficiência da reação, como o tamanho médio de partícula da amostra está 
abaixo de $100 \mu \mathrm{m}$, acreditou-se ter superfície de contato suficiente para que as reações acontecessem com êxito.

A amostra também foi levada para análise em MEV-FEG da Jeol (aumentos de 5000 e 2500 X) a fim de se identificar eventuais detalhes. Os resultados estão apresentados nas Figuras 29 e 31, as quais estão seguidas dos espectros correspondentes, nas Figuras 30 e 32. Sabe-se que as imagens geradas por elétrons secundários (SE) (no caso da utilização MEV-FEG) não apresentam relação entre as diferenças no contraste e o peso atômico do elemento, sendo utilizadas apenas para identificação da topografia da amostra (Goldstein, 2018).

Figura 29 - Imagem da matéria-prima gerada por SE com aumento de 5000x.

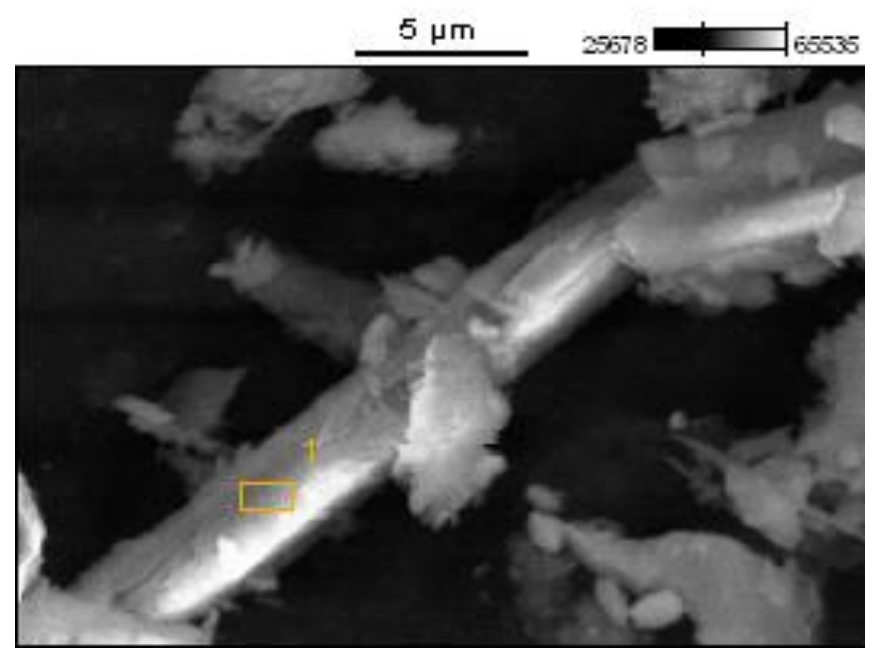

Figura 30 - Espectro de elementos gerados por análise de EDS.

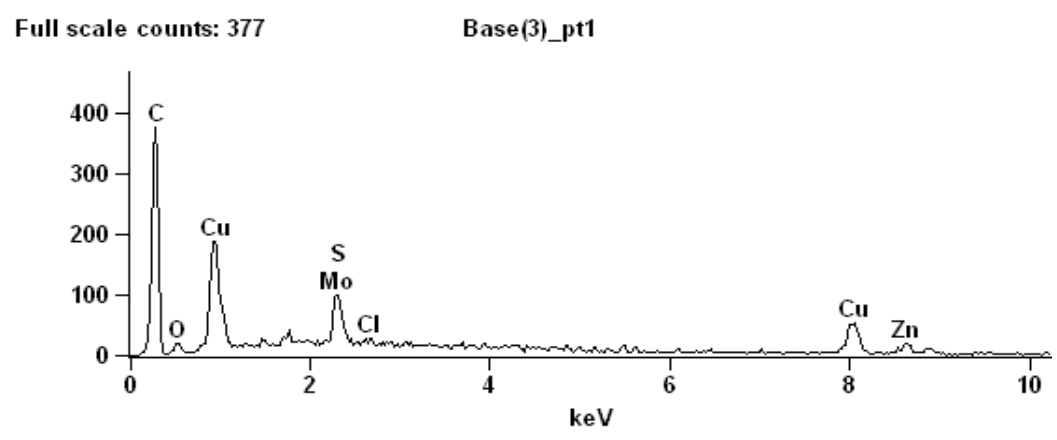


Figura 31 - Imagem da MP gerada por SE com aumento de 2500x

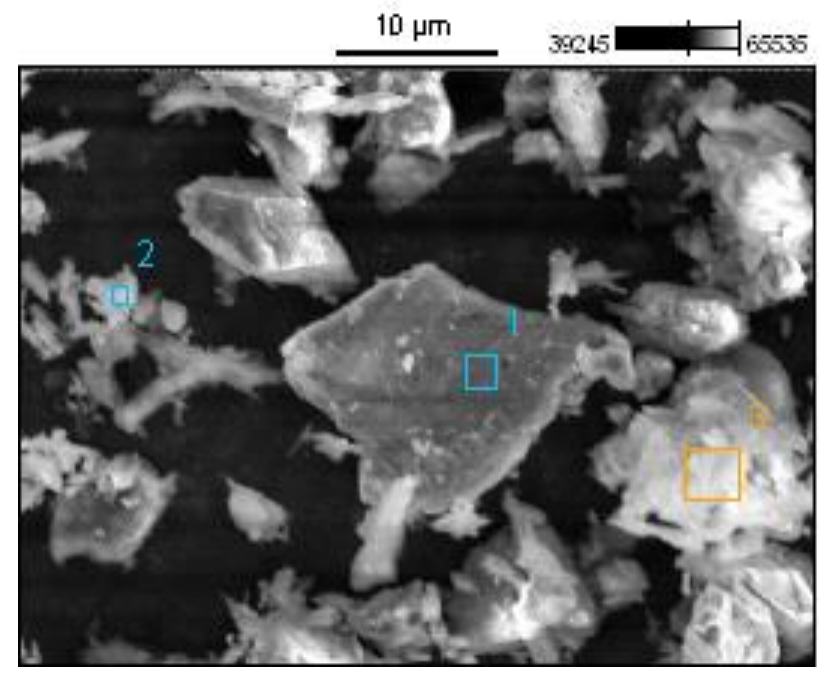

Figura 32 - Espectro de elementos gerados por análise de EDS

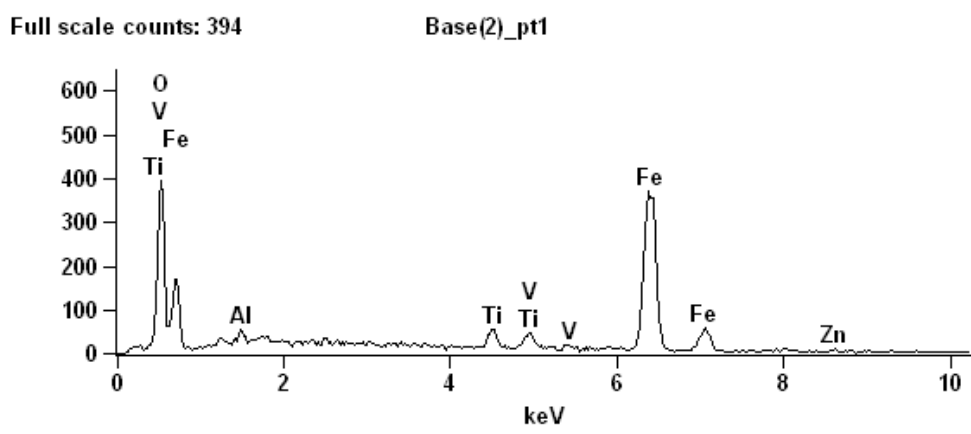

A partir destes resultados, pôde-se identificar grãos com morfologia cilíndrica. Esta morfologia diferenciada, observada em aumentos maiores, é justificada pela composição, também diferenciada, do grão, pois contém elementos que não foram captados anteriormente, tais como $\mathrm{Mo}, \mathrm{Cu}$ e $\mathrm{Zn}$. Esse resultado sugere que esses elementos estão presentes em quantidades pequenas e por isso não foram detectados em aumentos menores. Confirmou-se a presença de grãos contendo Fe e Ti, típicos da ilmenita, mas com a presença de $\mathrm{Al}$ e V.

\subsection{2.}

\section{Difração de Raios-X (DR - X)}

A análise de DR-X de um rejeito de mineração é complexa, pela quantidade de compostos e fases que pode conter. Sabendo que o minério pode conter $\mathrm{Ca}, \mathrm{Na}$, $\mathrm{Si}, \mathrm{Al}, \mathrm{Mg}, \mathrm{Mn}$, de acordo com Jena e colaboradores (1995) e Tathavdkar e Jha (2004), foi utilizado o software Highscore para determinar as melhores fases que se encaixam no difratograma da amostra. 
O programa indicou seis fases mais prováveis, conforme descrito na Tabela 7 abaixo, contudo uma das fases não possuía ficha catalográfica na base de dados ICSD, não sendo possível concluir a análise apurada no Topas.

Tabela 7 - Fases prováveis segundo análise de dr-X.

\begin{tabular}{llc} 
Mineral & Fórmula & Ficha \\
\hline Rutilo & $\mathrm{TiO}_{2}$ & ICSD 24277 \\
Anatásio & $\mathrm{TiO}_{2}$ & ICSD 9852 \\
Ilmenita & $\mathrm{FeO} \mathrm{TiO}_{2}$ & ICSD 91569' \\
Tremolita & $\left(\mathrm{Ca}_{1.97} \mathrm{Na}_{0.012} \mathrm{Fe}_{0.018}\right) \mathrm{Mg}_{5}\left(\mathrm{Si}_{8} \mathrm{O}_{22}\right)(\mathrm{OH})_{2}$ & ICSD 82412 \\
Clinocloro IIb-2 & $\left(\mathrm{Mg}_{2.96} \mathrm{Fe}_{1.69} \mathrm{Al}_{1.275}\right)\left(\mathrm{Si}_{2.624} \mathrm{Al}_{1.376} \mathrm{O}_{10}\right)(\mathrm{OH})_{8}$ & ICSD 66258 \\
Kaersutita & $\mathrm{NaCa}_{2}\left(\mathrm{Mg}, \mathrm{Fe}^{2+}\right)_{4} \mathrm{Ti}_{(}\left(\mathrm{Si}_{6} \mathrm{Al}_{2}\right) \mathrm{O}_{22}(\mathrm{OH})$ & - \\
\hline
\end{tabular}

Apesar de não poder incluir a kaersutita na análise quantitativa, a ficha dela, disponível no Highscore, pode ser visualizada na Figura 33. É possível visualizar na imagem, que os picos da ficha se encaixam muito bem aos da amostra.

Figura 33 - Difratograma qualitativo da kaersutita.

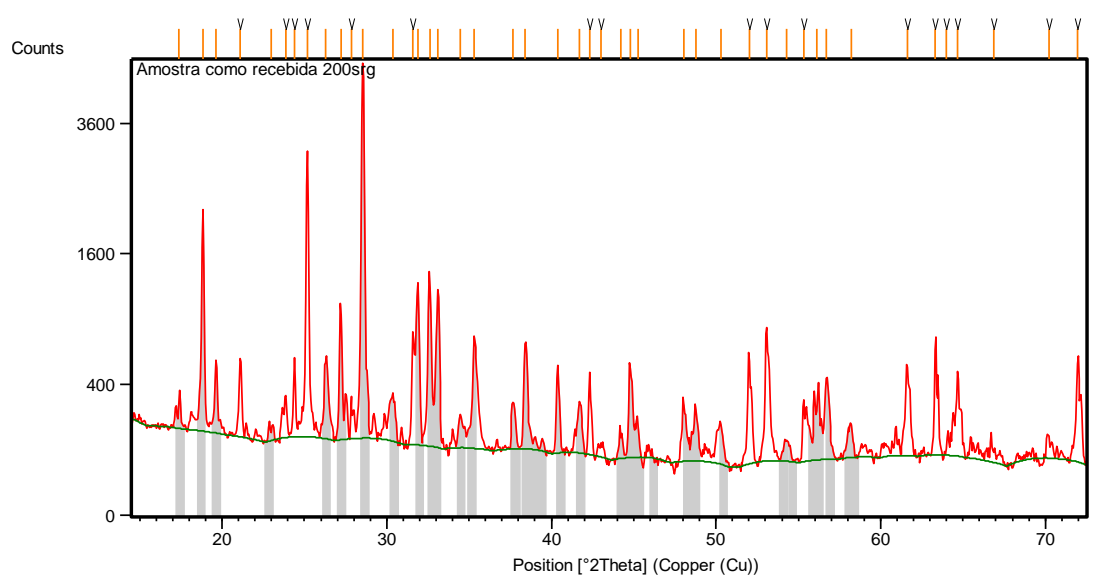

Ao adicionar as fichas catalográficas da Tabela 7 no programa Topas foi possível obter as quantidades quantitativas aproximadas dos compostos e fases presentes no minério recebido. O programa usa como base de cálculos o método de Rietveld. O difratograma ajustado pode ser visualizado na Figura 34.

Figura 34 - Difração de raios- $x$ da amostra como recebida.

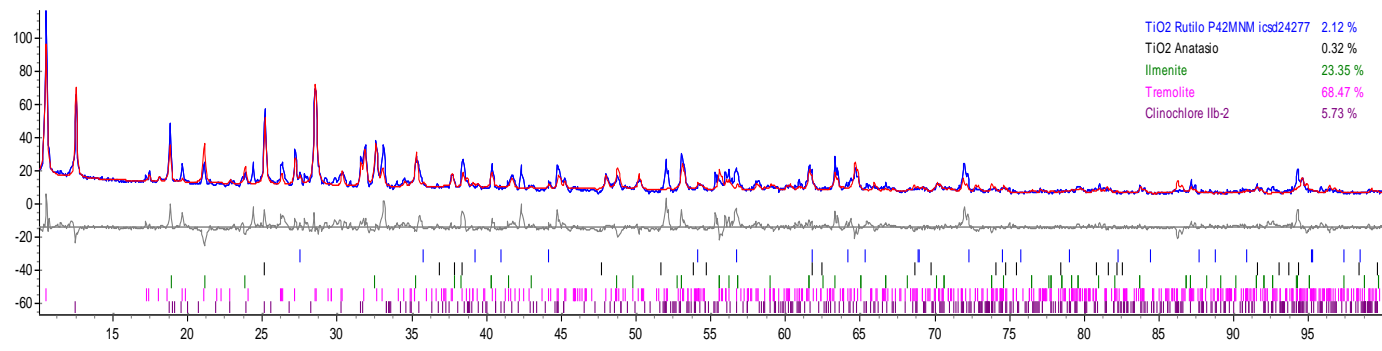


Mesmo com o melhor ajuste, ainda é possível verificar picos remanescentes, isso significa que não pode ser considerado preciso, por isso se faz necessário análises químicas complementares para que a caracterização seja mais precisa.

A análise indicou altos teores de tremolita e de ilmenita, valores detalhados na Tabela 8 , sugerindo que a maior parte do material está em forma complexa, com grãos contendo elementos misturados de $\mathrm{Fe}, \mathrm{Ca}, \mathrm{Mg}$ e Si. Já a maior parte do titânio se encontra na forma da ilmenita, contudo como não foi possível quantificar a kaersutita, mineral que contem titânio na sua formulação, não é possível saber quanto de Ti está contido em outras formas.

Tabela 8 - Ajuste composicional fornecido pelo Topas.

\begin{tabular}{cc} 
Mineral & Composição \\
\hline Rutilo & $2.12 \%$ \\
Anatásio & $0.32 \%$ \\
Ilmenita & $23.35 \%$ \\
Tremolita & $68.47 \%$ \\
Clinocloro IIb-2 & $5.73 \%$ \\
Kaersutita & - \\
\hline
\end{tabular}

Se considerarmos que as quantidades de composição fornecidas são acuradas, por meio de cálculos de balanço de massa onde se considera as quantidades de Ti contidas dentro de cada composto é possível encontrar uma estimativa de cerca de $9 \%$ de Ti na amostra.

Segundo Andreozzi e colaboradores (2017) a tremolita faz parte do restrito grupo do amianto.

\subsection{3.}

\section{Fluorescência de Raios - X $(\mathbf{F R}-\mathbf{X})$}

Buscando complementar as informações da análise de DR-X foi feita uma análise de FR-X. Essa análise revelou os principais elementos constituintes do material como recebido, as informações são dadas em termos de óxidos.

Os maiores constituintes da amostra são ferro e silício, correspondendo a $61.4 \%$ da amostra, o resultado detalhado está descrito na Tabela 9.

Tabela 9 - Dados composicionais fornecidos pelo FR-X. 
\begin{tabular}{l|llllllllll}
\hline Composição & $7.7 \%$ & $7.0 \%$ & $25.8 \%$ & $11.0 \%$ & $1.0 \%$ & $35.6 \%$ & $11.3 \%$ & $0.2 \%$ & $0.2 \%$ & $0.3 \%$ \\
\hline
\end{tabular}

A composição exata de um minério pode variar relativamente bastante de acordo com as características do depósito. Tanto Jena e colaboradores (1995) quanto Tathavadkar e Jha (2004) citam os óxidos e suas quantidades semelhantes ao encontrado no presente trabalho. Baltar e colaboradores (2008) comenta que o teor em $\mathrm{TiO}_{2}$ depende do grau de alteração da ilmenita do depósito.

Diferente da análise por DR-X, que identifica apenas os compostos cristalinos da amostra, o FR-X identifica todo os compostos, amorfos ou cristalinos, e por isso se justifica a diferença da quantidade de Ti calculada a partir do resultado do DR-X para este resultado do FR-X. Essa diferença entre os resultados sugere também que o Ti se encontra em compostos amorfos.

\subsection{4.}

\section{ICP - AES}

Está análise identificou os elementos metálicos que estevam presentes em quantidades muito pequenas na amostra, menores que $1,0 \%$. O resultado da análise está disposto na Tabela 10. Como o teor de titânio ultrapassa essa quantidade máxima da análise, foi necessário fazer uma análise independente para identificar o teor de titânio foi feita uma análise separada.

Tabela 10 - Dados composicionais fornecidos pelo ICP.

\begin{tabular}{c|ccccc}
\hline Elemento & $\mathrm{As}$ & $\mathrm{Ag}$ & $\mathrm{Ba}$ & $\mathrm{Cd}$ & $\mathrm{Co}$ \\
\hline Composição & $0.004 \%$ & $0.000 \%$ & $0.001 \%$ & $0.000 \%$ & $0.035 \%$ \\
\hline Elemento & $\mathrm{Cr}$ & $\mathrm{Cu}$ & $\mathrm{Ga}$ & $\mathrm{In}$ & $\mathrm{K}$ \\
\hline Composição & $0.003 \%$ & $0.047 \%$ & $0.003 \%$ & $0.002 \%$ & $0.774 \%$ \\
\hline Elemento & $\mathrm{Li}$ & $\mathrm{Mn}$ & $\mathrm{Mo}$ & $\mathrm{Ni}$ & $\mathrm{P}$ \\
\hline Composição & $0.011 \%$ & $0.298 \%$ & $0.004 \%$ & $0.025 \%$ & $0.016 \%$ \\
\hline Elemento & $\mathrm{Pb}$ & $\mathrm{Sr}$ & $\mathrm{Ti}$ & $\mathrm{V}$ & $\mathrm{Zn}$ \\
\hline Composição & $0.024 \%$ & $0.006 \%$ & $6.552 \%$ & $0.148 \%$ & $0.015 \%$ \\
\hline
\end{tabular}

Para quantidades muito elevadas (mais de 1,0\%), há um aumento no erro pois a amostra precisa ser diluída muitas vezes na abertura, contudo considerando que os valores de Ti estão semelhantes aos valores de $\mathrm{TiO}_{2}$ do $\mathrm{FR}-\mathrm{X}$ aceitasse a acuracidade das análises. 


\subsection{5.}

\section{Microscopia eletrônica de varredura - MEV}

Para complementar a análise de caracterização do material, foi utilizado um microscópio eletrônico de varredura TM 30000, que permite visualizar partículas muito pequenas, por meio de um detector de elétrons retroespalhados. Esse tipo de detector permite identificar a diferença entre as fases da amostra, regiões mais claras indicam maior número atômico, contudo as imagens geradas por esse tipo de detector não permitem diferenciar a topologia da amostra (Goldstein et al., 2018). O intuito era observar se os grãos possuíam mais de uma fase e se existiam grãos de ilmenita isolados. O mesmo microscópio também possui detector de EDS, permitindo que a composição estimada dos grãos fosse avaliada em conjunto. O programa do detector deste microscópio faz um ajuste que proporciona interpretar a característica morfológica das amostras.

Observando a amostra no microscópio, ilustrado na Figura 35, inicialmente pode-se identificar a diferença de contraste entre os grãos, bem como a diferença no tamanho das partículas mesmo num baixo aumento, de x100 no caso.

Figura 35 - Vista geral da amostra como recebida por elétrons retroespalhados.

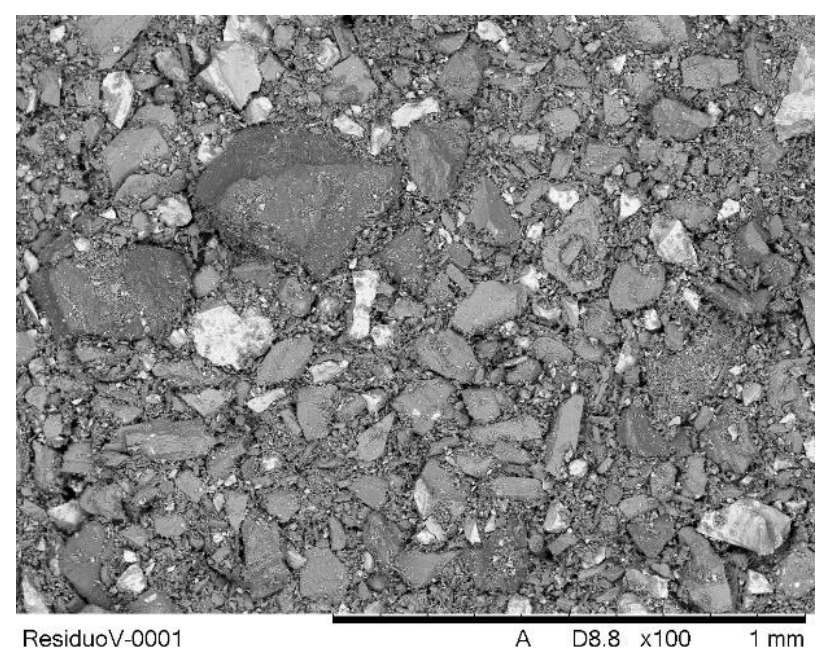

Na Figura 36 está o espectro de EDS da amostra, a presença do vanádio no espectro foi induzida, não tendo sido identificado naturalmente pelo programa. 
Figura 36 - Espectro geral da amostra como recebida.

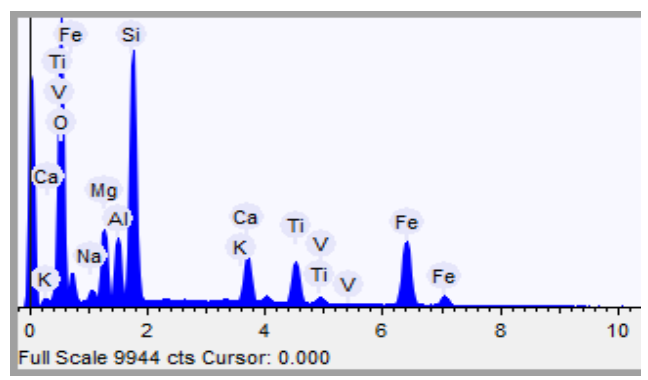

Os valores estimados estão descritos na Tabela 11, onde constata-se a presença marcante do oxigênio, o qual deve estar associado aos demais elementos. $\mathrm{Na}$ mesma tabela os percentuais destes elementos, calculados sem a presença do oxigênio, também estão apresentados.

Tabela 11 - Composição elementar da amostra como recebida, em massa, fornecido pelo EDS, considerando o valor total e o valor desconsiderando o oxigênio presente.

\begin{tabular}{lcc}
\hline Elemento & Peso \% & Peso \% (s/ oxigênio) \\
\hline Oxigênio & 48.253 & - \\
Sódio & 0.908 & 1.755 \\
Magnésio & 4.531 & 8.765 \\
Alumínio & 3.193 & 6.170 \\
Silício & 13.384 & 25.864 \\
Potássio & 0.174 & 0.336 \\
Cálcio & 4.111 & 7.944 \\
Titânio & 5.645 & 10.909 \\
Vanádio & 0.250 & 0.483 \\
Ferro & 19.551 & 37.782 \\
\hline
\end{tabular}

O resultado apontado para a concentração de Ti está consistente com aquele oriundo da FR-X e superior ao obtido pelo ICP.

Quando em aumentos ligeiramente maiores (com detector de elétrons retro-espalhados) foi possível identificar partículas com mais de uma fase pela diferença de contraste, conforme ilustrado na Figura 37. 
Figura 37 - Imagem por elétrons retroespalhados de uma partícula contendo mais de uma fase.

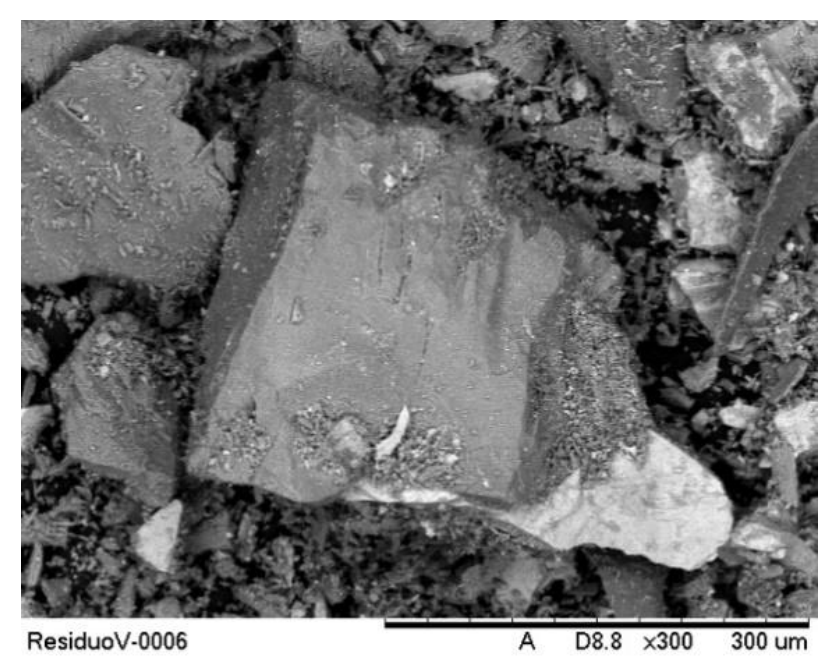

Já na Figura 38, é possível observar o efeito de carregamento na mesma partícula, isso acontece porque o material não é um bom condutor, então o feixe de elétrons que chega na amostra não encontra caminho até o porta amostra, se acumulando na partícula e emitindo um sinal muito alto para o detector (Goldstein et al., 2018). Então quanto maior o tempo em que o feixe permanece sobre a amostra e maior o aumento selecionado, maior o efeito de carregamento.

Figura 38 - Imagem por elétrons retroespalhados de uma partícula contendo mais de uma fase e apresentando efeito de carregamento.

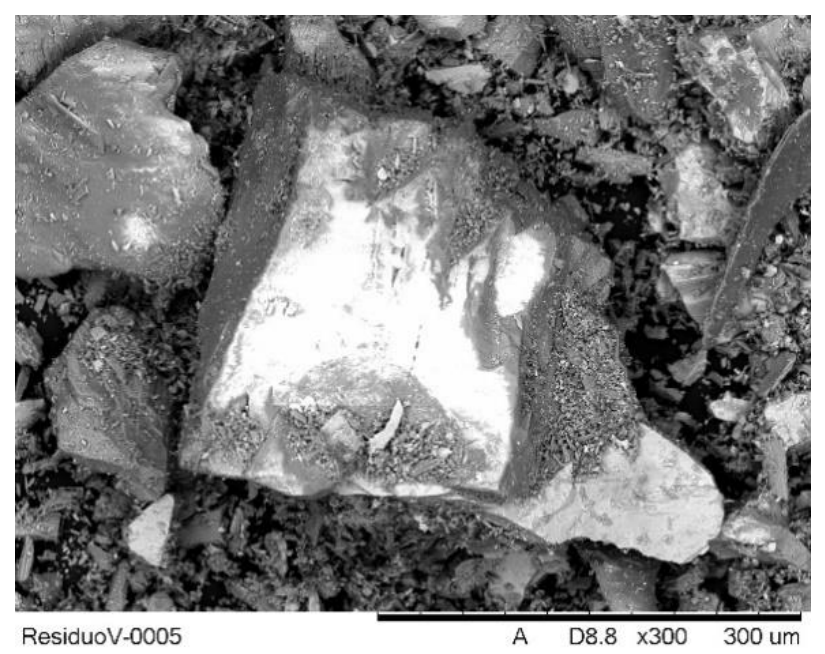

Mesmo em aumentos maiores, a superfície da grande maioria das partículas é extremamente lisa. 


\subsubsection{1.}

EDS de partículas selecionadas

Quando utilizado o detector EDS na amostra, para identificar a distinção entre os grãos com diferente contrate, foi possível verificar que os grãos mais claros têm maiores teores de $\mathrm{Fe}$ e Ti, conforme o grão identificado na Figura 39 e seu respectivo espetro de EDS, na Figura 40.

Figura 39 - Identificação da partícula 1 analisada por EDS.

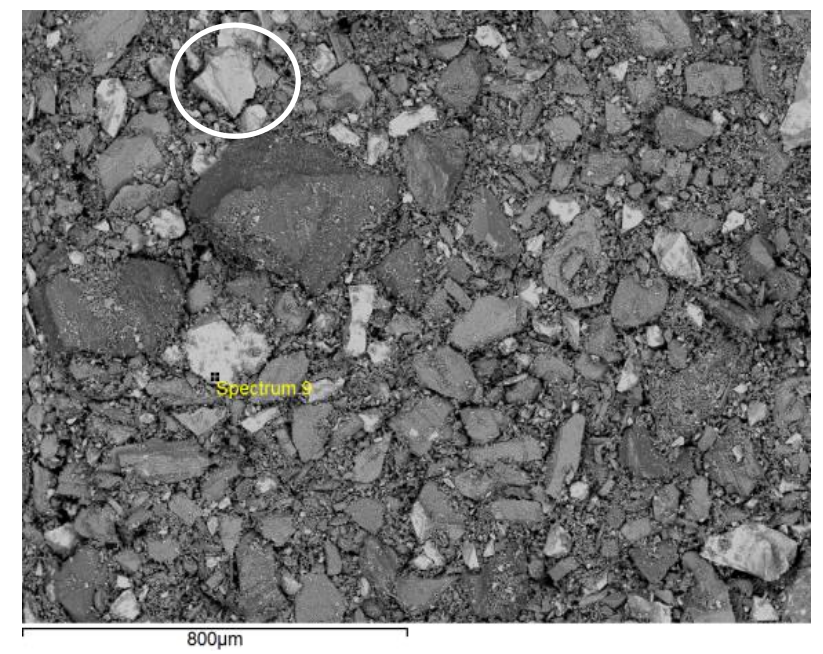

Figura 40 - Espectro de partícula 1 específica.

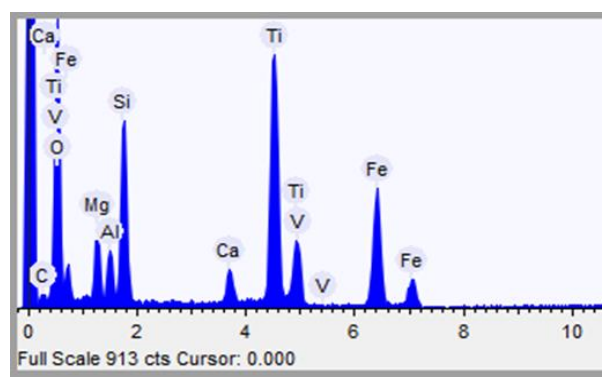

Na Tabela 12, a seguir, está a descrição da composição elementar estimada dessa partícula. A composição dessa partícula em níveis praticamente iguais de $\mathrm{Fe}$ e Ti sugere que a partícula identificada possa ser de ilmenita. Nessa partícula também foi identificado um teor significativo de V, ou seja, associado ao Ti e Fe. 
Tabela 12 - Espectro de partícula 1 específica.

\begin{tabular}{ll}
\hline Elemento & Peso \% \\
\hline Carbono & 3.402 \\
Oxigênio & 44.101 \\
Magnésio & 2.405 \\
Alumínio & 1.505 \\
Silício & 5.480 \\
Cálcio & 1.544 \\
Titânio & 19.722 \\
Vanádio & 1.848 \\
Ferro & 19.992 \\
\hline
\end{tabular}

Apesar da Tabela 12 mostrar a identificação do teor de carbono, não é aconselhável tentar quantificar esse elemento por EDS, pois a amostra é depositada sobre uma fita de carbono, que é responsável por permitir a conexão entre a amostra e porta amostra para que haja condução do feixe de elétrons pelo sistema sem carregamento. $\mathrm{O}$ detector pode captar sinais provenientes da fita em conjunto com os sinais da amostra, induzindo erro de leitura.

Ao selecionar outra partícula, desta vez com uma tonalidade mais escura, conforme indicado na Figura 41, é imediatamente notável a pelo espectro, identificado na Figura 42, a diminuição de intensidade dos sinais de Fe e Ti.

Figura 41 - Identificação da partícula 2 analisada por EDS.

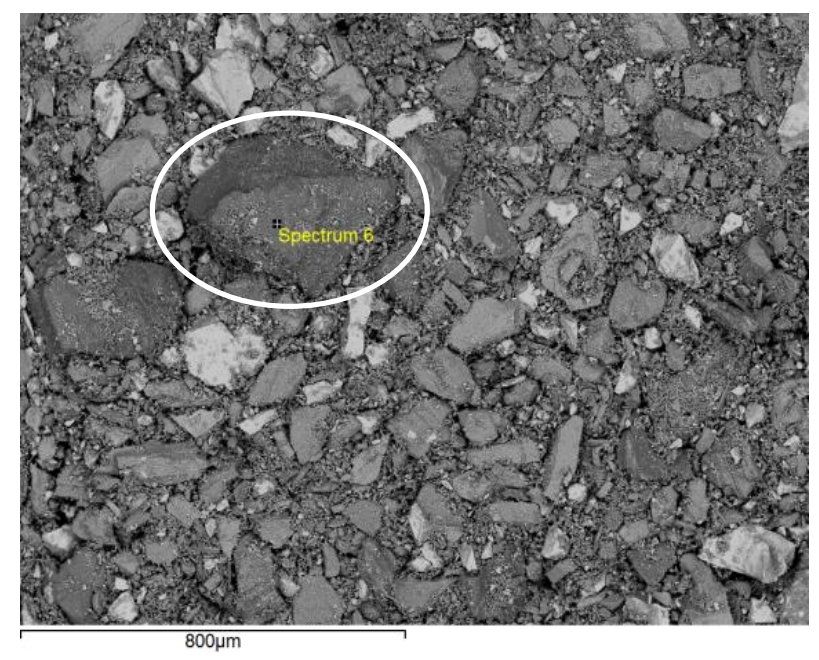


Figura 42 - Espectro de partícula 2 específica.

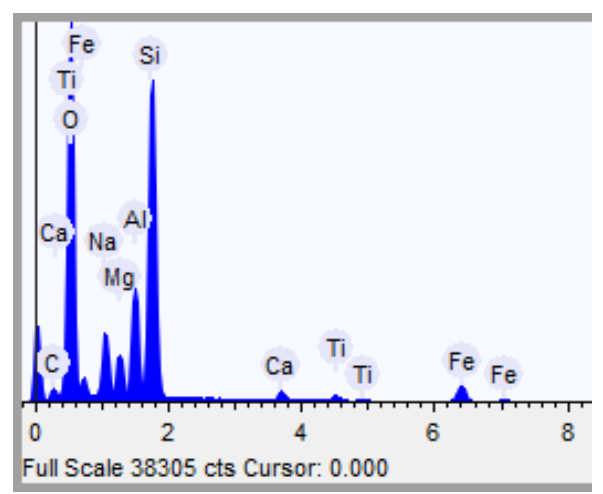

Ao observar a Tabela 13 confirma-se a drástica diminuição do teor de Fe e Ti e o aumento do teor de $\mathrm{Si}$ e sutil aumento de $\mathrm{Al}$, $\mathrm{Na}$ e $\mathrm{Mg}$, quando em comparação com a partícula anterior, exemplificada na Figura 39.

Tabela 13 - Espectro de partícula 2 específica.

\begin{tabular}{ll}
\hline Elemento & Peso \% \\
\hline Carbono & 5.985 \\
Oxigênio & 56.697 \\
Sódio & 4.860 \\
Magnésio & 2.477 \\
Alumínio & 5.525 \\
Silício & 17.727 \\
Cálcio & 0.842 \\
Titânio & 0.867 \\
Ferro & 5.019 \\
\hline
\end{tabular}

Muitas outras partículas foram analisadas, apresentando composição semelhante as apresentadas, mostrando um padrão condizente com as análises de DR-X.

\section{2.}

\section{Análise do sistema reacional}

Finalizada a caracterização do material como recebido, três reagentes possíveis para fazer a reação de fusão alcalina foram considerados: o carbonato de sódio $\left(\mathrm{Na}_{2} \mathrm{CO}_{3}\right)$, o sulfato de sódio $\left(\mathrm{Na}_{2} \mathrm{SO}_{4}\right)$ e uma mistura de fosfato de sódio 
mono $\left(\mathrm{NaH}_{2} \mathrm{PO}_{4}\right)$ e dissódico $\left(\mathrm{Na}_{2} \mathrm{HPO}_{4}\right)$. Os dois primeiros reagentes foram considerados por já serem utilizados industrialmente no processo de produção do $\mathrm{V}_{2} \mathrm{O}_{5}$ e a mistura de fosfatos por terem conseguido digerir completamente amostras de minério com características semelhantes (Chiweshe e Purcell, 2017).

Como o maior constituinte da amostra é o $\mathrm{Si}$, que assim deve ser atacado e em seguida removido da amostra, o critério de seleção adotado foi a reatividade desse elemento na formação de um produto que possibilite a sua solubilização. De modo ilustrativo nas Figuras 43, 44 e 45 é possível ver essa interação do óxido de silício com os reagentes.

Figura 43 - Simulação da reação do $\mathrm{SiO}_{2}$ com carbonato de $\mathrm{Na}$.

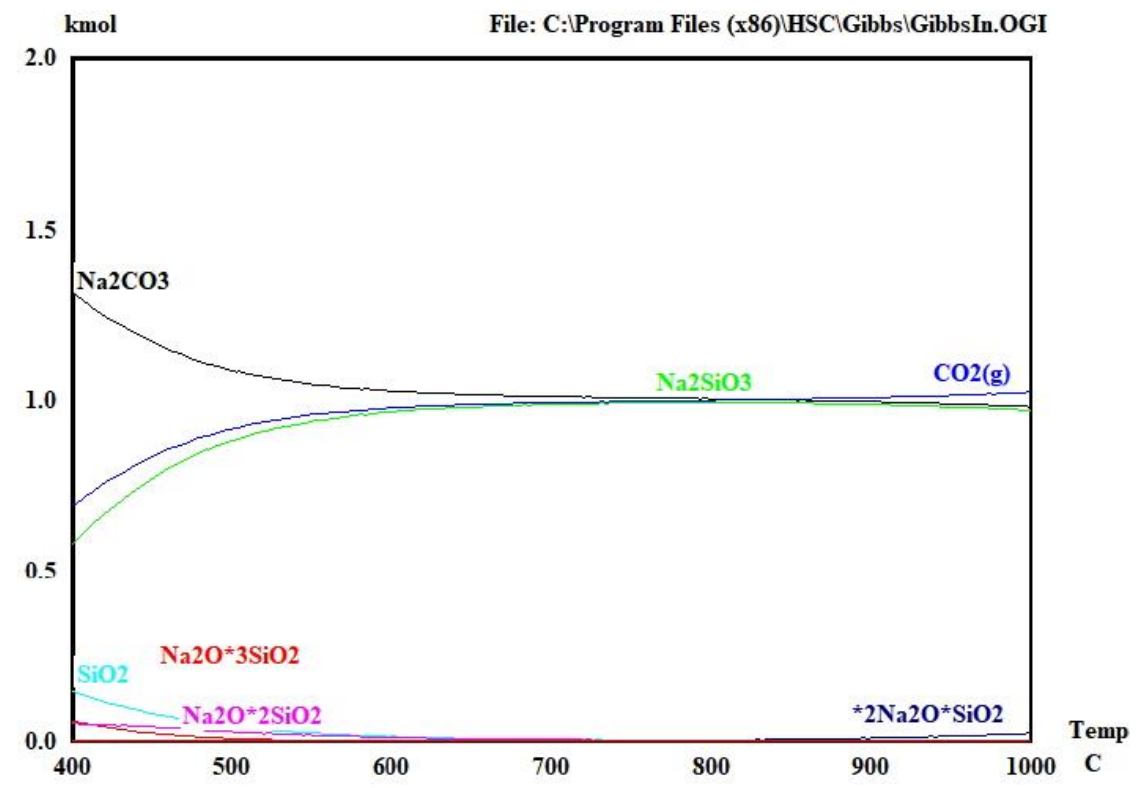


Figura 44 - Simulação da reação do $\mathrm{SiO}_{2}$ com fosfato de Na.

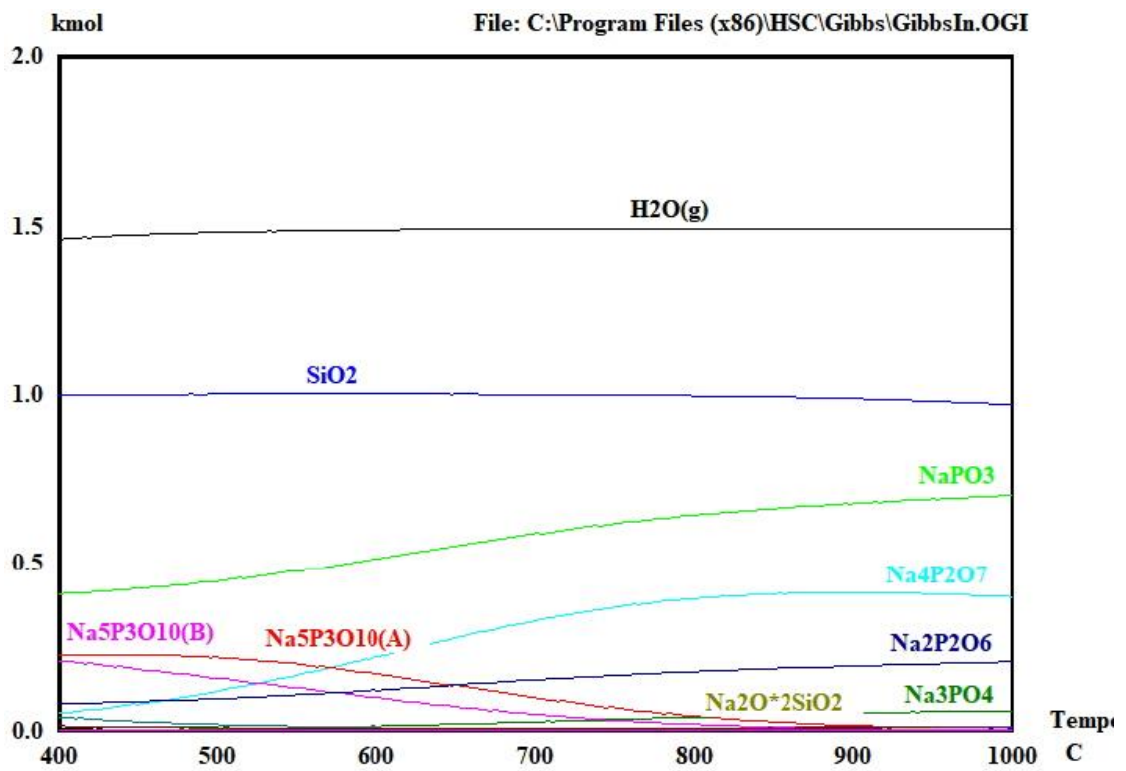

Figura 45 - Simulação da reação do $\mathrm{SiO}_{2}$ com sulfato de Na.

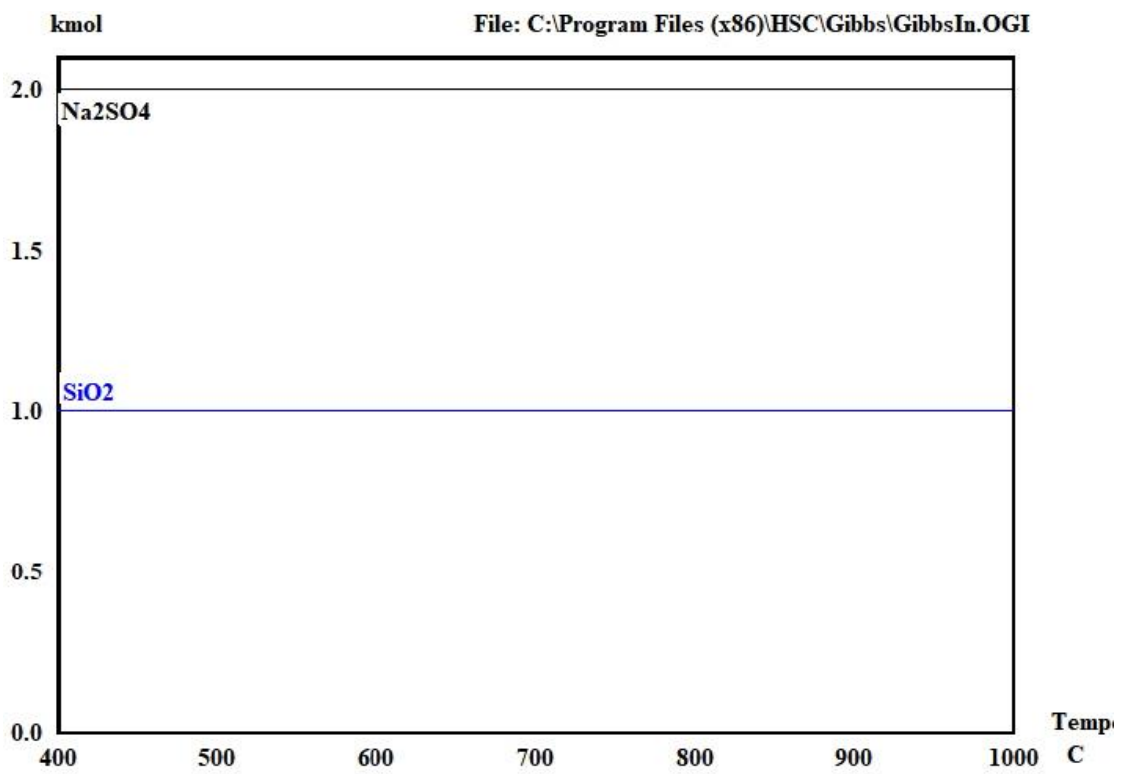

Apesar da boa digestão geral obtida por Chiweshe e Purcell (2017), utilizando uma mistura dos fosfatos de sódio, $\mathrm{NaH}_{2} \mathrm{PO}_{4}$ e $\mathrm{Na}_{2} \mathrm{HPO}_{4}$, o resultado gerado pelo $H S C$ indica que não há reação com o Si até $1000{ }^{\circ} \mathrm{C}$ e que, consequentemente, não seria possível removê-lo por uma solubilização posterior. 
O mesmo acontece para o sulfato de sódio, que reage com pouquíssimos elementos da mistura.

$\mathrm{Na}$ realidade, ao simular as reações entre os óxidos estimados na amostra, segundo análise por FR-X, e os possíveis reagentes a serem utilizados foi possível determinar quais seriam as prováveis reações a serem favorecidas no sistema reacional. Com auxílio do software $H S C$ o resultado das simulações está descrito na Tabela 14, na qual estão listados quais óxidos devem interagir com os reagentes, confirmando a maior reatividade do silício com o carbonato de sódio.

Tabela 14 - Interação dos reagentes com os óxidos contidos na amostra.

\begin{tabular}{l|ccccccccc}
\hline Óxido & $\mathrm{Al}_{2} \mathrm{O}_{3}$ & $\mathrm{CaO}$ & $\mathrm{Fe}_{2} \mathrm{O}_{3}$ & $\mathrm{MgO}$ & $\mathrm{Na}_{2} \mathrm{O}$ & $\mathrm{SiO}_{2}$ & $\mathrm{TiO}_{2}$ & $\mathrm{~K}_{2} \mathrm{O}$ & $\mathrm{MnO}$ \\
\hline $\mathrm{Na}_{2} \mathbf{C O}_{3}$ & $\mathrm{x}$ & & $\mathrm{x}$ & & $\mathrm{x}$ & $\mathrm{x}$ & $\mathrm{x}$ & $\mathrm{x}$ & \\
\hline $\mathrm{Na}_{2} \mathbf{S O}_{4}$ & & & & & $\mathrm{x}$ & & & $\mathrm{x}$ & $\mathrm{x}$ \\
\hline Fosfatos & $\mathrm{x}$ & $\mathrm{x}$ & & $\mathrm{x}$ & $\mathrm{x}$ & & & & \\
\hline
\end{tabular}

Já Tathavadkar e Jha (2004) descreveram um processo eficiente de fusão alcalina de minerais de ilmenita e rutilo usando o carbonato de sódio. Esse reagente interage tanto com o silício como com o alumínio formando produtos que são solúveis em água e possibilitando as suas remoções.

Considerando esses dados, o reagente selecionado foi o carbonato de sódio e a faixa de temperatura de reação foi a mesma adotada no artigo de Tathavadkar e Jha (2004).

As reações fornecidas pelo $H S C$, e devidamente balanceadas, são:

$$
\begin{gathered}
6 \mathrm{TiO}_{2}+6 \mathrm{Na}_{2} \mathrm{CO}_{3} \rightarrow \mathrm{Na}_{2} \mathrm{CO}_{3}+5 \mathrm{CO}_{2}(\mathrm{~g})+\mathrm{Na}_{8} \mathrm{Ti}_{5} \mathrm{O}_{14}+\mathrm{Na}_{2} \mathrm{TiO}_{3} \\
5 \mathrm{FeTiO}_{3}+5 \mathrm{Na}_{2} \mathrm{CO}_{3} \rightarrow \mathrm{Na}_{2} \mathrm{CO}_{3}+3 \mathrm{CO}_{2}(\mathrm{~g})+\mathrm{CO}(\mathrm{g}) \\
+\mathrm{Na}_{8} \mathrm{Ti}_{5} \mathrm{O}_{14}+\mathrm{Fe}_{2} \mathrm{O}_{3}+\mathrm{FeO} \\
\mathrm{SiO}_{2}+2 \mathrm{Na}_{2} \mathrm{CO}_{3} \rightarrow \mathrm{Na}_{2} \mathrm{CO}_{3}+2 \mathrm{CO}_{2}(\mathrm{~g})+\mathrm{NaSiO}_{3} \\
2 \mathrm{Al}_{2} \mathrm{O}_{3}+3 \mathrm{Na}_{2} \mathrm{CO}_{3} \rightarrow \mathrm{Na}_{2} \mathrm{CO}_{3}+2 \mathrm{CO}_{2}(\mathrm{~g})+\mathrm{Na}_{2} \mathrm{Al}_{2} \mathrm{O}_{4}+2 \mathrm{NaAlO}_{2}
\end{gathered}
$$

Considerando que o reagente escolhido pode se decompor, de acordo com a equação 7 , durante a reação na mufla, foi feito um teste colocando na mufla apenas a barquete com 1,0 g de carbonato, durante 60 minutos.

$$
\mathrm{Na} 2 \mathrm{CO} 3 \rightarrow \mathrm{Na}_{2} \mathrm{O}+\mathrm{CO}_{2}(\mathrm{~g})
$$


O carbonato de sódio possui ponto de fusão em $854{ }^{\circ} \mathrm{C}$ (Solvay) e é um composto altamente estável, como pode se observar pelos valores de energia da sua decomposição, ilustrados na Figura 46. Contudo o carbonato foi completamente decomposto na mufla, não sobrando nenhuma massa significativa na barquete.

Figura 46 - Energia livre de Gibbs para a reação de decomposição do $\mathrm{Na}_{2} \mathrm{CO}_{3}$.

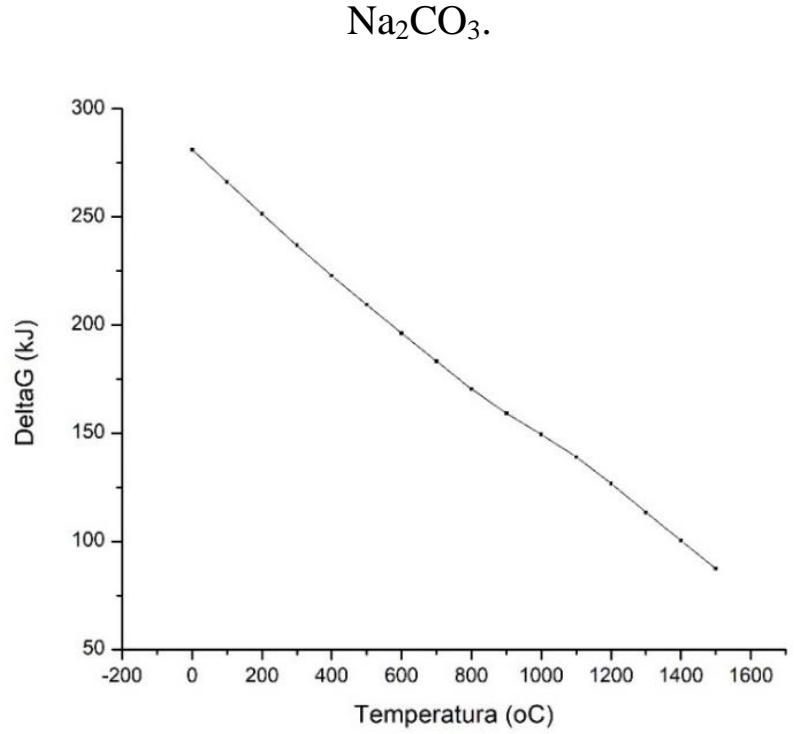

Contudo a Solvay Chemicals, Inc afirma que se o carbonato de sódio anidro, que é o caso do reagente utilizado no presente trabalho, for aquecido a perda de massa, proveniente da sua decomposição e volatilização, tem início a partir de $400{ }^{\circ} \mathrm{C}$. Na Tabela 15 estão descritas as pressões de vapor da decomposição do carbonato, e mesmos os valores sendo muito pequenos na faixa de temperatura abordada no presente trabalho, o tempo que a reação acontece no forno é suficiente para que todo o composto seja volatilizado.

Tabela 15 - Pressão de vapor da decomposição do $\mathrm{Na}_{2} \mathrm{CO}_{3}$.

\begin{tabular}{cc} 
Temp. $\left({ }^{\circ} \mathrm{C}\right)$ & Pressão de vap. $(\mathrm{atm})$ \\
\hline 800 & $1.32 \mathrm{E}-02$ \\
990 & $1.58 \mathrm{E}-02$ \\
1010 & $1.84 \mathrm{E}-02$ \\
1100 & $2.76 \mathrm{E}-02$ \\
1150 & $3.68 \mathrm{E}-02$ \\
1200 & $5.39 \mathrm{E}-02$ \\
1500 & 1 \\
\hline & Fonte: Solvay Chemicals, Inc.
\end{tabular}


Tathavadkar e Jha (2004) também fizeram essas considerações termodinâmicas com auxílio de outro programa, o FACT-Sage, obtendo resultados semelhantes. Eles levaram em consideração que a reação do carbonato com os óxidos contidos nos minérios que estudaram, o resultado está na Figura 47.

Figura 47 - Considerações termodinâmicas.

$$
\begin{aligned}
& \mathrm{Na}_{2} \mathrm{CO}_{3}(s) \rightarrow \mathrm{Na}_{2} \mathrm{O}(s)+\mathrm{CO}_{2}(g) \\
& \mathrm{TiO}_{2}(s)+2 \mathrm{Na}_{2} \mathrm{CO}_{3}(s) \rightarrow \mathrm{Na}_{4} \mathrm{TiO}_{4}(s)+2 \mathrm{CO}_{2}(\mathrm{~g}) \text { [2] } \\
& \mathrm{TiO}_{2}(s)+\mathrm{Na}_{2} \mathrm{CO}_{3}(s) \rightarrow \mathrm{Na}_{4} \mathrm{TiO}_{3}(s)+\mathrm{CO}_{2}(g) \\
& 5 \mathrm{TiO}_{2}(s)+4 \mathrm{Na}_{2} \mathrm{CO}_{3}(s) \rightarrow \mathrm{Na}_{8} \mathrm{Ti}_{5} \mathrm{O}_{14}(s)+4 \mathrm{CO}_{2}(\mathrm{~g}) \text { [4] } \\
& 3 \mathrm{TiO}_{2}(s)+\mathrm{Na}_{2} \mathrm{CO}_{3}(s) \rightarrow \mathrm{Na}_{2} \mathrm{Ti}_{3} \mathrm{O}_{7}(s)+\mathrm{CO}_{2}(g) \\
& 6 \mathrm{TiO}_{2}(s)+\mathrm{Na}_{2} \mathrm{CO}_{3}(s) \rightarrow \mathrm{Na}_{2} \mathrm{Ti}_{6} \mathrm{O}_{13}(s)+\mathrm{CO}_{2}(g) \\
& \mathrm{Fe}_{2} \mathrm{O}_{3}(s)+\mathrm{Na}_{2} \mathrm{CO}_{3}(s) \rightarrow \mathrm{Na}_{2} \mathrm{Fe}_{2} \mathrm{O}_{4}(s)+\mathrm{CO}_{2}(\mathrm{~g}) \text { [7] } \\
& \mathrm{SiO}_{2}(s)+\mathrm{Na}_{2} \mathrm{CO}_{3}(s) \rightarrow \mathrm{Na}_{2} \mathrm{SiO}_{3}(s)+\mathrm{CO}_{2}(g) \\
& \mathrm{Al}_{2} \mathrm{O}_{3}(s)+\mathrm{Na}_{2} \mathrm{CO}_{3}(s) \rightarrow \mathrm{Na}_{2} \mathrm{Al}_{2} \mathrm{O}_{4}(s)+\mathrm{CO}_{2}(g) \text { [9] } \\
& \mathrm{Fe}_{2} \mathrm{TiO}_{5}(s)+\mathrm{TiO}_{2}(s) \rightarrow \mathrm{Fe}_{2} \mathrm{O}_{3}(s)
\end{aligned}
$$

Fonte: Tathavadkar e Jha, 2004.

Além disso, eles também observaram as energias livres de Gibbs, ilustrado na Figura 48, para predizer qual as reações favorecidas, uma vez que, apresentaram mais de uma possibilidade reacional para a interação com o $\mathrm{TiO}_{2}, \mathrm{o}$ que não foi possível obter utilizando o HSC. 
Figura 48 - Energia livre de Gibbs das considerações termodinâmicas ao longo da variação de temperatura.

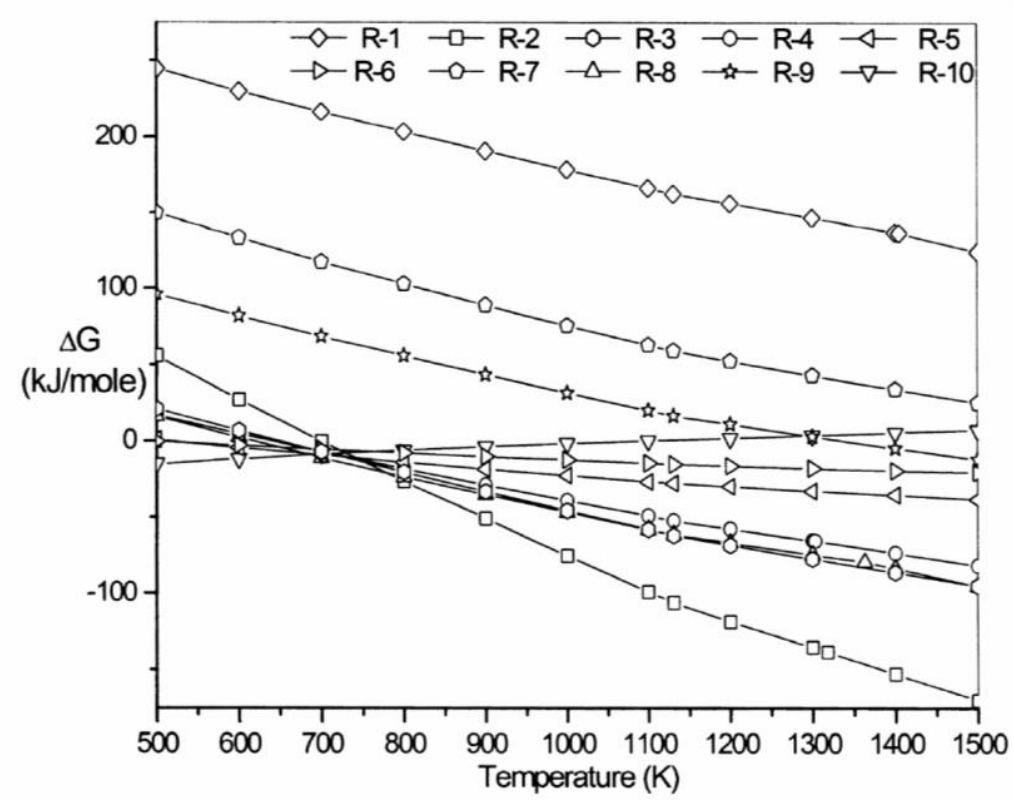

Fonte: Tathavadkar e Jha, 2004.

Embora as reações sejam as mesmas, o programa $H S C$ considere que sempre haverá uma parcela de carbonato que não irá reagir com os óxidos, diferente do programa utilizado no trabalho deles, o FACT-Sage, que considera que não há sobras. No presente trabalho, optou-se pela reação termodinâmica que há sobra de reagente, para diminuir a possibilidade de parte dos óxidos não reagirem.

Conhecendo as reações majoritárias foi possível fazer o balanço de massa da reação e obter a quantidade estequiométrica de reagente necessária para que fossem consumidos completamente. Todos os óxidos reagem na proporção $1: 1$, exceto o alumínio que reage e $2: 3$ e o silício que reage $1: 2$.

A massa necessária de reagente encontrada foi de $\mathbf{1 , 4 2 3 5} \mathrm{g}$ para reagir com $1,000 \mathrm{~g}$ de amostra, essa quantidade é a chamada de 'esteq.' na tabela de ensaios do item 3.5.2. A partir desse valor, foi utilizado $50 \%$ mais e menos, correspondendo à $2,1352 \mathrm{~g}$ e $0,7114 \mathrm{~g}$, respectivamente.

Ainda analisando o sistema reacional no software, foi possível verificar que o $\mathrm{HCl}$ não ataca o $\mathrm{TiO}_{2}$, reagindo somente com o Fe contido em forma de óxidos e na ilmenita. Habashi (1997) e Baltar e colaboradores (2008) confirmam essa tendência ao afirmar que o $\mathrm{TiO}_{2}$ é um oxido com alta estável e resiste ao ataque de ácido sulfúrico ou clorídrico diluídos. 
4.3.

Determinação do tempo reacional

Definidas as condições necessárias para a reação, foram feitos uma serie de 5 experimentos para avaliar se o tempo reacional determinado por Tathavadkar e Jha (2004), que é 120 minutos, seria o mesmo aplicado no trabalho.

$\mathrm{Na}$ tabela 16 estão dispostos os valores obtidos de perda de massa na mufla para cada tempo reacional.

Tabela 16 - Resultados dos ensaios de tempo reacional.

\begin{tabular}{c|cccc}
\hline \multirow{2}{*}{ Ensaio } & \multicolumn{2}{|c|}{ Variáveis Reais } & Inicial & Final \\
\cline { 2 - 5 } & $\mathrm{T}\left({ }^{\circ} \mathrm{C}\right)$ & Tempo (min) & Massa (g) & Massa (g) \\
\hline 1 & 850 & 15 & 2.0013 & 1.7718 \\
2 & 850 & 30 & 2.0045 & 1.7315 \\
3 & 850 & 60 & 2.0086 & 1.6466 \\
4 & 850 & 90 & 2.0051 & 1.5880 \\
5 & 850 & 120 & 2.0037 & 1.5858 \\
\hline
\end{tabular}

Foi então possível traçar um gráfico, ilustrado na Figura 49, da \% de perda de massa pela mistura amostra-reagente ao longo do tempo. Considerando que o tempo inicial não há perda de massa, os resultados geraram um gráfico com tendência exponencial. O ajuste do gráfico gerou $\mathrm{R}^{2}=09716$, indicando um comportamento quase previsível.

Figura 49 - Perda de massa ao longo do tempo.

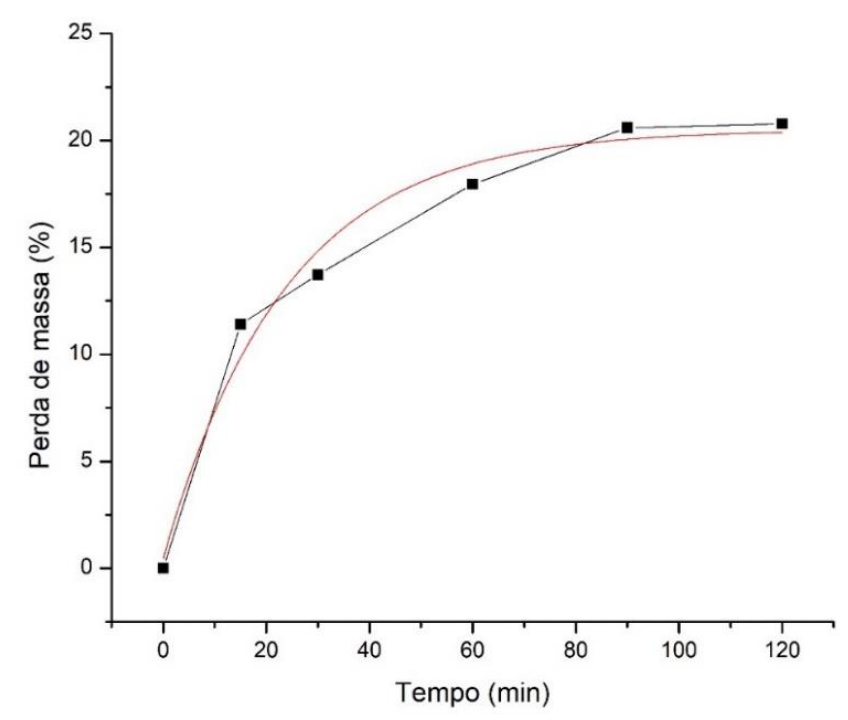


Pode-se observar, tanto pelos valores da tabela quanto pelo gráfico, que não há aumento da perda de massa significativo depois do tempo de 90 minutos. Isso sugere que a reação começa a estabilizar após esse tempo.

Foi determinado então, que o tempo utilizado nos próximos experimentos seriam 90 minutos ao invés de 120 min.

\section{4.}

\section{Ensaios de reação de fusão com reagente alcalino}

Determinados os parâmetros e a as variáveis reacionais, foram feitos os ensaios para estudar o comportamento reacional ao longo de todas as etapas. Inicialmente o parâmetro utilizado foi perda de massa. Os resultados estão dispostos na Tabela 17.

A primeira etapa é referente a massa depois da reação na mufla, a segunda é depois da solubilização em água e a final é depois da solubilização em ácido.

Tabela 17 - Resultado das perdas de massa ao longo das etapas do processo.

\begin{tabular}{|c|c|c|c|c|c|c|}
\hline \multirow{2}{*}{ Ensaio } & \multicolumn{2}{|c|}{ Variáveis Reais } & \multirow{2}{*}{$\begin{array}{c}\text { Inicial } \\
\text { Massa (g) }\end{array}$} & \multirow{2}{*}{$\begin{array}{c}\mathbf{1} \\
\text { Massa (g) }\end{array}$} & \multirow{2}{*}{$\begin{array}{c}\mathbf{2} \\
\text { Massa (g) }\end{array}$} & \multirow{2}{*}{$\begin{array}{c}\text { Final } \\
\text { Massa (g) }\end{array}$} \\
\hline & $\mathrm{T}\left({ }^{\circ} \mathrm{C}\right)$ & R. mássica (g) & & & & \\
\hline 1 & 800 & $50 \%(-)$ & 1.7146 & 1.5061 & 1.1400 & 0.3039 \\
\hline 2 & 800 & Esteq & 2.4288 & 2.1346 & 1.1065 & 0.3931 \\
\hline 3 & 800 & $50 \%(+)$ & 3.1382 & 2.7943 & 1.1165 & 0.2395 \\
\hline 4 & 850 & $50 \%(-)$ & 1.7164 & 1.4081 & 1.2486 & 0.1989 \\
\hline 5 & 850 & Esteq & 2.4271 & 1.8878 & 1.1632 & 0.2817 \\
\hline 6 & 850 & $50 \%(+)$ & 3.1372 & 2.5524 & 1.2160 & 0.1773 \\
\hline 7 & 900 & $50 \%(-)$ & 1.7160 & 1.4139 & 1.3025 & 0.5212 \\
\hline 8 & 900 & Esteq & 2.4267 & 1.8499 & 1.2710 & 0.4971 \\
\hline 9 & 900 & $50 \%(+)$ & 3.1342 & 2.4850 & 1.3493 & 0.4841 \\
\hline 10 & 950 & $50 \%(-)$ & - & - & - & - \\
\hline 11 & 950 & Esteq & - & - & - & - \\
\hline 12 & 950 & $50 \%(+)$ & - & - & - & - \\
\hline
\end{tabular}

A mistura formou compostos que fundiam a partir de $850{ }^{\circ} \mathrm{C}$, o carbonato e os sais formados com o $\mathrm{Al} \mathrm{e} \mathrm{o} \mathrm{Si}$ (Roine, 2006). Quanto maior a quantidade de reagente e mais alta a temperatura, mais rígido se tornava o produto final ao resfriar, tornando muito difícil a retirada da amostra dos barquetes. Por conta 
dessa dificuldade não foi possível realizar as reações na temperatura de $950{ }^{\circ} \mathrm{C}$. Para Tathavadkar e Jha (2004), que utilizaram minérios de anatásio e ilmenita esse efeito aconteceu em $1000{ }^{\circ} \mathrm{C}$.

Cada ensaio, após reação e solubilização em água, gerou uma amostra com aspecto físico distinto, conforme pode ser visto na Figura 50. Tendo sido as amostras de $800{ }^{\circ} \mathrm{C}$ e $900{ }^{\circ} \mathrm{C}$ muito semelhantes entre si, respectivamente.

Figura 50 - Aspecto físico das amostras após reação e solubilização em água.

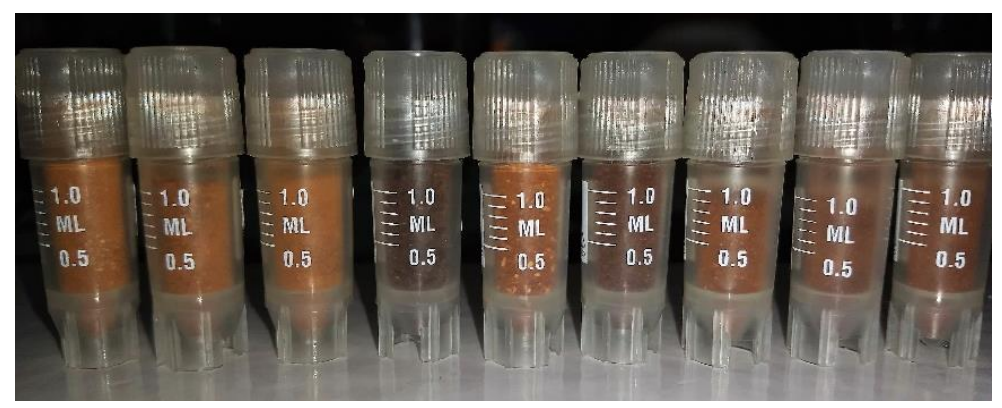

A partir dos dados, obtidos de cada reação, foi possível traçar os gráficos ilustrados nas Figuras 51, 54 e 55, observando o comportamento ao longo do aumento da temperatura de reação. As medidas apresentadas não são acumuladas, são sempre referentes a diferença de massa inicial e final da etapa.

$\mathrm{Na}$ Figura 51 pode-se observar que as maiores perdas de massa acontecem na relação mássica estequiométrica, também se observa que há uma tendência de maior perda de massa conforme a temperatura é elevada. A perda de massa nessa etapa é proveniente da formação de $\mathrm{CO}_{2} / \mathrm{CO}$ como produto das reações, conforme descrito nas equações 3 a 6, sugerindo que nas temperaturas mais altas há maior interação reacional entre o reagente e a amostra. 
Figura 51 - Perda de massa ao final da reação na mufla.

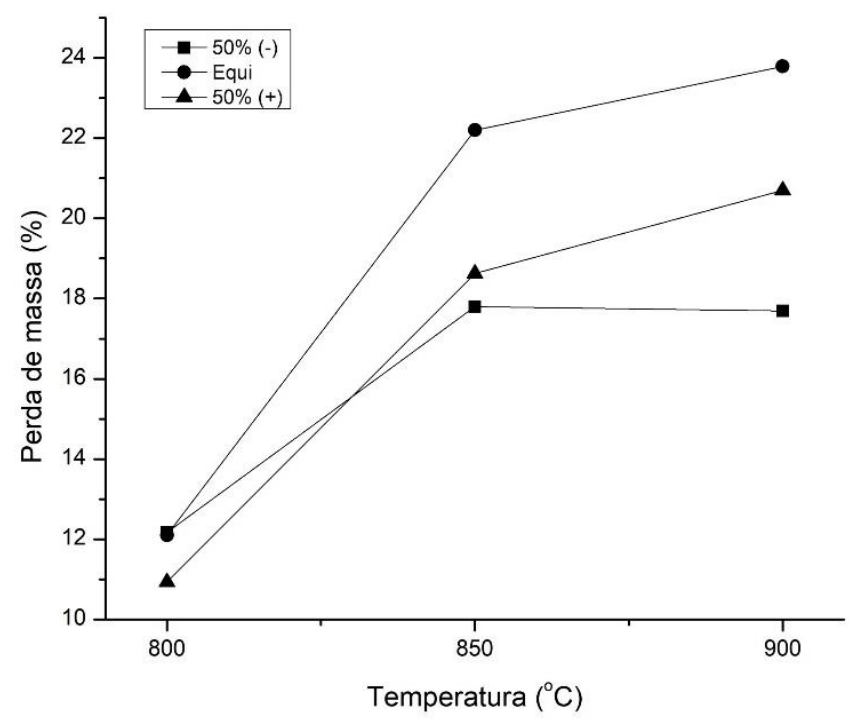

Após a reação na mufla, além da amostra adquirir coloração avermelhada/marrom, a amostra a partir do ensaio 3 começou apresentar uma coloração esverdeada na parte da amostra em contato com a barquete.

Com o aumento da temperatura e da quantidade de reagente, esse fenômeno se intensificou, adquirindo no último ensaio fortíssima coloração azul e verde. Como a caracterização da amostra como recebida indicou teores de $\mathrm{Cu}$ e $\mathrm{Ni}$, atribui-se a eles a coloração. O fenômeno pode ser observado na Figura 52.

Figura 52 - Imagens das amostras após reação na mufla. (a) amostra do ensaio 8. (b) amostra do ensaio 9.

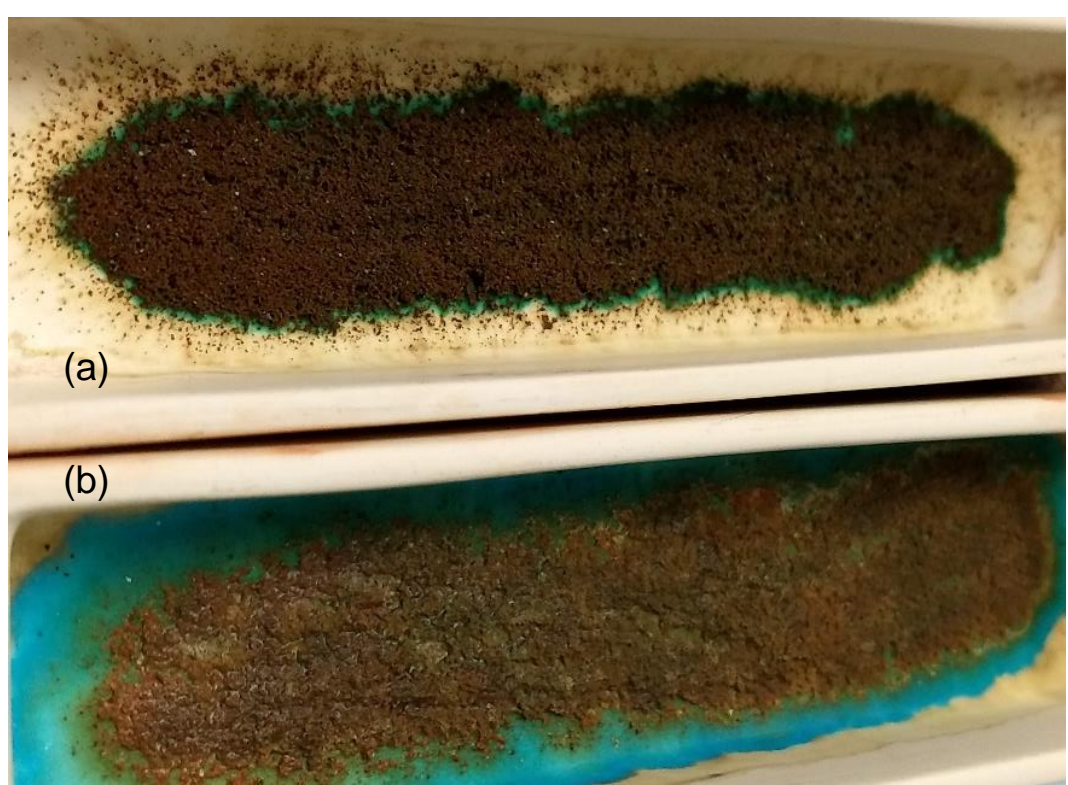


Também é possível notar grande diferença entre o aspecto físico das amostras, comparando as duas amostras, da figura 52 e a amostra da Figura 53, podemos ver que nas condições mais brandas de temperatura, pode-se identificar que onde havia maior quantidade de reagente a coloração é mais clara e onde havia maior quantidade de amostra a cor é mais intensa. Já nas condições de temperatura mais elevada, não é mais possível fazer distinção entre qualquer área da amostra, contudo no último ensaio o aspecto da amostra era de completamente fundida, tendo sido esse o ensaio que houve maior dificuldade de remoção da amostra da barquete.

Figura 53 - Imagem da amostra, do ensaio 3, após reação na mufla.

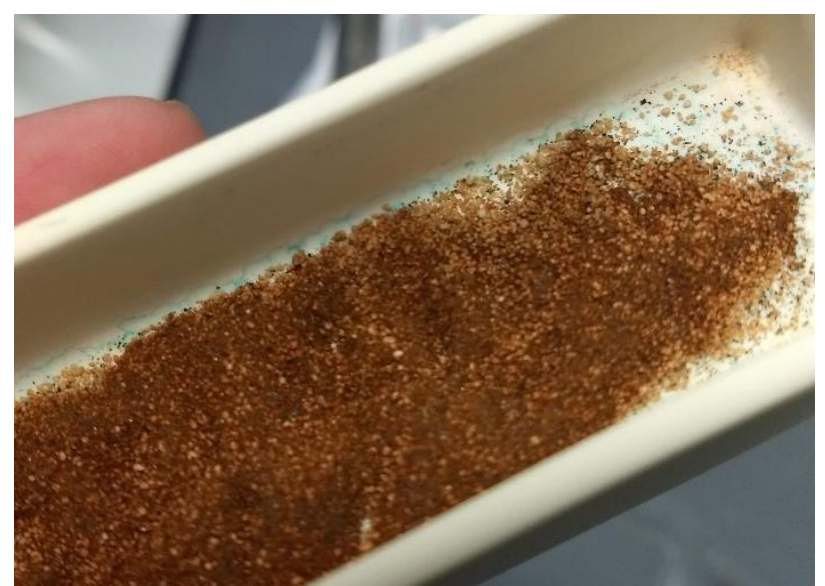

Já na etapa de solubilização em água, Figura 54, observa-se que quanto maior a quantidade de reagente utilizada, mais produtos solúveis são formados e removidos, vale ressaltar que há possibilidade de parte dessa massa solubilizada ser o carbonato não reagido, pois este também é solúvel em água. 
Figura 54 - Perda de massa ao final da solubilização em água.

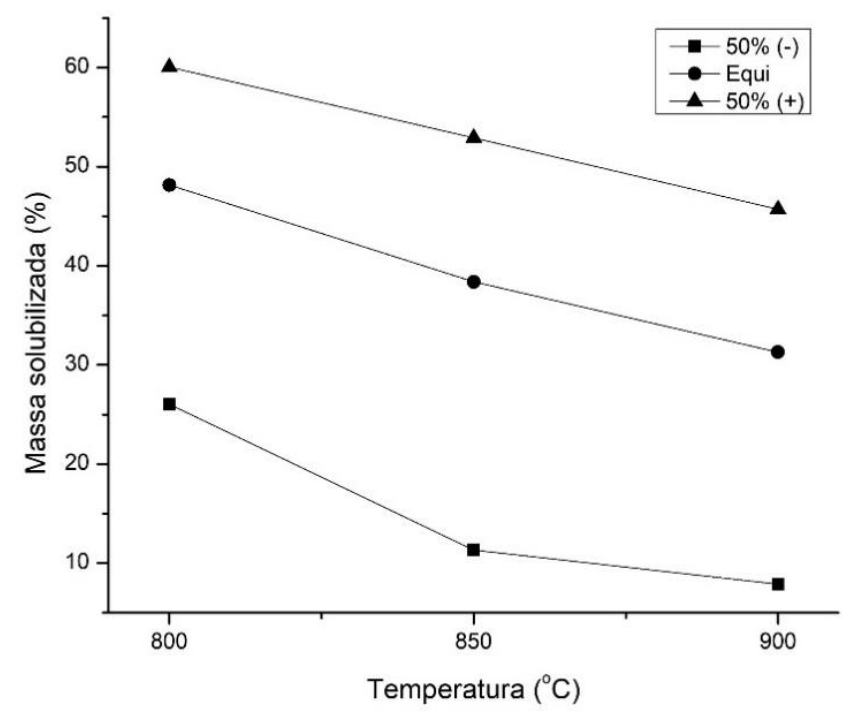

Há uma tendência de decréscimo dessa solubilização de acordo com o aumento da temperatura, isso indica que, quanto maior a temperatura, são formados maior quantidade de produtos insolúveis mais estáveis. Embora o aumento da temperatura tenha intensificado a formação dos produtos de coloração azul/verde que foram removidos na lavagem com água.

$\mathrm{O}$ pH final das soluções variou em torno de 10 e 11 . Além dos compostos solúveis em água de Si e Al, Habashi (1997) diz que o óxido de titânio é atacado por fusões básicas formando compostos com esse caráter, contudo as suas formas básicas são instáveis em água.

Lasheen (2008) afirma que em condições semelhantes, qualquer vanádio associado com a amostra deve ser convertido em metavanadato sódico solúvel em água.

Ao analisar a o gráfico de perda de massa depois da solubilização em ácido diluído, ilustrado na Figura 55, confirma-se a tendência da formação de compostos mais estáveis na maior temperatura estudada. Em 800 e $850{ }^{\circ} \mathrm{C}$ há um crescimento na quantidade, que logo em seguida cai drasticamente, estando todos os resultados, dos ensaios em $900{ }^{\circ} \mathrm{C}$, muito próximos e menores. 
Figura 55 - Perda de massa ao final da solubilização em $\mathrm{HCl}$.

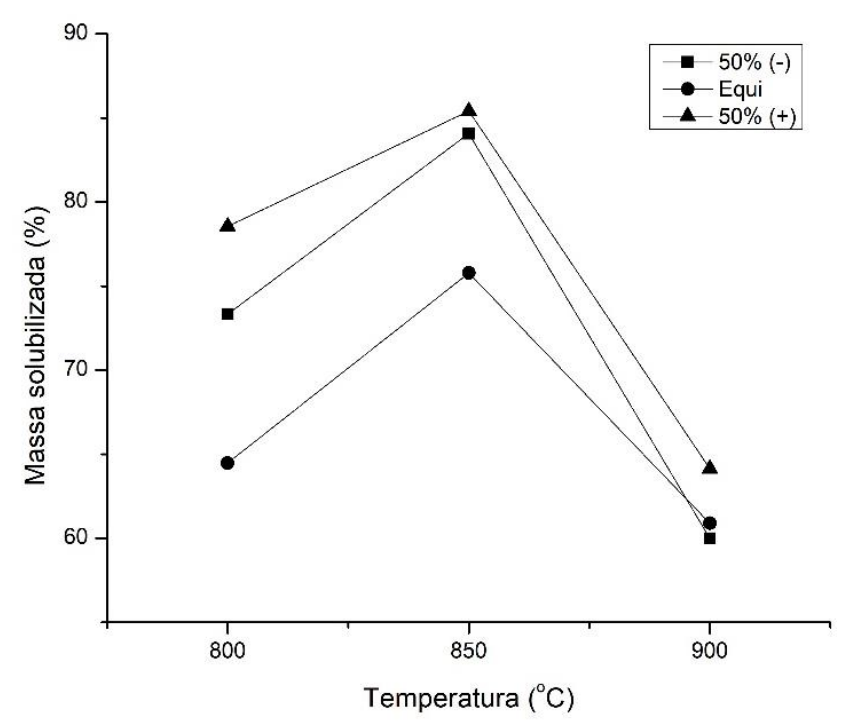

Tathavadkar e Jha (2004) descrevem a formação de sais com fase complexa de Na-Fe-Si-O, que não se solubilizam na etapa de água, quando a reação acontece em $950{ }^{\circ} \mathrm{C}$.

Observa-se também que a menor massa solubilizada está na relação estequiométrica, enquanto que nas outras proporções, os compostos formados solubilizam valores mais aproximados, em questão de \% de massa.

A solução gerada pela digestão ácida apresentou coloração amarela, conforme apresentado na Figura 56, quanto menor a massa final, mais amarela a solução era. Segundo Wesp e Brode (1934) essa coloração pode ser associada a formação do $\mathrm{FeCl}_{3}$, que quando diluído em água apresenta a cor amarela, o que corrobora com o a relação entre menor massa final e cor mais intensa.

Figura 56 - Solução exemplo resultante da solubilização em ácido.

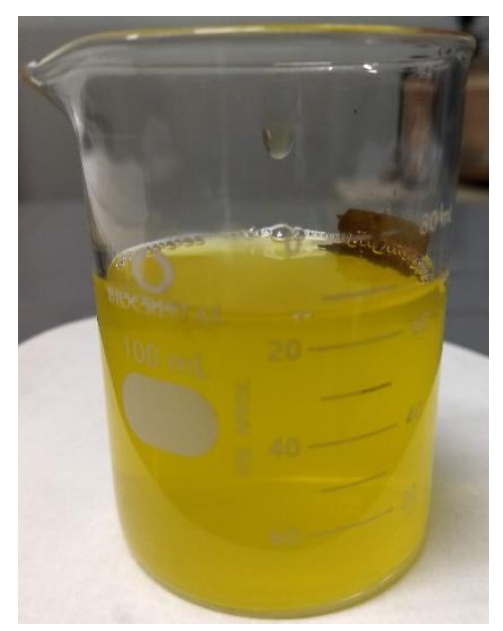


Esses dados obtidos experimentalmente foram usados para traçar gráficos, ilustrados nas Figuras de 57 a 62, de modo a comparar a perda mássica (\%) ao longo de todas as etapas em sequência. Os valores considerados, desta vez foram as diferenças entre massa final da etapa sempre em comparação a massa inicial antes da reação na mufla.

Nos primeiros 3 gráficos, se mantem a mesma relação amostra/reagente variando a temperatura. Já nos 3 últimos, se mantem a mesma faixa de temperatura variando a relação amostra/reagente. Os gráficos, no geral, são semelhantes, apresentando uma tendência quase que linear.

Observando os gráficos individualmente, a Figura 57 apresenta grande diferença na quantidade de massa removida até antes solubilização em água, menos de $40 \%$, para a quantidade removida após, entre $70 \%$ e $90 \%$. Isso mostra que apesar dessa relação formar menor quantidade de produtos solúveis em água, ainda há boa remoção de massa com na etapa ácida.

Figura 57 - Perda de massa ao longo das etapas do processo na condição de massa de $50 \%(-)$.

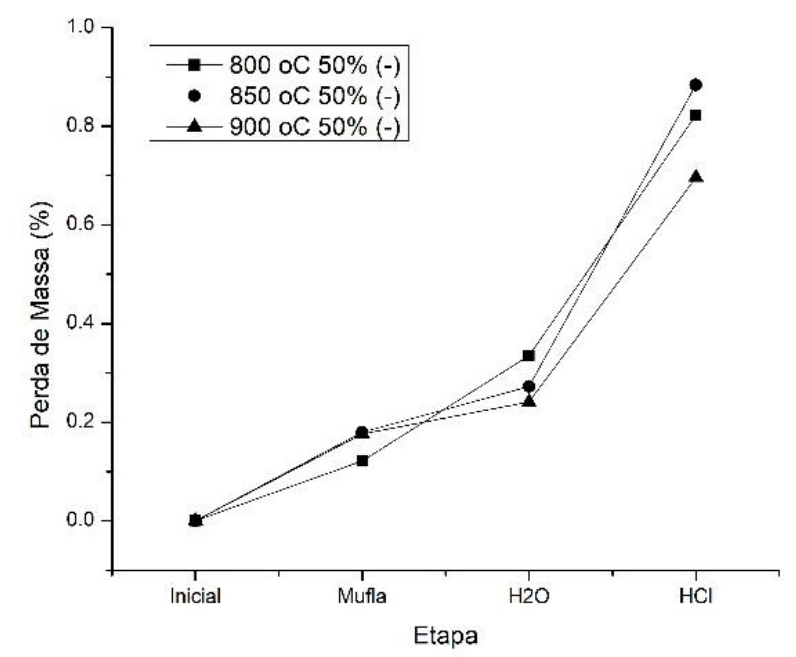

No gráfico da Figura 58, utilizando excesso de reagente, é perceptível a mudança de comportamento, quando na etapa de solubilização em água já é possível atingir cerca de $60 \%$ de massa removida. Percebe-se, então, a influência da quantidade de reagente sobre a eficiência da solubilização, contudo, é prudente levar em consideração que o reagente também é solúvel em água. 
Figura 58 - Perda de massa ao longo das etapas do processo na condição de massa de $50 \%(+)$.

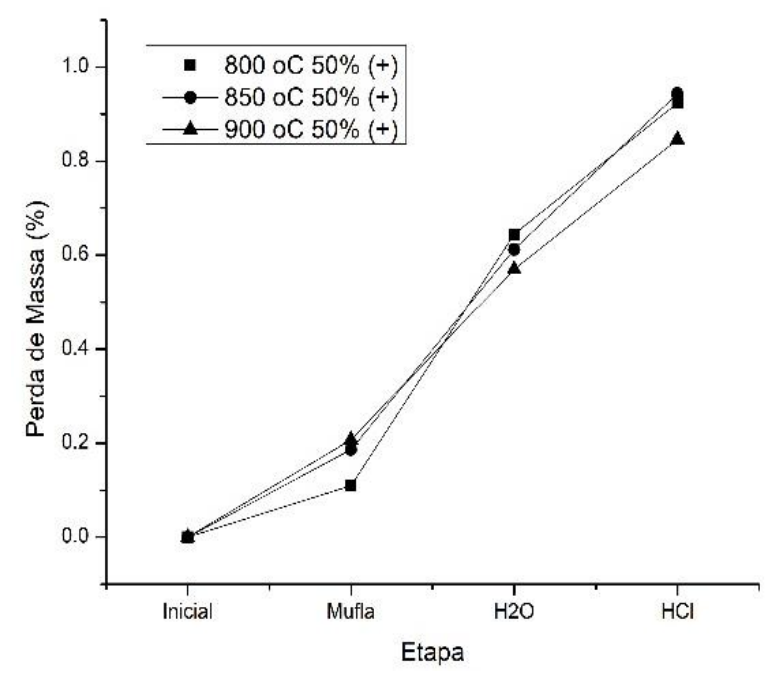

No gráfico da Figura 59, correspondente ao valor de relação mássica intermediária entre os dois gráficos anteriores, observa-se uma tendência praticamente linear e proporcional na perda de massa. Sendo essas as condições as que mais obtiveram resultados próximos.

Figura 59 - Perda de massa ao longo das etapas do processo condição estequiométrica de massa.

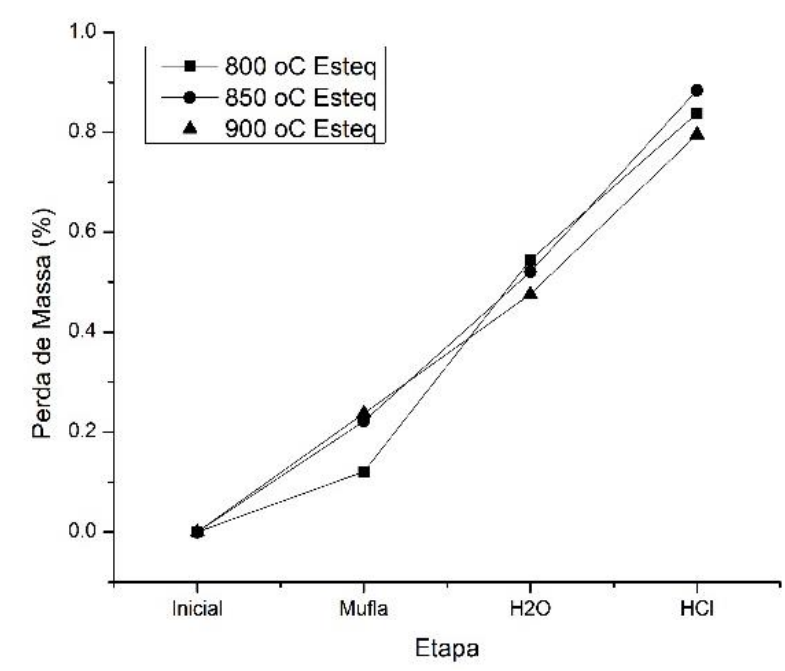

O resultado desses gráficos indica que a temperatura não possui grande influência sobre a perda e massa, uma vez que, os valores obtidos são muito próximos.

Nos próximos 3 gráficos, Figuras 60, 61 e 62, já se nota que a relação entre amostra/reagente exerce uma influência maior, principalmente na etapa de 
solubilização em água. Na relação $50 \%$ (-), em todas as 3 temperaturas, houve menor formação de produtos solúveis em água, isso sugere que essa quantidade de reagente é insuficiente para consumir parte da amostra.

Figura 60 - Perda de massa ao longo das etapas do processo na condição de $800{ }^{\circ} \mathrm{C}$.

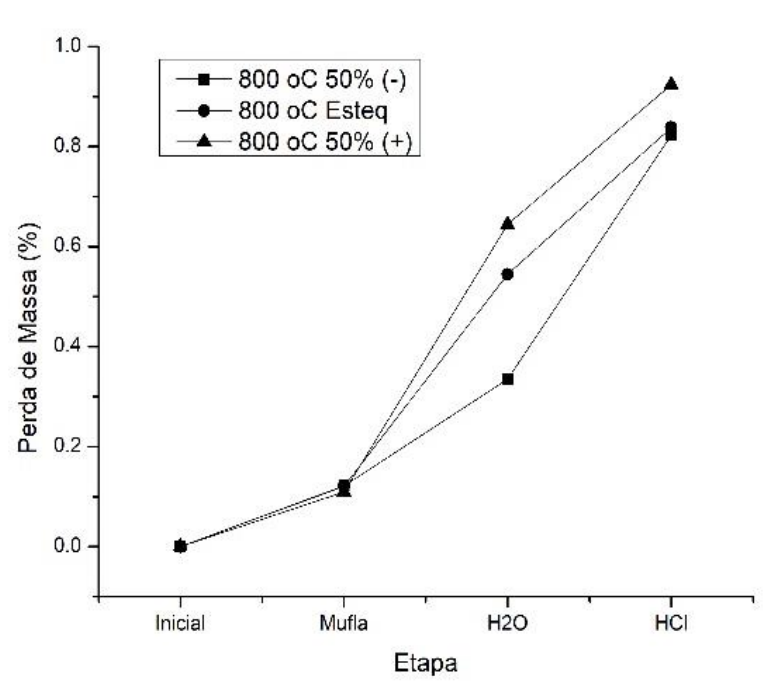

Figura 61 - Perda de massa ao longo das etapas do processo condição de $850{ }^{\circ} \mathrm{C}$.

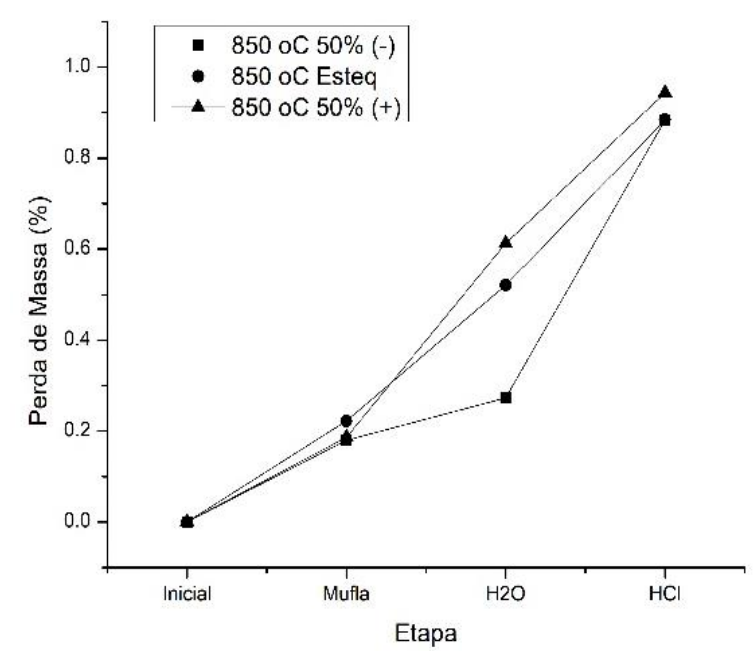


Figura 62 - Perda de massa ao longo das etapas do processo na condição de $900{ }^{\circ} \mathrm{C}$.

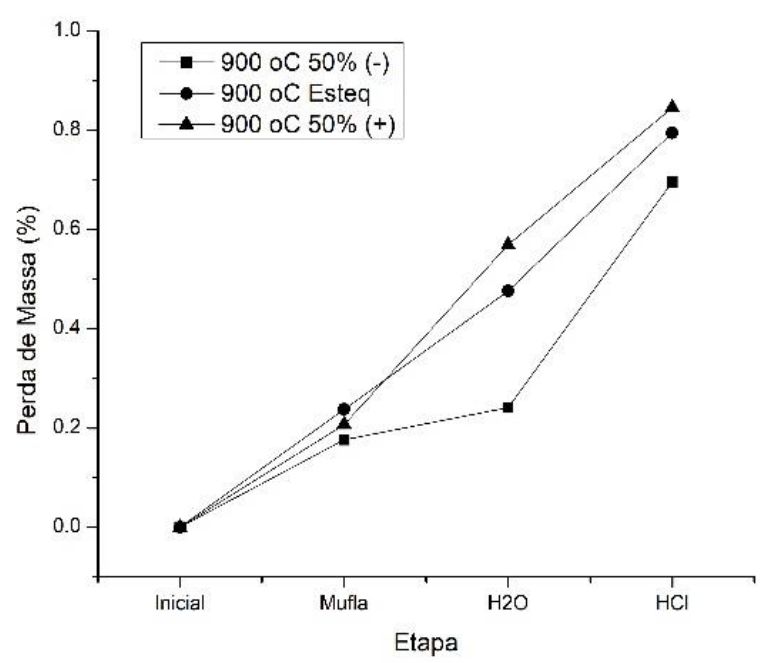

A relação com maior teor de massa removida é a de $50 \%(+)$, embora as 3 relações apresentem resultados praticamente iguais ao fim da reação de alcalina, nas mesmas temperaturas de reação na mufla.

Ao final das etapas, em todas as condições estudadas, observou-se perda da massa inicial entre $85 \%$ e $95 \%$. Esse resultado indica que o processo poderia ser considerado excelente, caso o material final fosse constituído, essencialmente, de $\mathrm{TiO}_{2}$, visto que o teor deste na massa inicial é da ordem de $10 \%$.

\subsection{1.}

MEV

Essas análises foram feitas no MEV TM 10000, a diferença principal entre esse e o TM 30000 é o detector de EDS, o detector disponível no TM 10000 não faz análise pontual e também não é capaz de identificar elementos de número atômico baixo, como por exemplo o oxigênio.

Ao observar as amostras finais no MEV TM 1000 é possível observar, mesmo nas condições mais brandas de reação, que há grande diminuição no tamanho de partícula, assemelhando as imagens a uma camada de pó. Tathavadkar e Jha (2004) confirmam que esse efeito de redução do tamanho de partícula é em grande parte consequência da fragmentação de grãos porosos, do material, por conta da fusão alcalina e subsequente solubilização em ácido.

Também foi observado de maneira geral que a superfície dos grãos não tinha mais o aspecto liso, como observado no item 4.1.1 da caracterização da amostra como recebida, demonstrando o ataque, contudo as imagens mostram 
aspectos semelhantes e também bem distintos dos grãos de cada amostra. A maioria das partículas observadas estavam, em sua grande maioria, abaixo de $200 \mu \mathrm{m}$.

O maior aumento possível nesse microscópio foi de x6000 dependendo da amostra, contudo, não foi observado significativo efeito de carregamento nessas amostras, indicando que diferente da amostra como recebida, os produtos são condutores. Ainda assim, nesse tipo de microscópio não é possível observar com detalhes a maior parte das partículas, sendo necessário fazer uso de um microscópio mais potente.

Fazendo uma análise das imagens geradas individualmente, começamos pela ordem de ensaios.

Na Figura 63, observa-se nas duas imagens superiores com aumento de x150 o aspecto geral da amostra. Nas duas imagens inferiores o detalhe de partículas selecionadas, que apresentam estrutura morfológica distinta,

Figura 63 - Amostra do ensaio 1, a $800{ }^{\circ} \mathrm{C}$ e $50 \%$ (-) de reagente.
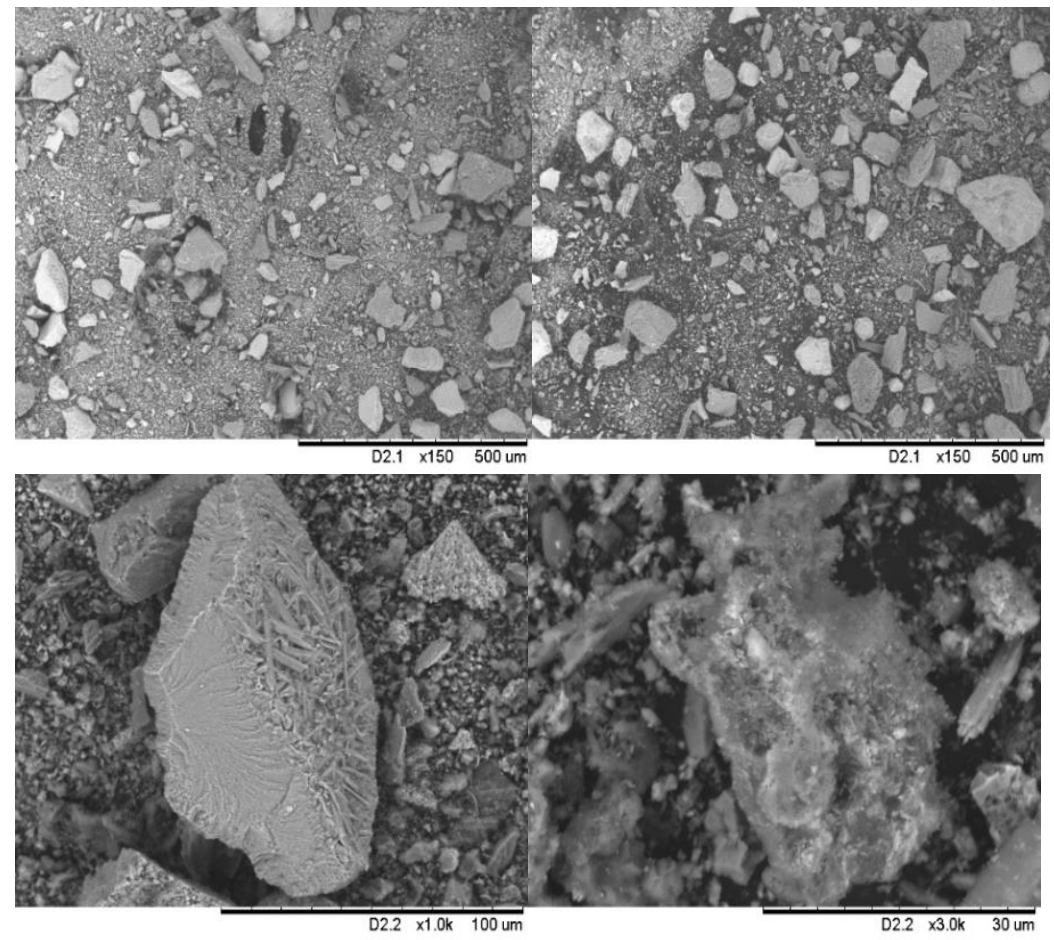

Ao intensificar o aumento nas duas partículas selecionadas, foi possível utilizar o EDS para estimar suas composições. Nas Figuras 64 e 66 estão as imagens das áreas selecionadas e nas figuras 65 e 67 estão os espectros gerados. Observam-se nítidas diferenças dentre as respectivas morfologias, a primeira partícula sendo rica em $\mathrm{Ti}$ e $\mathrm{Fe}$, com presença de $\mathrm{Al}$ e $\mathrm{Si}$, mostra superfícies retas 
com formas bem definidas, enquanto que a segunda, com altíssimo teor de Fe e a presença de $\mathrm{V}, \mathrm{Ti}, \mathrm{Al}, \mathrm{Si}, \mathrm{Ca}$, apresentou superfície com aglomeração de partículas arredondadas. A composição de cada área está descrita na Tabela 18, indicando que a continuidade da pesquisa pode levar a separação destas espécies e atingir, assim, os seus objetivos originais.

Figura 64 - Área selecionada para análise de EDS, de uma amostra rica em Ti.

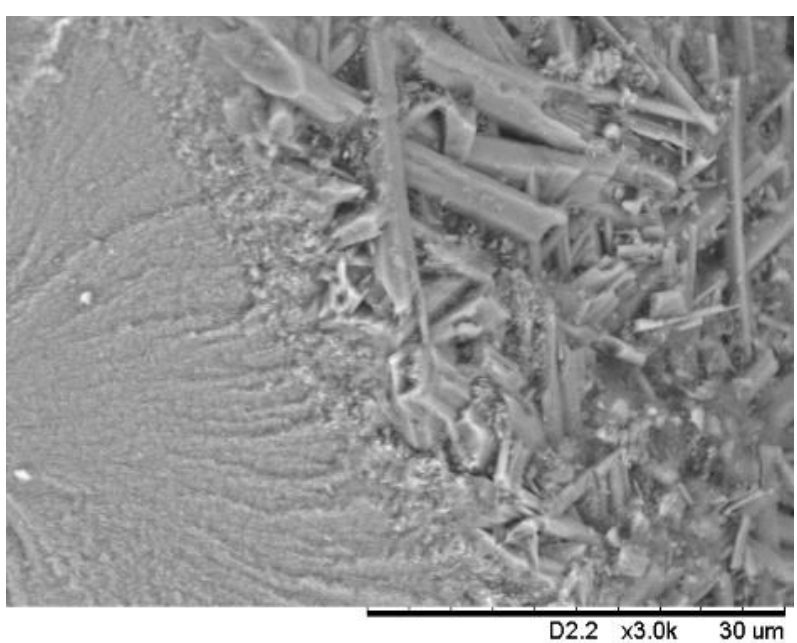

Figura 65 - Espectro da área selecionada, de uma amostra rica em Ti.

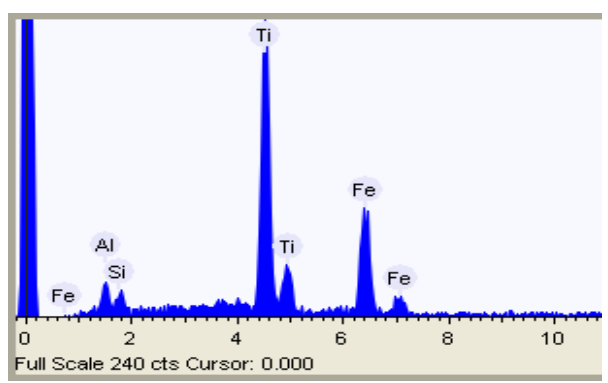


Figura 66 - Área selecionada para análise de EDS, de uma amostra rica em Fe.

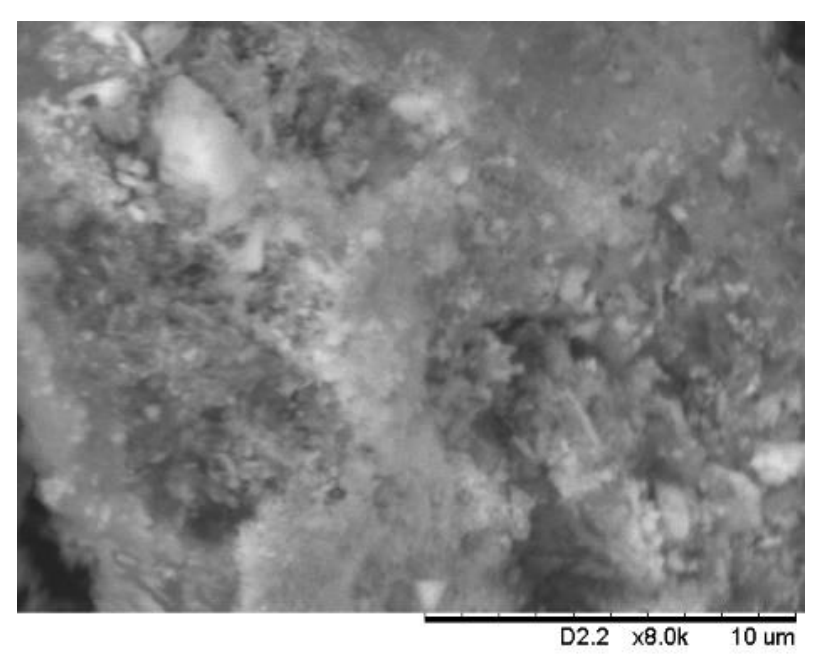

Figura 67 - Espectro da área selecionada, de uma amostra rica em Fe.

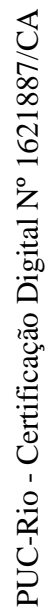

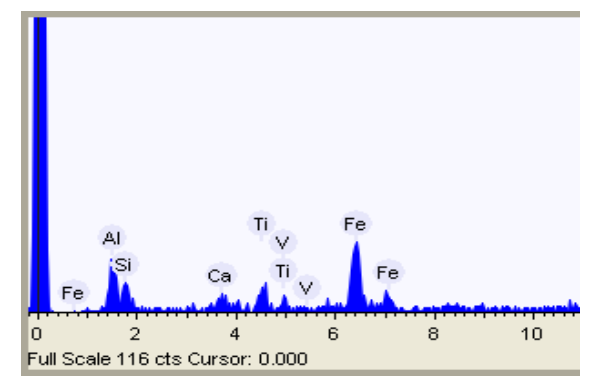

Tabela 18 - Composição das áreas das partículas, ${ }^{1}$ rica em Ti e ${ }^{2}$ rica em Fe, respectivamente.

\begin{tabular}{lll}
\hline Elemento & Peso $^{1} \%$ & Peso $^{2} \%$ \\
\hline $\mathrm{Al}$ & 2.9 & 12.7 \\
$\mathrm{Si}$ & 1.6 & 5.8 \\
$\mathrm{Ti}$ & 52.6 & 9.4 \\
$\mathrm{Fe}$ & 42.9 & 64.6 \\
$\mathrm{Ca}$ & - & 3.4 \\
$\mathrm{~V}$ & - & 4.1 \\
\hline
\end{tabular}


A diferença de composição está diretamente ligada com o tipo de estrutura morfológica que a partícula irá ter, bem como o tipo de ataque que sofrerá.

Monteiro (2016) e Ziemniak e colaboradores (1993) descreveram partículas ricas em Ti com estrutura morfológica semelhante à apresentada na Figura 64, mesmo os dois trabalhos tendo abordado processos bem distintos.

Observando as imagens dispostas na Figura 68, nota-se que foi encontrado menor quantidade de partículas muito finas, contudo se assemelha ao tipo de partículas observadas na amostra anterior.

Figura 68 - Amostra do ensaio 2 , a $800{ }^{\circ} \mathrm{C}$ e quantidade estequiométrica de reagente.
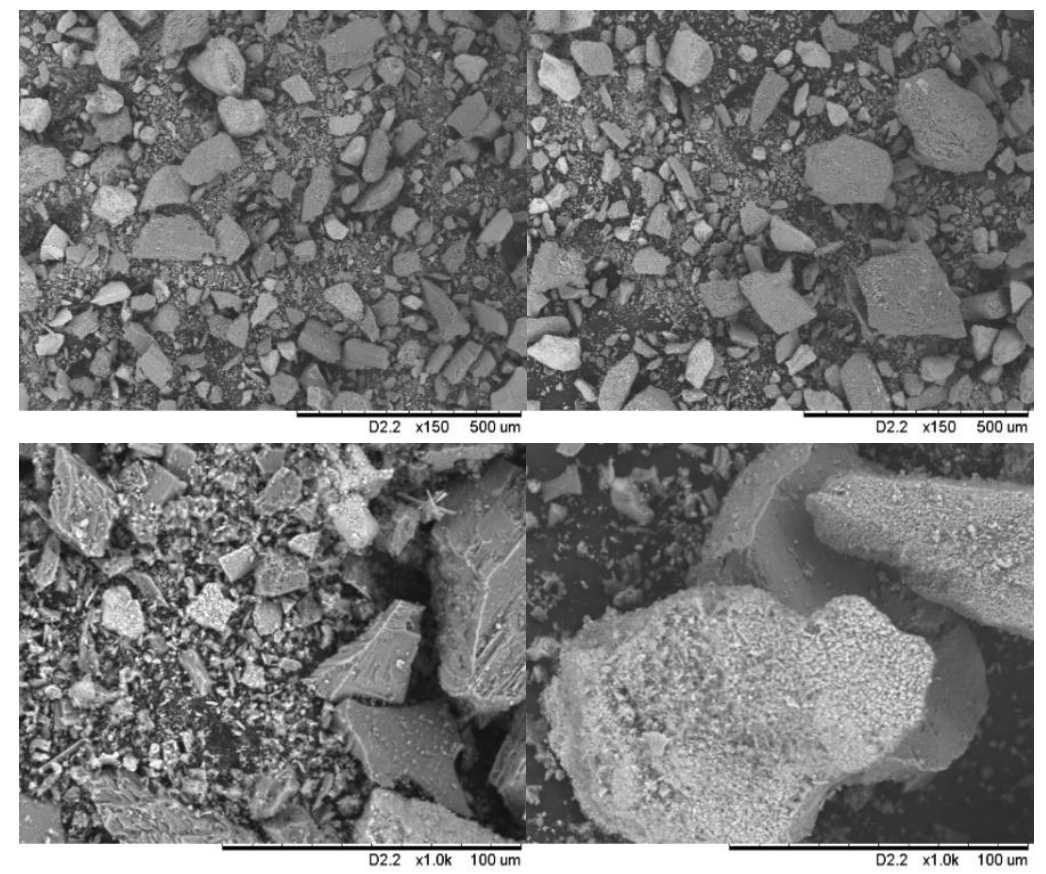

Nas imagens da Figura 69, as imagens superiores seguem semelhantes às das amostras anteriores, contudo nas imagens inferiores, tem-se duas partículas com aspecto muito liso, semelhante aspetos das partículas encontradas na amostra como recebida, sugerindo que não sofreram ataque, utilizou-se o detector de EDS para identificar a composição das amostras e assim tentar entender porque não parecem ter reagido. 
Figura 69 - Amostra do ensaio 3, a $800{ }^{\circ} \mathrm{C}$ e $50 \%$ (+) de reagente.
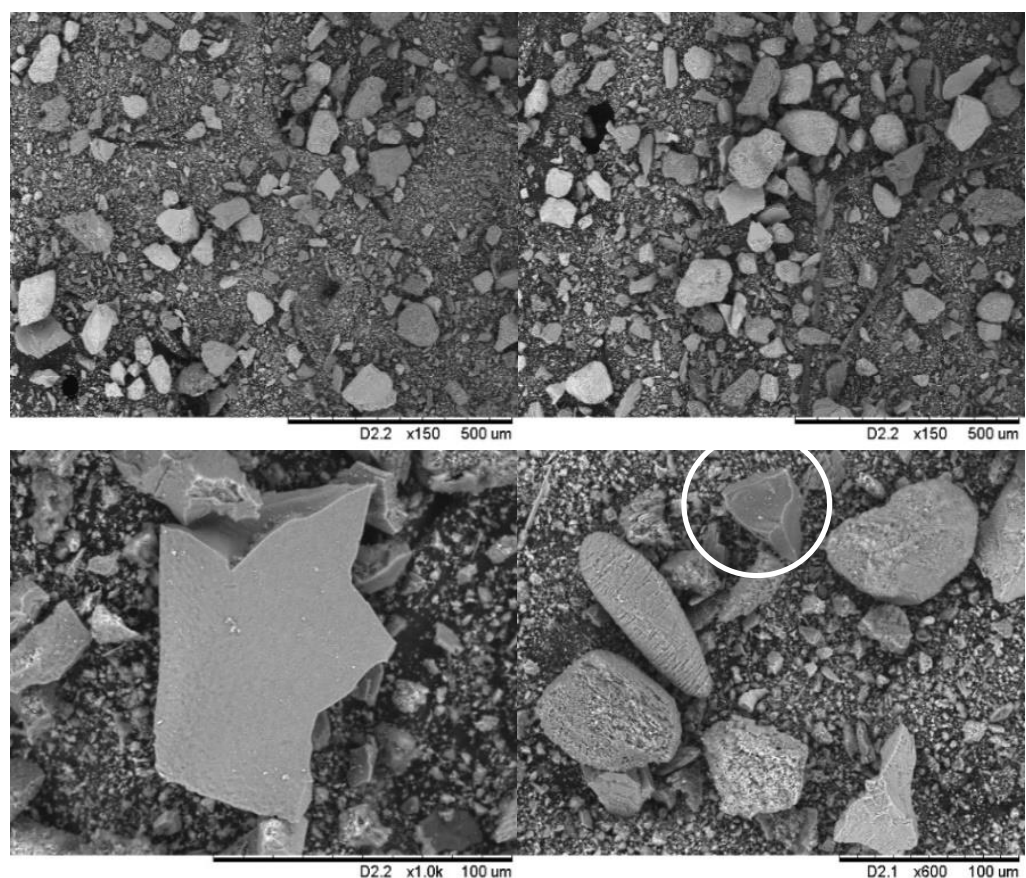

Ao intensificar o aumento nas duas partículas selecionadas, foi possível observar os aspectos da superfície nas Figuras 70 e 72, respectivamente correspondendo a parte inferior da esquerda e direita.

Observando a imagem Figura 70 é possível notar, que embora tenha aspecto muito liso na superfície, há resquícios de um ataque sutil, pela superfície irregular. Essa amostra apresenta altos teores de $\mathrm{Fe}$, e quantidades muito relevantes de $\mathrm{Si}$, $\mathrm{Ca}$ e $\mathrm{Al}$, que podem ser interpretado pelo sinal de alta intensidade na Figura 71.

Figura 70 - Área selecionada para análise de EDS, de uma amostra rica em Fe.

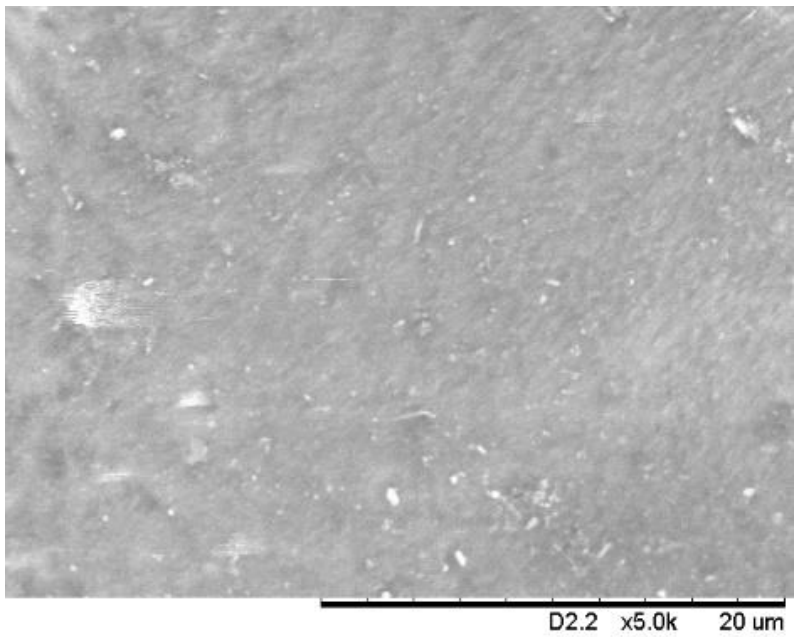


Figura 71 - Espectro da área selecionada, de uma amostra rica em Fe.

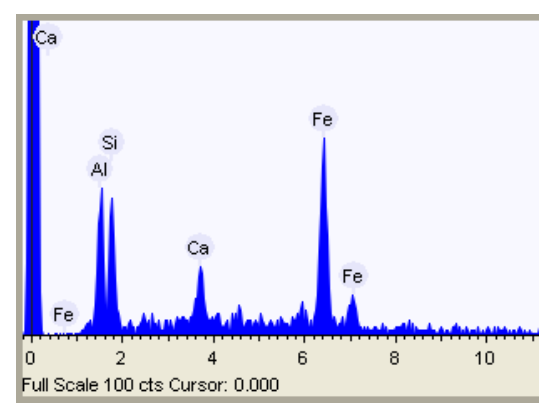

Essa partícula sugere a formação de compostos estáveis e resistentes aos ataques do processo.

Observando agora a imagem ilustrada na Figura 72, nota-se um aspecto muito regular na superfície, como se o ataque sobre ela não tivesse sido efetivo, e na Figura 73 está o espectro identificando os elementos que a compõe.

Figura 72 - Área selecionada para análise de EDS, da amostra 3.

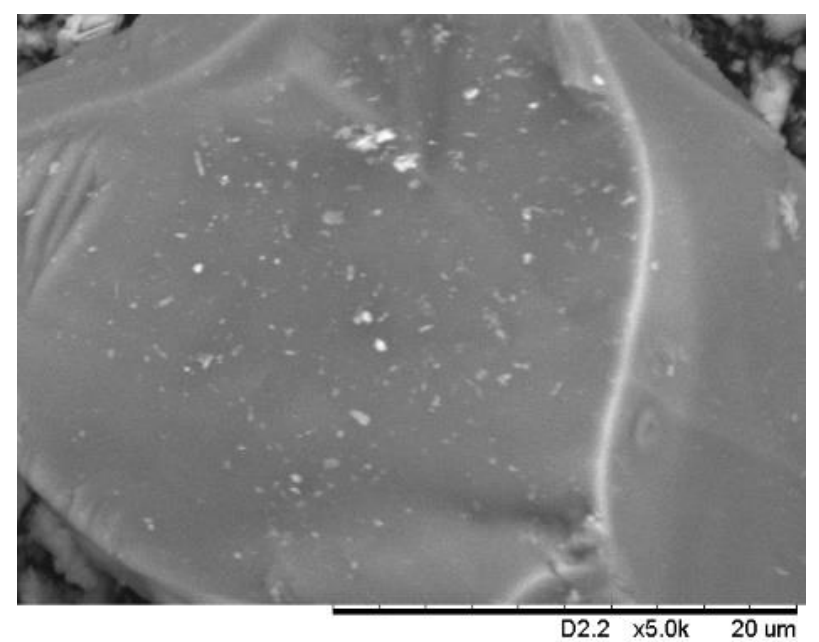

Figura 73 - Espectro da área selecionada, da amostra 3.

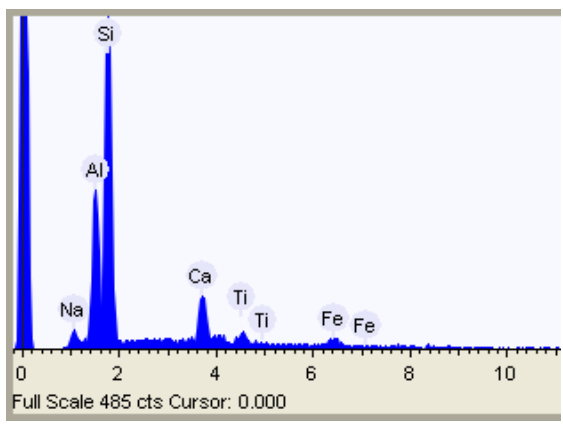

A diferença composicional das partículas está descrita na Tabela 19. 
Tabela 19 - Composição das áreas das partículas, ${ }^{1}$ complexa e ${ }^{2}$ rica em $\mathrm{Si}$, respectivamente.

\begin{tabular}{lll}
\hline Elemento & Peso $^{1} \%$ & Peso $^{2} \%$ \\
\hline $\mathrm{Al}$ & 14.4 & 21.2 \\
$\mathrm{Si}$ & 14.0 & 53.4 \\
$\mathrm{Ca}$ & 5.1 & 12.6 \\
$\mathrm{Fe}$ & 66.5 & 4.1 \\
$\mathrm{Na}$ & - & 4.3 \\
$\mathrm{Ti}$ & - & 4.5 \\
\hline
\end{tabular}

$\mathrm{Na}$ próxima amostra, especificamente nas imagens superiores da Figura 74, percebe-se que as partículas são menores que $100 \mu \mathrm{m}$, embora não apresentem grandes diferenças de contraste, foi possível identificar partículas com grandes diferenças.

Figura 74 - Amostra do ensaio 4, a $850{ }^{\circ} \mathrm{C}$ e $50 \%$ (-) de reagente.
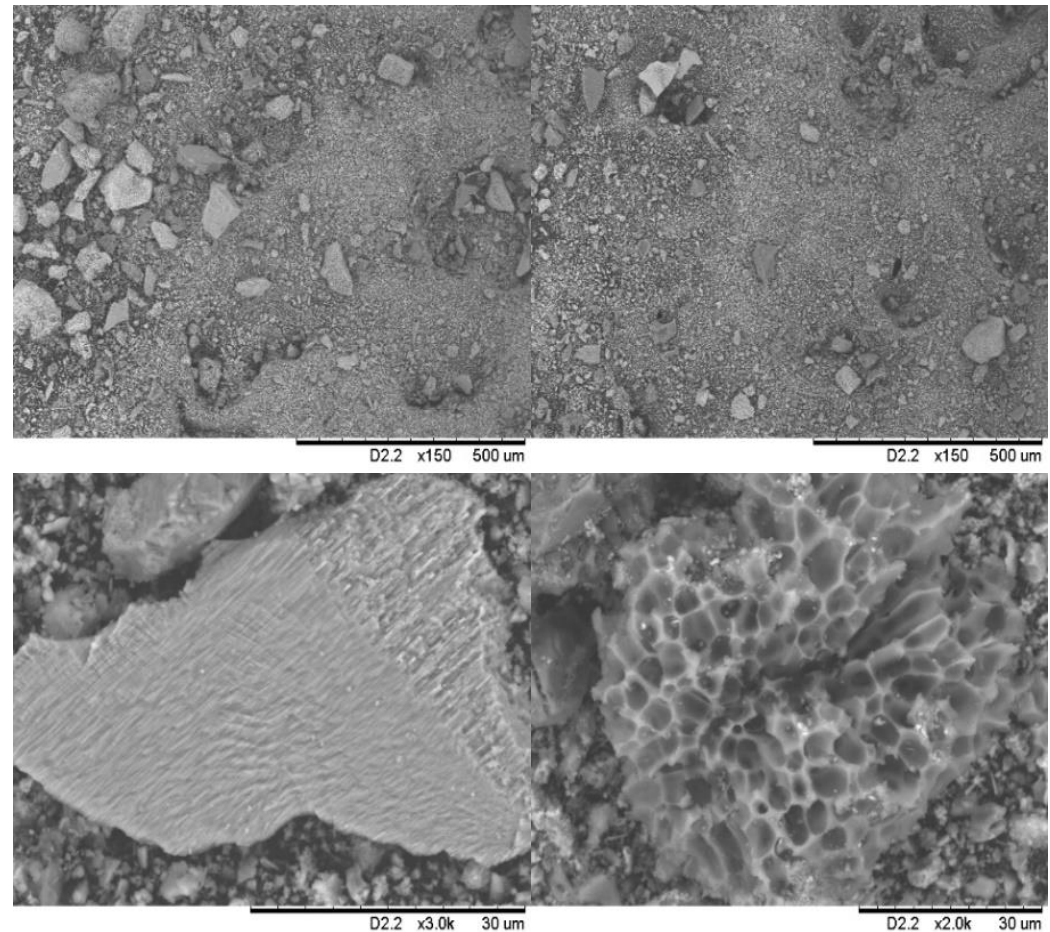

Já nas imagens inferiores da Figura 74, apresenta-se duas partículas com morfologia bastante distinta, tendo a imagem inferior esquerda se assemelhado, em aparência e composição, à Figura 66. 
Foi feito o registro da partícula, do quadrante inferior direito, em maior aumento, bem como a análise de EDS, apresentados nas Figuras 75 e 76 . Também é uma partícula muito rica em Si.

Figura 75 - Área selecionada para análise de EDS, da amostra 4.

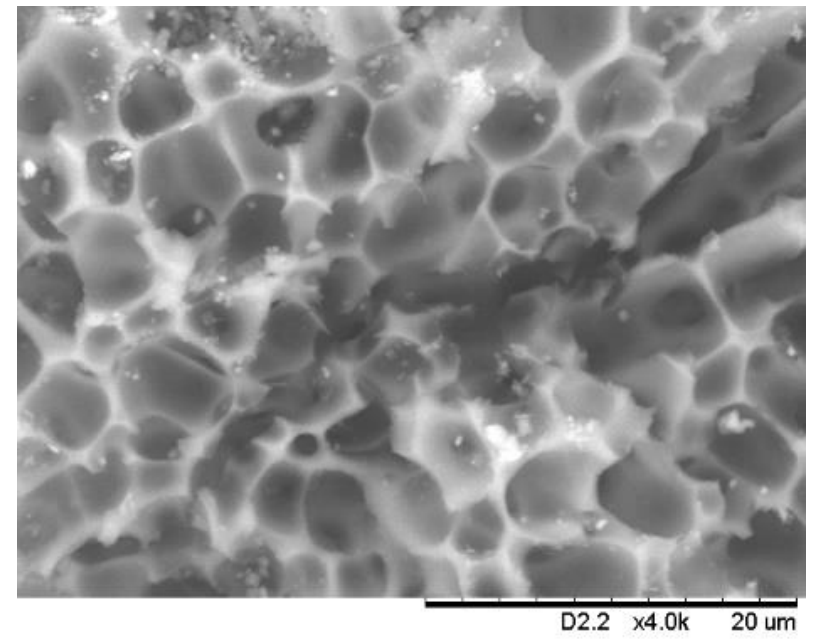

Figura 76 - Espectro da área selecionada, da amostra 4.

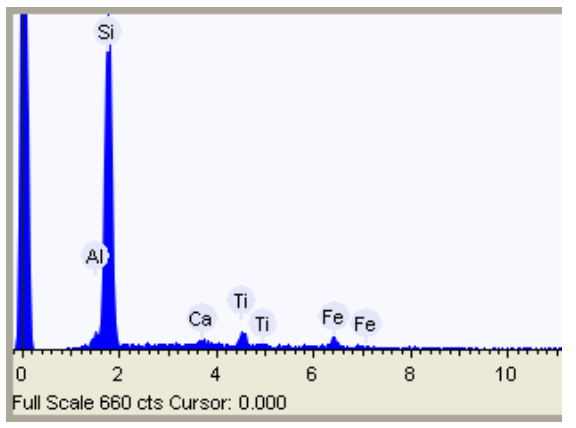

Apesar de apresentar morfologia bem distinta, pode-se apontar semelhanças com a partícula da Figura 72, como os 'veios' de contraste mais claro e a aparência arredondada de suas extremidades, além de que apresentam teores dos mesmos elementos.

Na Figura 77, nota-se um tamanho de partículas ainda menor que das amostras anteriores, na qual mesmo as maiores partículas parecem estar cobertas por menores. A partícula do quadrante inferior esquerdo se assemelha as identificadas nas figuras 72 e 75 . 
Figura 77 - Amostra do ensaio 5 , a $850{ }^{\circ} \mathrm{C}$ e quantidade estequiométrica de reagente.
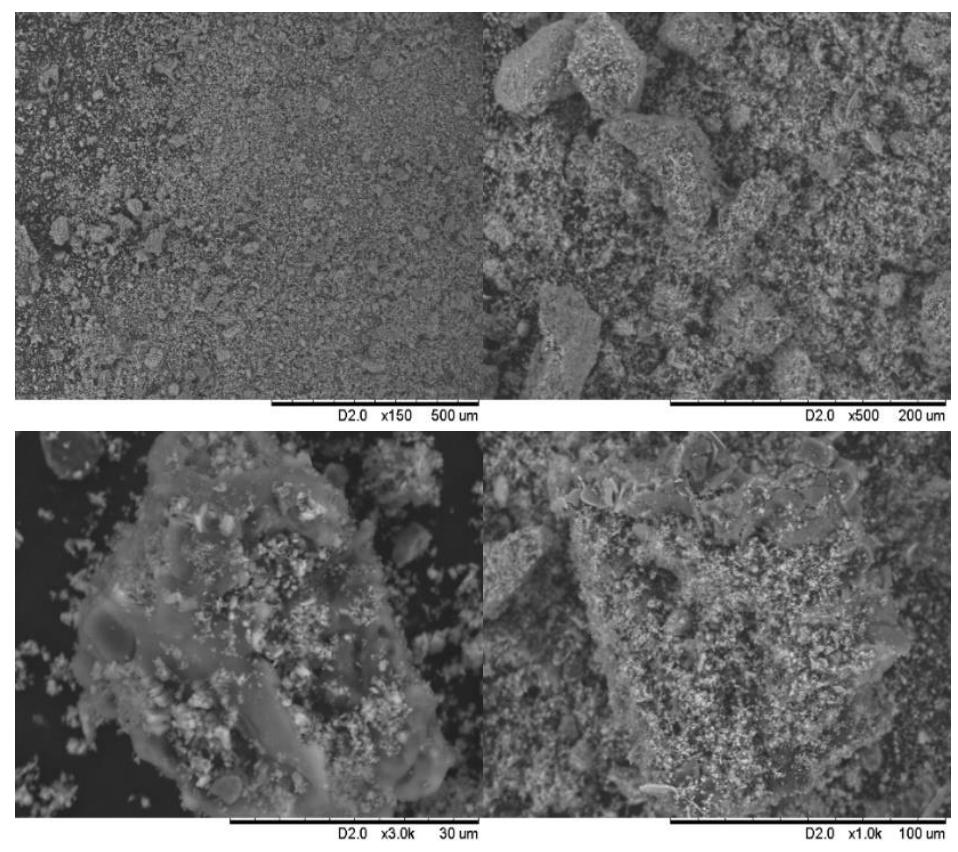

Contudo os grãos que estão cobertos por partículas menores apresentaram maiores teores de Fe e Ti em relação os grãos semelhantes sem essa camada de cobertura, sugerindo que as partículas, menores que $3 \mu \mathrm{m}$, são ricas nesses elementos.

A composição analisada, das duas partículas da Figura 77, não identificou teores de Ca. Além disso, as duas partículas apresentaram valores muito semelhantes na sua composição quando comparadas entre si e com a identificada na amostra anterior, conforme comparação da Tabela 20. 
Tabela 20 - Composição das áreas das partículas, da Figura 77 e do quadrante inferior ${ }^{1}$ esquerdo $\mathrm{e}^{2}$ direito da ${ }^{3}$ Figura 72 , respectivamente.

\begin{tabular}{llll}
\hline Elemento & Peso $^{1} \%$ & Peso $^{2} \%$ & Peso $^{3} \%$ \\
\hline $\mathrm{Al}$ & 21.2 & 13.1 & 8.4 \\
$\mathrm{Si}$ & 53.4 & 35.7 & 24.3 \\
$\mathrm{Ca}$ & 12.6 & - & - \\
$\mathrm{Fe}$ & 4.1 & 34.7 & 46.9 \\
$\mathrm{Mg}$ & - & 1.5 & 2.4 \\
$\mathrm{Na}$ & 4.3 & 1.1 & - \\
$\mathrm{Ti}$ & 4.5 & 13.8 & 18.0 \\
\hline
\end{tabular}

A amostra, exibida na Figura 78, é muito semelhante a amostra do ensaio anterior, contudo foi possível focalizar partículas a aumentos maiores, e assim visualizar mesmos partículas com menos de $20 \mu \mathrm{m}$ parecem estar cobertas por partículas menores, ou um aglomerado de partículas pequenas.

Figura 78 - Amostra do ensaio 6, a $850{ }^{\circ} \mathrm{C}$ e $50 \%$ (+) de reagente.
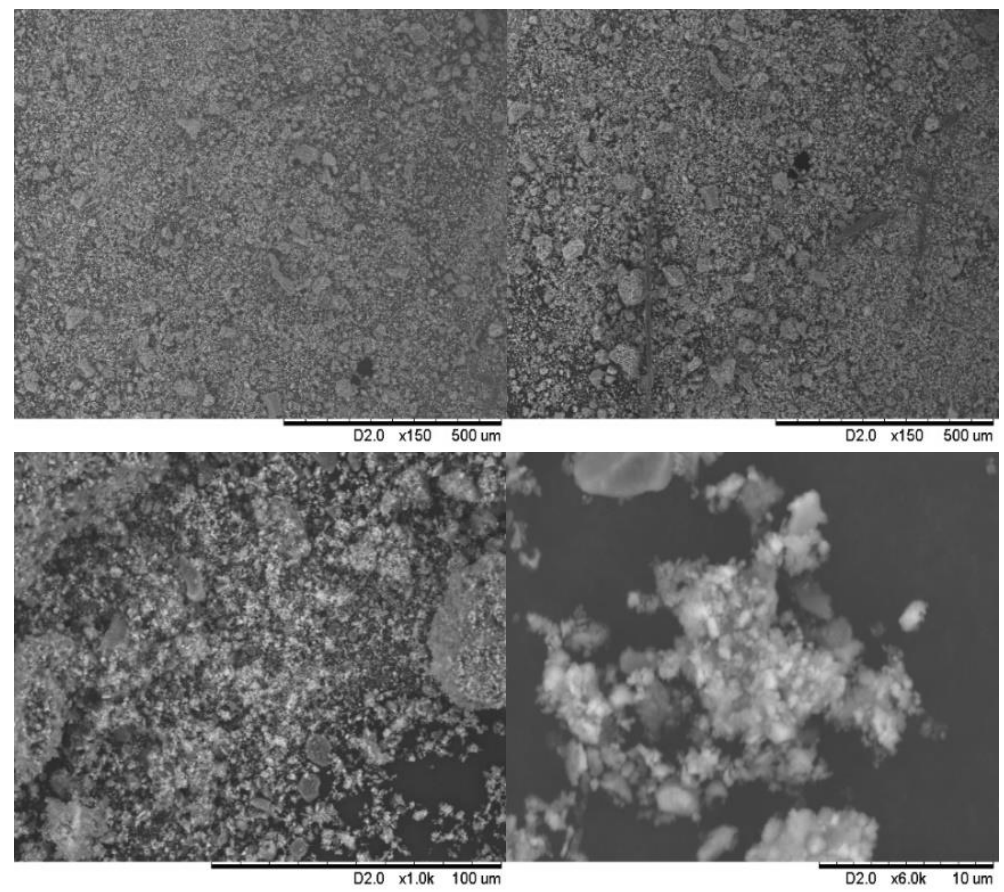

Quando observamos as imagens da Figura 79, podemos ver que parece haver um aumento na quantidade de partículas maiores, assim como não há mais o efeito de cobertura com partículas menores, em contrapartida, a imagem do quadrante inferior esquerdo se assemelha com a identificada na Figura 66. 
Figura 79 - Amostra do ensaio 7 , a $900{ }^{\circ} \mathrm{C}$ e $50 \%$ (-) de reagente.

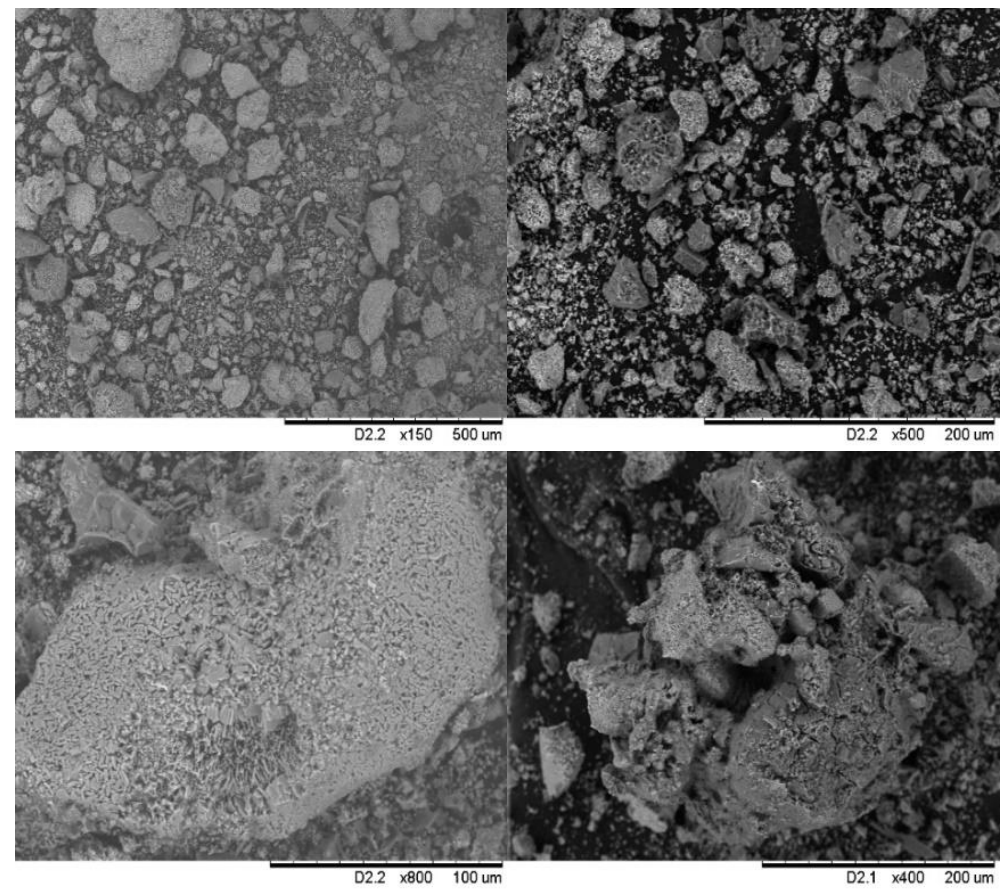

No quadrante inferior direito, a partícula parece um aglomerado de partículas fundidas, corroborando com o indício de que na temperatura utilizada nesse ensaio, os produtos da reação não são solúveis em água, mantendo a estrutura fundida mesmo após as solubilizações.

O aumento do tamanho de partícula está diretamente ligado a diminuição da capacidade de solubilização, tanto em ácido quanto em água, isso porque como já citado o aumento da temperatura favorece a formação de compostos mais estáveis e insolúveis, e a diminuição do tamanho de partículas está justamente associada a quebra das partículas solúveis em água.

As imagens da Figura 80 voltam a apresentar aspectos semelhantes aos identificados nas figuras dos ensaios 1,2, 3 e 4, com temperaturas mais brandas.

Embora nas análises de FR-X e ICP não tenham identificado zircônio, a análise de EDS da imagem do quadrante inferior esquerdo mostrou teores de $\mathrm{Zr}$, conforme indicado na Figura 81. A diferença de contraste apresentando uma cor clara mais intensa indica que há algum elemento mais claros tem maior número atômico (Goldstein et al., 2018), podendo não ser necessariamente o $\mathrm{Zr}$, mas algum que emita o sinal, captado pelo detector, de raios-x semelhante. 
Figura 80 - Amostra do ensaio 8 , a $900{ }^{\circ} \mathrm{C}$ e quantidade estequiométrica de reagente.
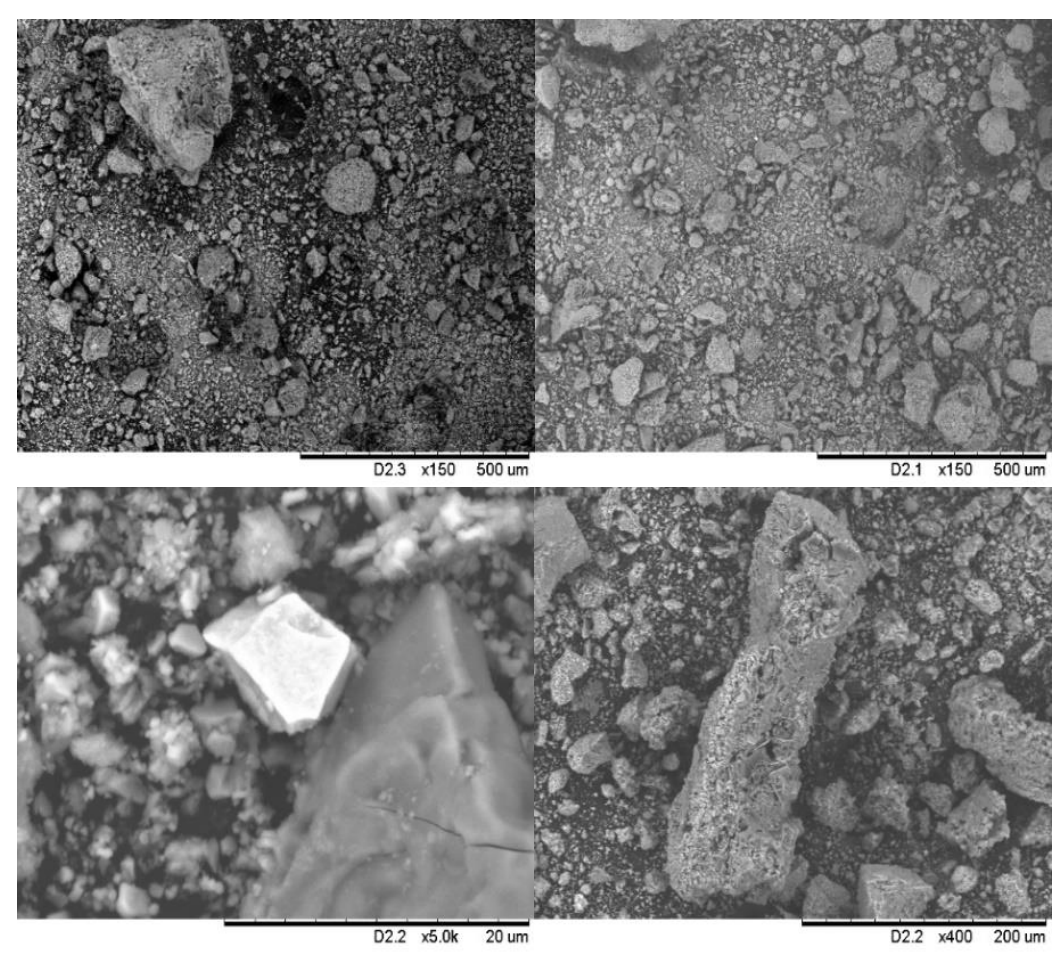

Figura 81 - EDS da imagem do quadrante inferior esquerdo da figura 75.

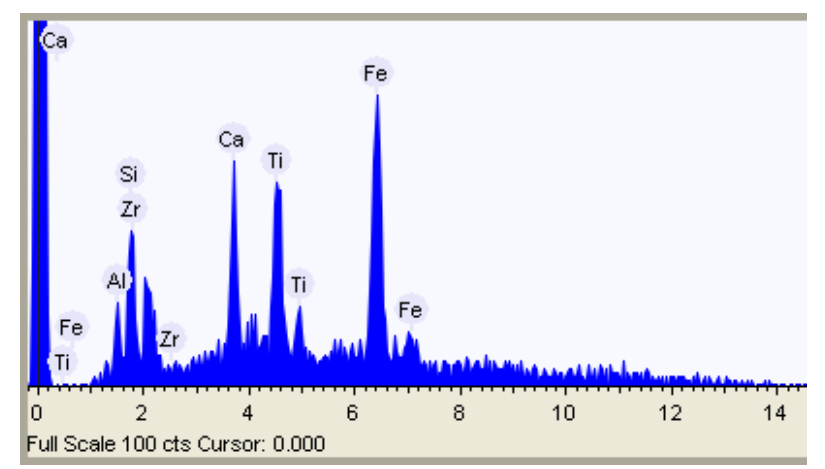

Como o detector não é capaz de fazer uma leitura pontual, o espectro captou sinal de todas as partículas contidas na imagem, por conta disso pode-se ver os sinais de $\mathrm{Si}, \mathrm{Ca}$ e $\mathrm{Al}$, que provavelmente não são sinais emitidos pela partícula.

Na Figura 82 há novamente a diminuição do tamanho de partícula e o efeito de 'cobertura' dos grãos com partículas menores, além disso as partículas parecem não se aglomerar tanto quanto nas amostras anteriores. 
Figura 82 - Amostra do ensaio 9, a $900{ }^{\circ} \mathrm{C}$ e $50 \%(+)$ de reagente.
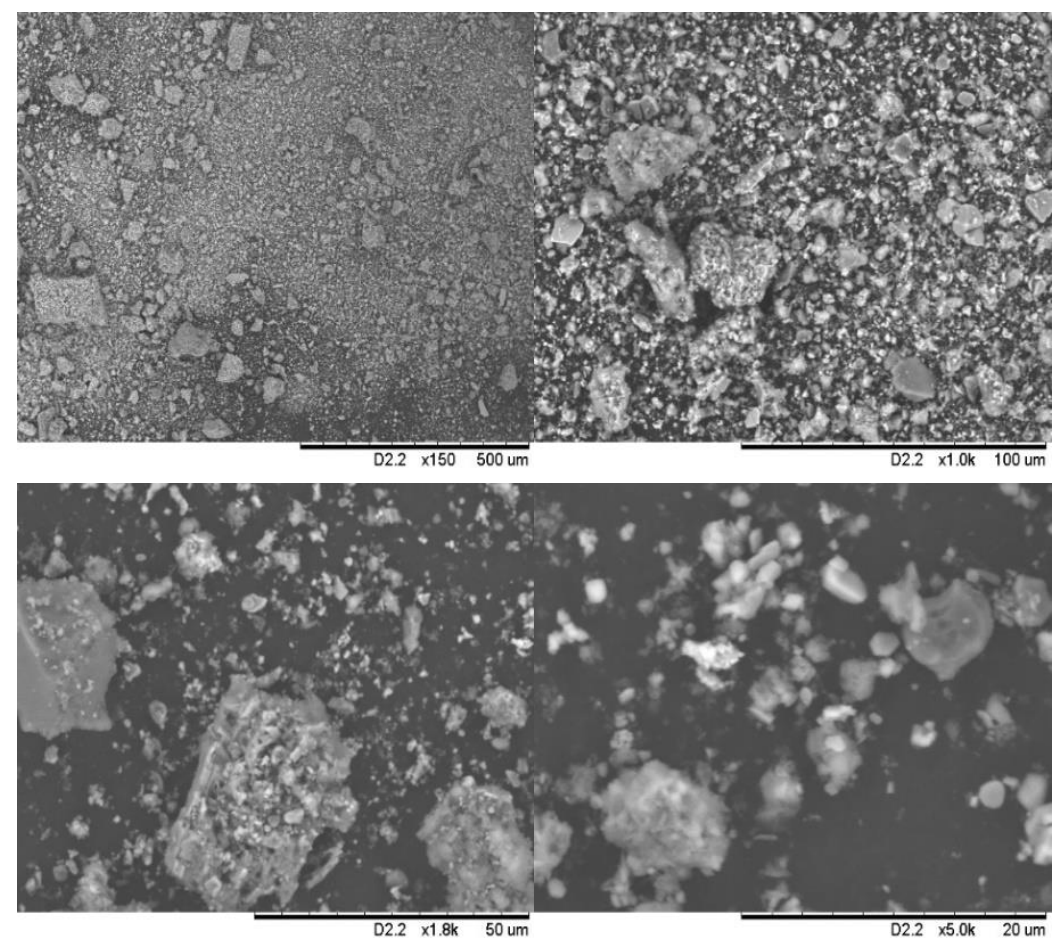

As 3 primeiras amostras, que correspondem aos ensaios em $800{ }^{\circ} \mathrm{C}$, apresentaram tamanhos de partícula maior, isso porque, conforme já citado, a diminuição do tamanho de partícula é consequência da fusão que acontece na mufla, como os compostos gerados (sais de $\mathrm{Si}$ e $\mathrm{Al}$ ) e o reagente começam a fundir a partir de $850{ }^{\circ} \mathrm{C}$, contudo em $900{ }^{\circ} \mathrm{C}$ há indícios da formação de produtos mais complexos e insolúveis em água, gerando ligeiro aumento no tamanho das partículas.

Apenas nas primeiras amostras foram encontradas partículas que tivessem morfologia semelhantes, de acordo com trabalhos já citados, a partículas de $\mathrm{TiO}_{2}$, o que sugere que nas demais amostras foram formados complexos contendo titânio, como por exemplo a perovskita.

\subsection{2. EDS}

Para estimar melhor as quantidades elementares as amostras, foram feitas algumas capturas em mais de uma região por amostra, a média dos resultados foi plotada nos gráficos a seguir, contidos nas Figuras 83, 84 e 85.

Observando os gráficos separadamente, podemos identificar a influência da temperatura na concentração dos elementos, numa mesma relação de massa amostra/reagente. No gráfico da Figura 83, nota-se que a maior temperatura 
corresponde a maior concentração de Fe, sugerindo que nessas concentrações de reagente, o ferro começa a formar complexos que dificultam sua remoção, já o Si diminuição da concentração quase que linear com o aumento da temperatura. Nota-se também um pico da concentração de $\mathrm{Al}$ na temperatura de $850{ }^{\circ} \mathrm{C}$, bem como discretos aumentos de Ca e Ti.

Figura 83 - Quantificação (\%) vs elemento das amostras de relação molar $50 \%(-)$.

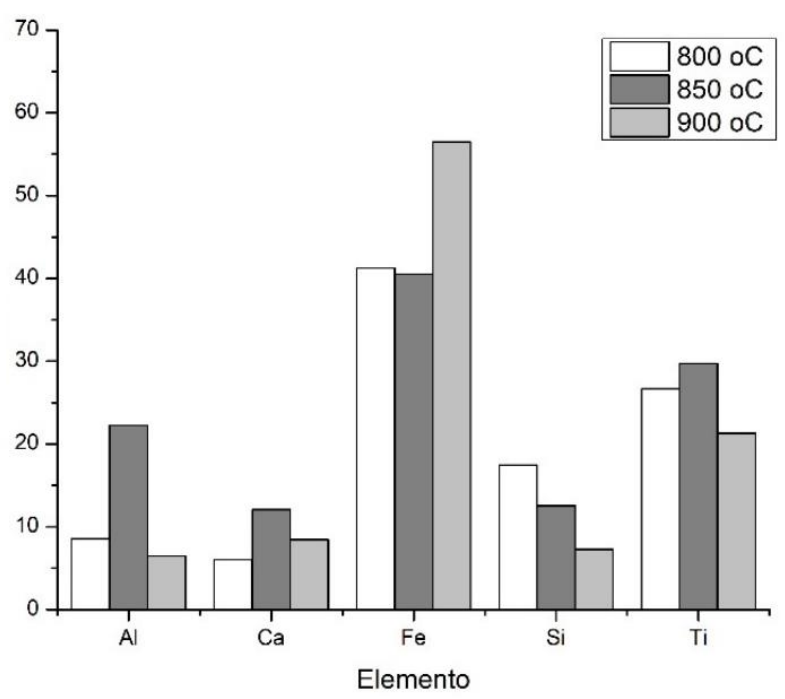

Já observando os resultados contidos na Figura 84, podemos perceber que há o efeito contrário sobre o $\mathrm{Al}$, tendo ele, na temperatura intermediária, uma queda da concentração. Do mesmo modo, nessa temperatura há o aumento de Fe, Ti, e discreta diminuição de Si. Além disso, essas análises sugerem que há quase que completa remoção de $\mathrm{Ca}$ nas temperaturas de $850{ }^{\circ} \mathrm{C}$ e $900{ }^{\circ} \mathrm{C}$. 
Figura 84 - Quantificação (\%) vs elemento das amostras de relação molar estequiométrica.

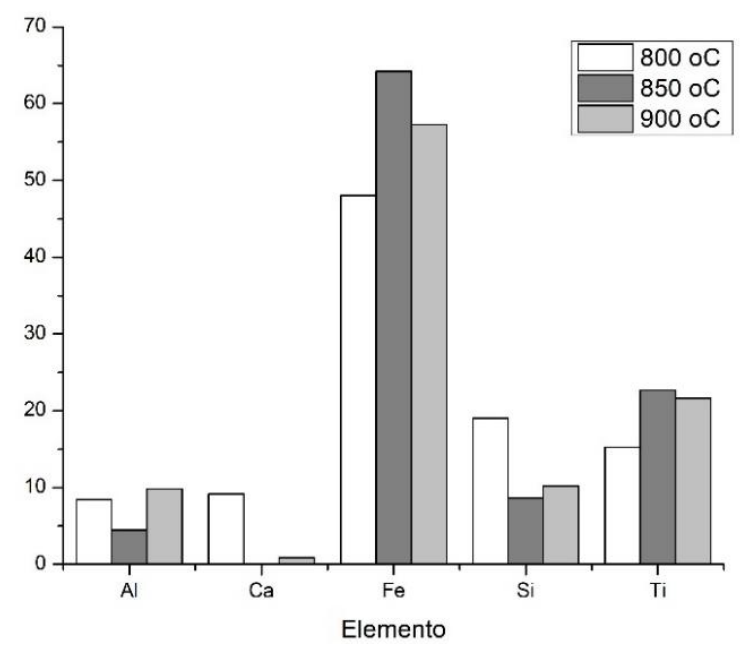

Os resultados da Figura 85, mostram quase que proporcional relação entre diminuição de teores de $\mathrm{Si}$ e Ti, com o aumento dos de Fe. Os valores de $\mathrm{Al}$ praticamente não sofreram alteração, e assim como os resultados da figura anterior, nesta percebemos quase que total remoção de $\mathrm{Ca}$ nas mesmas temperaturas.

Figura 85 - Quantificação (\%) vs elemento das amostras de relação molar $50 \%(+)$.

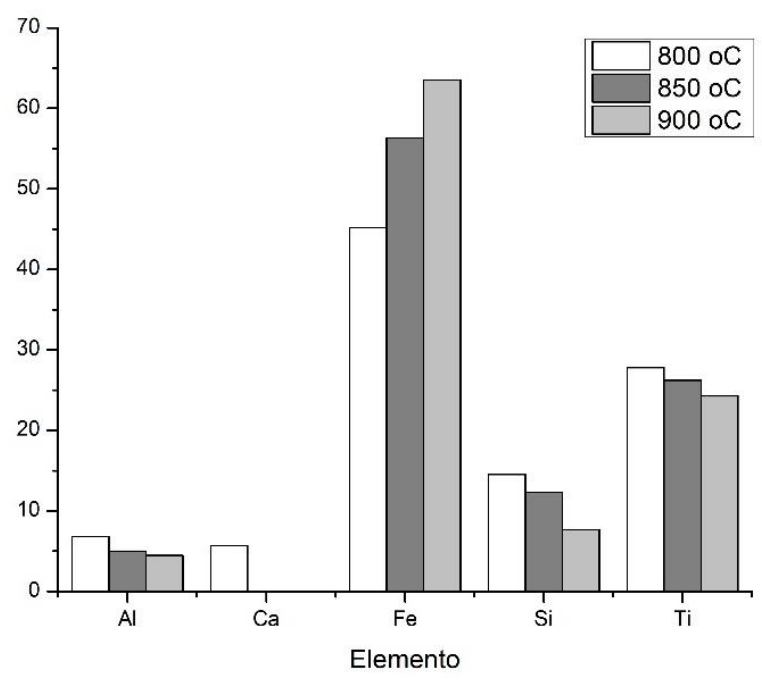

Em todos eles, pode-se notar que as quantidades do teor de Ti variam entre 20 e $30 \%$, em contrapartida com o inicial que variava de 6 a $11 \%$. Por outro lado, houve grande aumento nas quantidades de Fe de cerca de $30 \%$ para uma faixa de $40 \%$ a $70 \%$. Já o Si, não varia tanto comparado com o valor inicial, contudo 
sugere-se ligeira diminuição de cerca de $30 \%$ para menos de $20 \%$ em todas as análises.

Quanto menor a temperatura, maiores as concentrações de $\mathrm{Si}$, em todas as relações de massa amostra/reagente. Já a respeito do titânio, pode-se supor que a temperatura de $850^{\circ} \mathrm{C}$ apontam para maiores teores.

\subsection{3.}

\section{DR-X e Análise Química}

Para a amostra final, só foi possível fazer uma leitura dos espectros com o programa qualitativo, obtendo sugestões de composição de fases, contudo não se tem um ajuste de curva necessário para confirmar a certeza da presença das fases sugeridas, contudo nas Tabelas 21 e 22 estão listadas as fases mais prováveis.

Tabela 21 - Sugestão das fases que compões as amostras 1, 2 e 3.

\begin{tabular}{l|l|l} 
Amostra 1 & \multicolumn{1}{l}{ Amostra 2 } & Amostra 3 \\
\hline $\mathrm{Ca}_{0.4} \mathrm{FeNa}_{0.6} \mathrm{O}_{6} \mathrm{Si}_{2}$ & $\mathrm{Al}_{0.6} \mathrm{CaMg}_{0.7} \mathrm{O}_{6} \mathrm{Si}_{1.7}$ & $\mathrm{Al}_{0.03} \mathrm{Fe}_{0.015} \mathrm{Mg}_{2} \mathrm{O}_{6} \mathrm{Si}_{2}$ \\
$\mathrm{Ca}_{3} \mathrm{Fe}_{1.88} \mathrm{O}_{12} \mathrm{Si}_{2}$ & $\mathrm{Fe}_{2} \mathrm{TiO}_{4}$ & $\mathrm{Al}_{6} \mathrm{Ca}_{9} \mathrm{O}_{18}$ \\
$\mathrm{Fe}_{2} \mathrm{O}_{3}$ & $\mathrm{Fe}_{2} \mathrm{O}_{3}$ & $\mathrm{Fe}_{2} \mathrm{TiO}_{4}$ \\
$\mathrm{FeNaTiO}_{4}$ & $\mathrm{TiO}_{2}$ & $\mathrm{Fe}_{2} \mathrm{O}_{3}$ \\
$\mathrm{Mg}_{2} \mathrm{TiO}_{4}$ & $\mathrm{SiO}_{2}$ & $\mathrm{Fe}_{3} \mathrm{O}_{4}$ \\
$\mathrm{TiO}_{2}$ & & $\mathrm{Mg}_{2} \mathrm{O}_{4}$ \\
$\mathrm{~V}_{2} \mathrm{O}_{3}$ & & $\mathrm{TiO}_{2}$ \\
& & $\mathrm{SiO}_{2}$ \\
\hline
\end{tabular}

Tabela 22 - Sugestão das fases que compões as amostras 4 a 9 .

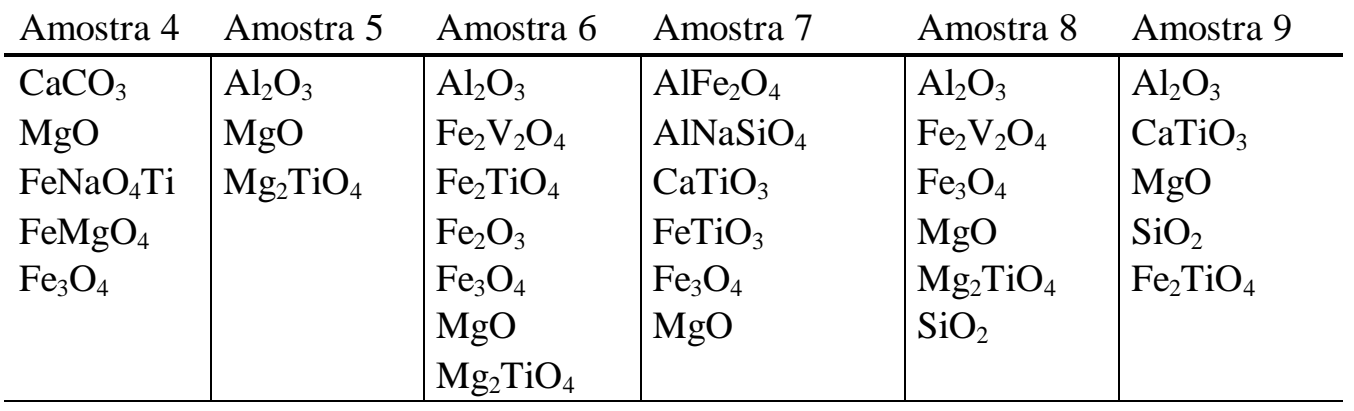

As fases sugeridas contêm elementos que não foram captados pela análise de DR-X, vale ressaltar que o detector utilizado é de menor capacidade que o utilizado na caracterização da matéria-prima.

Também foram feitas análises químicas da composição específica de Ti e Fe para amostras selecionadas. Amostras do ensaio na condição de $850{ }^{\circ} \mathrm{C}$ e 
quantidade estequiométrica de regente (amostra 5), do ensaio na condição de 850 ${ }^{\circ} \mathrm{C}$ e $50 \%$ (+) de reagente (amostra 6) e por último do ensaio na condição de 900 ${ }^{\circ} \mathrm{C}$ e quantidade estequiométrica de reagente (amostra 8). Os resultados estão dispostos na Tabela 23, de modo a comparar os valores de cada sistema reacional e com o resultado da amostra como recebida.

Tabela 23 - Quantificação do teor de Fe e Ti por análise química em amostras selecionadas, respectivamente amostras 6, 5 e 8, vs material como recebido.

\begin{tabular}{c|c|cc}
\hline \multicolumn{2}{c|}{ Amostra } & \multicolumn{2}{c}{ Composto } \\
\cline { 1 - 3 } Relação mássica & Temperatura & Fe & Ti \\
\hline $50 \%(+)$ & \multirow{2}{*}{$850{ }^{\circ} \mathrm{C}$} & $19.4 \%$ & $12.9 \%$ \\
\cline { 3 - 4 } Estequiométrica & & $27.1 \%$ & $17.4 \%$ \\
\cline { 3 - 4 } & $90{ }^{\circ} \mathrm{C}$ & $23.3 \%$ & $11.3 \%$ \\
\hline \multicolumn{2}{c}{ Como recebida } & $20-26 \%$ & $6-9 \%$ \\
\hline
\end{tabular}

A análise mostra que as reações realizadas não foram muito eficientes para concentração de Ti, embora haja um relativo aumento. Isso pode ser justificado, como já comentado, pela possível formação de complexos insolúveis, o que se confirma pela dificuldade de remoção de Fe, incluindo a pouca eficiência da sua solubilização na etapa de reação com $\mathrm{HCl}$.

Pela análise de DR-X esse resultado já era esperado, pois foram identificados qualitativamente vários compostos de Fe, além de outros de $\mathrm{Al}$ e Si. Sem excluir a possibilidade de terem sido formados compostos amorfos, os quais não são identificados por DR-X.

Essa dificuldade de processamento de minérios é consequência das características do produto inicial, como funcionalidade intrínseca, pureza das estruturas cristalinas ou da superfície do grão, referente ao teor e a natureza dos contaminantes, morfologia e tamanho final de partícula (Ciminelli, 2008).

4.5.

\section{Análise de perda de massa ao longo do tempo}

Com intuito de identificar padrões de tendência de perda de massa em diferentes tempos reacionais, foram feitos outros 16 ensaios, a partir desses ensaios foram traçados 3 gráficos, ilustrados nas Figuras 86, 87 e 88. Os 
resultados no tempo de 90 minutos foram os obtidos nos ensaios realizados anteriormente no item 4.4.

Os resultados ilustrados na Figura 86 mostraram-se muito semelhantes ao teste feito no item 4.3, com outra proporção de massa amostra/reagente, mostrando uma tendência exponencial, embora os resultados em $800{ }^{\circ} \mathrm{C}$ tenham apresentado uma tendência linear, variando de cerca de $5 \%$ até $14 \%$ de perda de massa na mufla.

Figura 86 - Perda de massa na mufla ao longo do tempo.

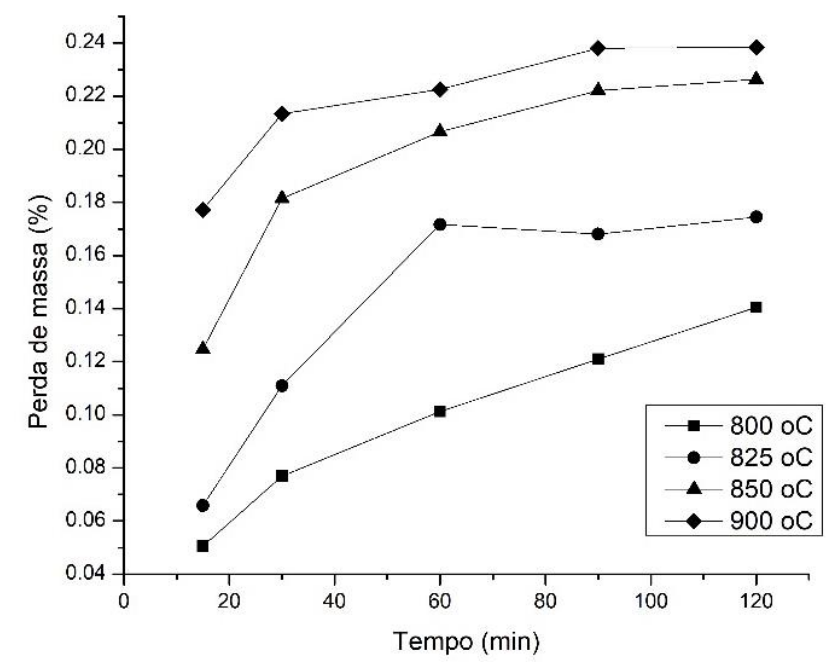

Os aspectos da amostra ao final de cada reação também seguiram o padrão apresentado no item 4.4, com a aparição e intensificação da cor verde/azul com o aumento da temperatura e da quantidade de reagente.

Os resultados da Figura 87 não apresentaram uma tendência clara. Embora em todas as temperaturas, tenha acontecido a diminuição quase linear na quantidade de massa solubilizada nos primeiros 60 minutos, nos minutos seguintes cada temperatura apresentou diferentes tendências.

$\mathrm{O}$ resultado com maior quantidade de massa solubilizada, $60 \%$, foi a $800{ }^{\circ} \mathrm{C}$ e $15 \mathrm{~min}$. Esse resultado é um indicativo de que quanto maior a temperatura e o tempo de reação maiores quantidades de reagente são consumidas formando produtos insolúveis. 
Figura 87 - Perda na solubilização em água, em diferentes tempos e temperaturas de reação na mufla.

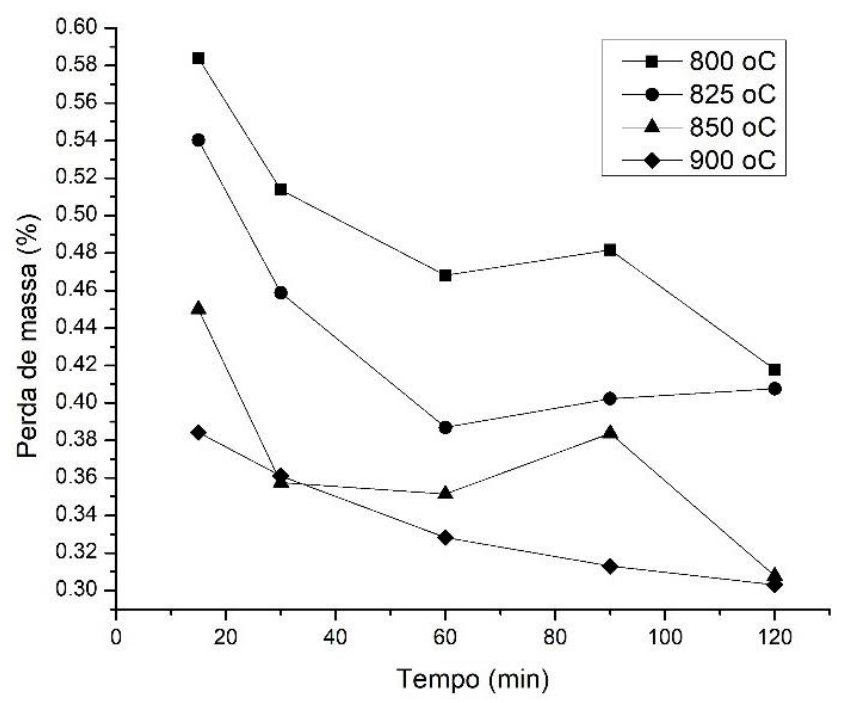

As reações em $800{ }^{\circ} \mathrm{C}, 850{ }^{\circ} \mathrm{C}$ e $900{ }^{\circ} \mathrm{C}$ apresentaram tendência de diminuição ao longo do tempo, tendo, as duas primeiras, apresentado um ligeiro pico no tempo de 90 minutos, sugerindo que nesse tempo houve formação de mais produtos solúveis e ao passar desse tempo os produtos formam novamente complexos insolúveis.

$\mathrm{Na}$ temperatura de $900{ }^{\circ} \mathrm{C}$ formaram-se, quase que linearmente, maiores quantidades de produtos insolúveis ao longo do tempo de reação.

Já a temperatura de $825{ }^{\circ} \mathrm{C}$, o último tempo apresentou comportamento contrário aos demais ensaios, tendo aumentado a quantidade de produtos solúveis com o decorrer do tempo, ou seja, não houve a formação de compostos mais estáveis em 120 minutos. Contudo se observarmos a Figura 87, pode-se notar que, em 90 e 120 minutos a perda de massa na mufla também não segue a tendência dos demais ensaios, o que indica que houve algum fenômeno diferente nesses ensaios.

Por último, na Figura 88 temos o comportamento da perda de massa nas solubilizações em ácido clorídrico. Esses resultados foram os que apresentaram menor padrão comportamental, tendo em apenas as duas primeiras temperaturas se comportado de maneira muito semelhante. 
Figura 88 - Perda na solubilização ácida em diferentes tempos e temperaturas de reação na mufla.

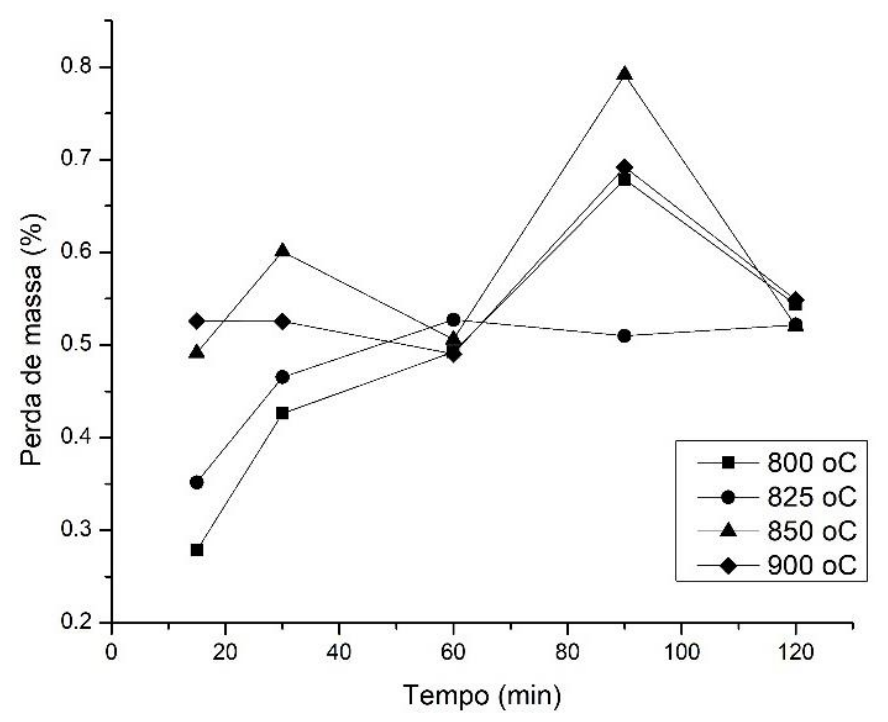

Além disso, como os resultados de 90 minutos foram aproveitados dos ensaios do item 4.4, pode-se notar que há grande discrepância dos resultados, havendo um pico com valores mais de $30 \%$ maiores que o esperado. Isso porque houve uma diferença na concentração da solução ácida utilizada nos dois conjuntos de ensaios. A solução ácida utilizada nessa série de experimentos estava mais diluída que a solução utilizada no conjunto anterior, $1 \%$ e $5 \%$ de concentração, respectivamente.

Isso demonstra que, a quantidade de ácido exerce grande influência na digestão. Gregory (1983) estudou sistemas contendo a reação de óxidos de ferro com $\mathrm{HCl}$ em alta temperatura e descreveu a influência da quantidade de $\mathrm{HCl}$ utilizada na formação de diferentes compostos férricos.

Os resultados indicam que quanto maior a concentração da solução ácida, melhor o desempenho de solubilização e remoção de Fe, contudo o ácido clorídrico concentrado pode reagir com o Ti também, o que não é desejado.

4.6.

Ensaio sobre a influência da concentração da solução ácida

Para avaliar a influência da concentração de ácido, foram feitos ensaios comparativos, utilizando as mesmas condições em todas as etapas do processo e variando apenas a concentração do ácido. 
Também foi avaliado a influência da etapa de solubilização em água, utilizando as mesmas condições de processo, variando apenas a adição/remoção da etapa de lixiviação em água.

Os três ensaios foram comparados e estão ilustrados na Figura 89. Pode-se visualizar claramente que a concentração de ácido tem grande influência na quantidade de massa ao final de todos os processos, a capacidade de solubilização é reduzida quase que pela metade.

Figura 89 - Influência da concentração de ácido e da adição da etapa de solubilização em água, na comparação da perda de massa.

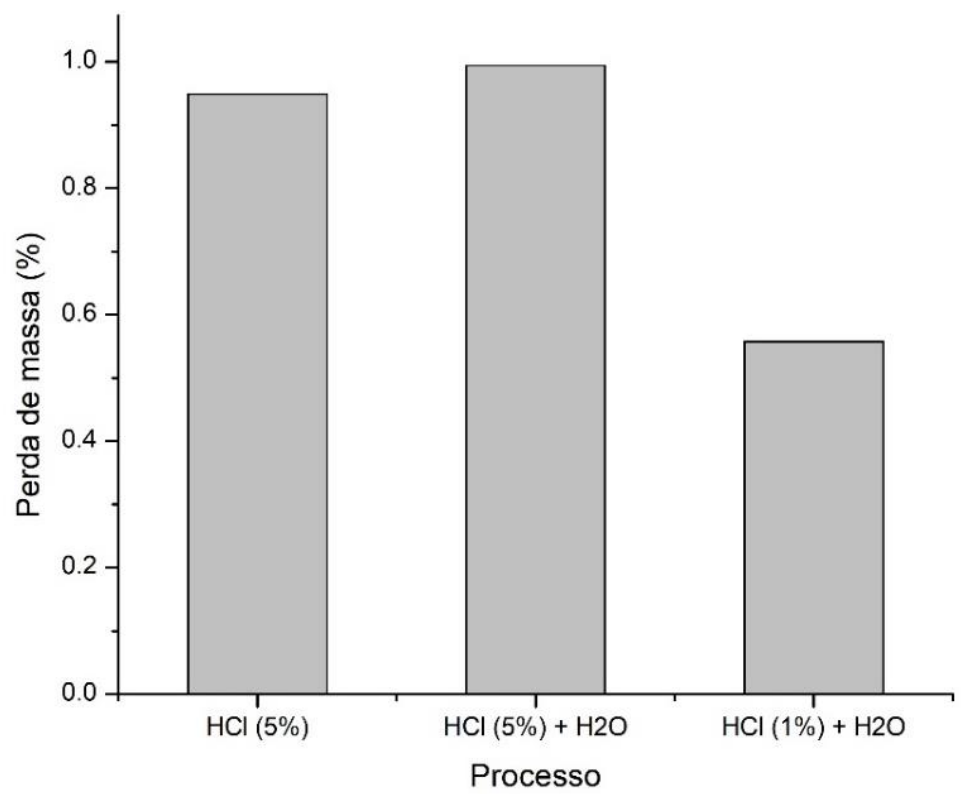

Já quando se compara a influência da etapa em água, nota-se que a diferença do resultado final é muito pequena, contudo o resultado do ensaio no qual a amostra passou por todas as etapas, atingiu resultado ligeiramente melhor.

O parâmetro de temperatura adotado, como já visto, gera muitos produtos insolúveis em água. Existem grande probabilidade de que se os resultados fossem realizados em menor temperatura e concentração de ácido, a diferença entre a adição da etapa em água seria mais evidente.

\section{7.}

\section{Obtenção de um composto rico em $\mathrm{Ti}$}

O material obtido no ensaio 4 e mencionado no item $4.3\left(850{ }^{\circ} \mathrm{C}\right.$, relação de massa 1:1, 90 minutos de digestão) foi submetido a uma lixiviação com $\mathrm{HCl}$ (5\%) 
gerando um produto final de $0,0942 \mathrm{~g}$ e representando menos do que $10 \%$ da massa do resíduo inicial. A evolução da perda de massa deste ensaio (completo) está ilustrada na Figura 90.

Figura 90 - Perda de massa ao longo das etapas do processo de teste.

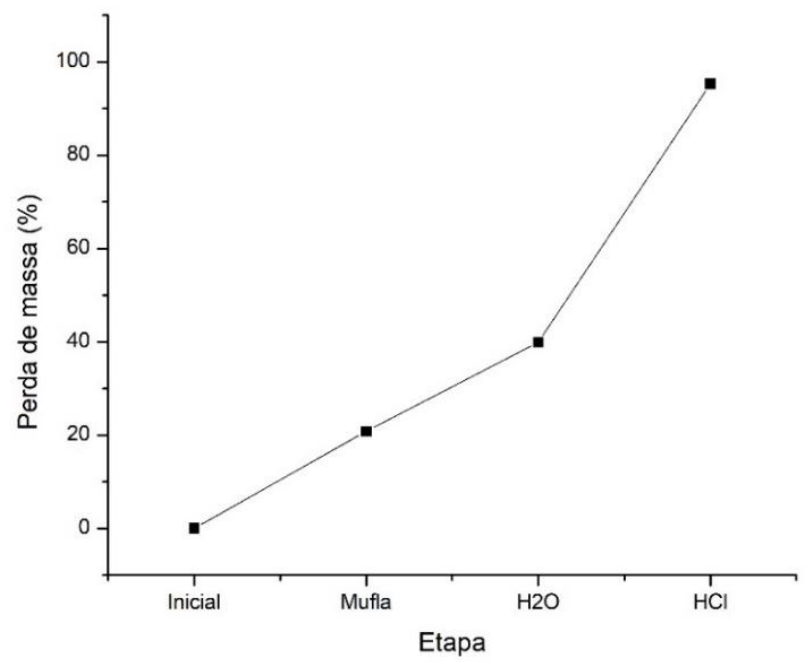

O composto final apresentou característica de um pó muito fino, de cor bege, muito diferente do produto inicial, e dos produtos intermediários, avermelhados devido a presença de óxidos de ferro.

O resultado da caracterização por DR-X está disposto na Figura 91.

Figura 91 - Análise DR-X do teste de solubilização.

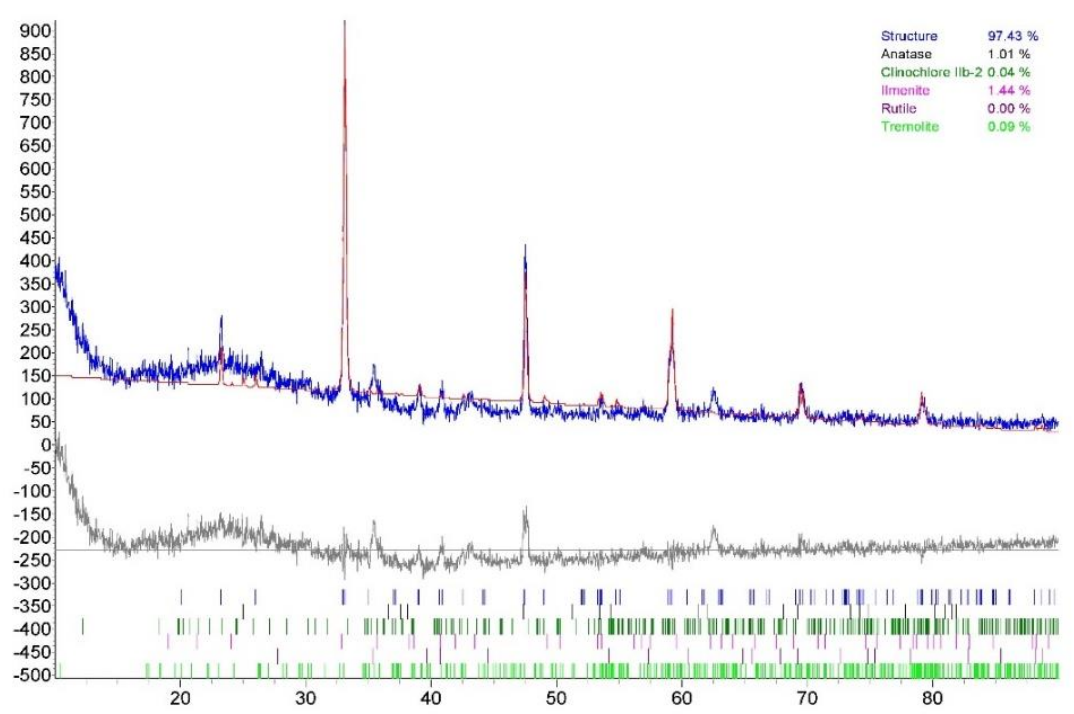


Além de demonstrar uma decomposição robusta das fases iniciais, o ajuste feito através do Topas indicou que o produto formado era, majoritariamente, a perovskita, mesmo utilizando as fichas dos compostos iniciais na definição do ajuste composicional, confirmando uma severa transformação do material de origem. O resultado do ajuste praticamente não apresenta picos remanescentes (Figura 91).

A quantificação das \% de cada fase está ilustrada na Tabela 24. E possível observar que os compostos minerais de tremolita e clinocloro foram completamente consumidos, assim como praticamente todos os minerais de titânio foram convertidos em perovskita.

Tabela 24 - Comparação composicional dos resultados de DR-X do teste de solubilização.

\begin{tabular}{ccc}
\multicolumn{3}{c}{ solubilização. } \\
Mineral & Composição Inicial & Composição Final \\
\hline Rutilo & $2.12 \%$ & $0.00 \%$ \\
Anatásio & $0.32 \%$ & $1.01 \%$ \\
Ilmenita & $23.35 \%$ & $1.44 \%$ \\
Tremolita & $68.47 \%$ & $0.09 \%$ \\
Clinocloro IIb-2 & $5.73 \%$ & $0.04 \%$ \\
Perovskita & - & $97.43 \%$ \\
\hline
\end{tabular}

É válido mencionar que o resultado apresentado pelo DR-X não exclui a possibilidade de terem sido formados produtos amorfos, os quais não podem ser identificados por esse tipo de análise, particularmente, considerando que Baltar e colaboradores (2008) citam a possível característica amorfa, além dos vários graus cristalinos, do leucoxênio.

Ao levar a amostra para análise no MEV TM 30000, obteve-se uma estimativa composicional da amostra, ilustrada da Figura 45. Comparando-a com os resultados iniciais, foi possível perceber um aumento nas concentrações de $\mathrm{Ca}$ e $\mathrm{Ti}$, e ligeiramente de $\mathrm{Si}$, ao mesmo tempo que houve decréscimo de $\mathrm{Fe}, \mathrm{Al}$ e $\mathrm{Mg}$. 
Figura 92 - Diferença de composição entre a amostra como recebida e a final, por análise de EDS.

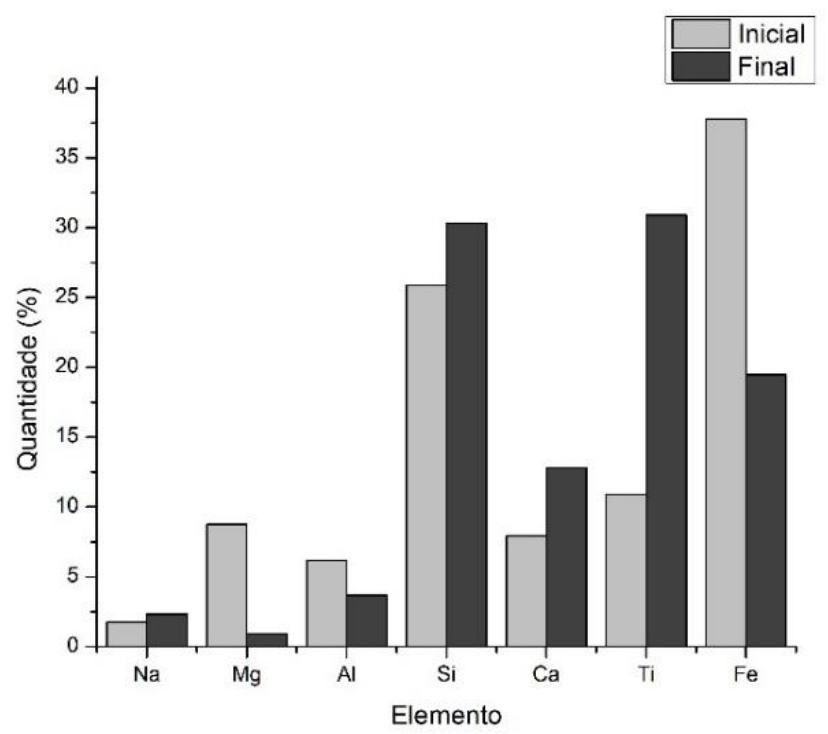

Esse resultado corrobora com o obtido por DR-X, indicando que realmente houve formação de $\mathrm{CaTiO}_{3}$. Ele também sugere que o $\mathrm{Fe}$ e o $\mathrm{Si}$ podem ter formado compostos amorfos.

Visando uma apreciação mais detalhada desta amostra, foi realizada uma comparação da presença do Ti e do Fe em relação ao material como recebido.

Observando a Tabela 25, percebe-se que, diferentemente dos resultados encontrados e expostos no item 4.4.3, o teor de Ti superou o do Fe, indicando que as condições adotadas neste ensaio favorecem a seletividade desejada e, consequentemente, a um aumento na recuperação do Ti.

Tabela 25 - Condições do ensaio e teor de Fe e Ti na amostra final e no material como recebido.

\begin{tabular}{c|c|cc}
\hline \multicolumn{2}{c|}{ Amostra } & \multicolumn{2}{c}{ Composto } \\
\hline Relação mássica & Temperatura & Fe & Ti \\
\hline $1: 1$ & $850{ }^{\circ} \mathrm{C}$ & $14.9 \%$ & $19.4 \%$ \\
\hline \multicolumn{2}{c|}{ Como recebida } & $20-26 \%$ & $6-9 \%$ \\
\hline
\end{tabular}

Apesar do resultado de DR-X ter identificado que a maior parte do material cristalino é constituído de $\mathrm{CaTiO}_{3}$, a presença do Fe suporta a suspeita de que compostos amorfos devem fazer parte do material. Com base nos pesos molares e considerando que todo Ti (massa molar $=48 \mathrm{~g}$ ) está na forma de 
$\mathrm{CaTiO}_{3}$ (massa molar $=136 \mathrm{~g}$ ), aproximadamente $55 \%$ da amostra seria perovskita e os $14.9 \%$ de Fe estariam nos $45 \%$ restantes.

Entende-se, então, que ajustes nas condições operacionais das etapas do processo podem proporcionar incrementos no teor e na recuperação do Ti.

Desta forma, o conjunto de resultados obtidos neste trabalho indica que, embora seja um processo desafiador, há grande potencial do mesmo viabilizar a concentração do titânio como constituinte de algum composto, não necessariamente $\mathrm{TiO}_{2}$, visto este não ter sido ainda detectado. 


\section{5 \\ Conclusões}

Um rejeito gerado a partir do processo de concentração da magnetita foi recebido com indicativo de teores razoáveis de $\mathrm{Ti}$, que motivou a pesquisa atual para recuperação desse conteúdo. A caracterização do material, a partir de diferentes técnicas, indica um conteúdo de Ti em torno de $7 \%$, com altos percentuais de $\mathrm{Fe}(\approx 25 \%)$ e $\mathrm{Si}(\approx 35 \%)$, indicando ainda a formação de minerais complexos com outros elementos, principalmente nas frações mais finas do material.

As considerações termodinâmicas permitiram que fosse selecionado o reagente mais promissor para interação com a amostra (digestão) e posterior separação (solubilização), tendo como principal critério a interação com o Si para facilitar a sua remoção. Dentre os reagentes estudados, o carbonato de sódio apresentou-se como o mais promissor.

Os testes foram realizados buscando encontrar a melhor temperatura, tempo e concentração de reagente para a reação. A digestão apresentou perda de massa exponencial ao longo dos tempos de reação, tendo essa perda de massa se mostrado relativamente estável a partir de 90 minutos, tendo sido esse tempo então o escolhido como mais adequado para os ensaios.

Houve crescente perda de massa com o aumento da temperatura, contudo subsequente diminuição na quantidade de massa que podia ser solubilizada em água e ácido, indicando a formação de compostos complexos e insolúveis, que dificultaram a remoção de $\mathrm{Fe}$ e Si e consequentemente a recuperação do Ti. A temperatura de $850{ }^{\circ} \mathrm{C}$ apresentou os resultados mais promissores de digestão da matéria prima, considerando as solubilizações subsequentes.

Também foi avaliado o efeito da relação resíduo/reagente, na digestão, sendo observado que o aumento da quantidade de reagente acima do estimado como estequiométrico é responsável por aumento nas quantidades solubilizadas, as quais não devem conter titânio. 
Identifica-se uma diminuição das quantidades solubilizadas em água com o decorrer do tempo e um ligeiro aumento nas quantidades solubilizadas em ácido.

Ao final das etapas, em todas as condições estudadas, observou-se perda da massa inicial entre $85 \%$ e $95 \%$. Esse resultado indica que o processo poderia ser considerado excelente, caso o material final fosse constituído, essencialmente, de $\mathrm{TiO}_{2}$, visto que o teor deste na massa inicial é da ordem de $10 \%$.

Os resultados da caracterização da espécie insolúvel final indicam que alterações dos parâmetros reacionais interferem no tipo de compostos formados na digestão e, consequentemente, nos índices de solubilização e na composição do produto. Nota-se que a formação de compostos complexos, por conta da presença significativa de $\mathrm{Fe}$ e $\mathrm{Si}$, dificulta as reações seletivas para obtenção de óxido de titânio, em particular a remoção do Si.

Contudo, constatou-se a possibilidade da amostra final ser constituída prioritariamente de perovskita $\left(\mathrm{CaTiO}_{3}\right)$, a qual se caracteriza por um teor de titânio em torno de 35\%. A amostra final obtida neste trabalho tem cerca de $20 \%$.

Uma apreciação geral dos resultados do trabalho desenvolvido permite supor a viabilidade do processo, o qual requer ainda maiores estudos voltados para o detalhamento das reações envolvidas e otimização das variáveis operacionais. 


\section{6 \\ Sugestões de trabalhos futuros}

Buscando ampliar e eventualmente consolidar as conclusões iniciais obtidas neste trabalho, assim como fortalecer a compreensão dos fenômenos químicos envolvidos, é possível sugerir as seguintes abordagens para os trabalhos futuros:

- Detalhamento das reações envolvidas.

- Estudo mais preciso sobre as possíveis formações de fases complexas e/ou amorfas.

- Identificação das condições adequadas para a remoção seletiva do silício e do ferro.

- Otimização das variáveis operacionais das etapas do processo de forma a aumentar o teor de titânio no material final assim como a sua recuperação. 


\section{7 \\ Referências bibliográficas}

ASSOCIAÇÃO BRASILEIRA DE NORMAS TÉCNICAS. (2004) ABNT NBR 10004: Resíduos Sólidos - Classificação. Rio de Janeiro/RJ

ALKAN, G.; SCHIER, C.; GRONEN, L.; STOPIC, S.; FRIEDRICH, B. A mineralogical assessment on residues after acidic leaching of bauxite residue (red mud) for titanium recovery. Metals, 7: 458, 2017.

ANDREOZZI, G. $\quad$ B.; PACELLA, $\quad$ A.; CORAZ ZARI, I.; TOMATIS, M. Surface reactivity of amphibole asbestos: a comparison between crocidolite and tremolite. Nature Scientific Reports, 7(14696), 2017.

BALTAR, C. A. M.; SAMPAIO, J. A.; ANDRADE, M. C. PINTO, D. C. Titânio: minerais de titânio. IN: Rochas e Minerais Industriais no Brasil: usos e especificações. 2.ed, cap 37. Rio de Janeiro: CETEM/MCTI, 2008.

BROCCHI, E. A. Processos gerais de beneficiamento mineral: curso de Pirometalurgia Extrativa, 4-11 de ago. de 2017. Notas de aula.

CARVAlHO, G. A.; LOPES, J. C.; VICENTE, F. B. Estudo da influência do tratamento térmico na microestrutura do Ti (titânio) grau 2. Revista Ciência e Tecnologia, 20(36): 67-74, 2017.

CHIWESHE, T. T.; PURCELL, W. Chromium isolation from different mineral ores. Proceedings of EMC, 2017.

CIMINELLI, R. R. Titânio: minerais de titânio. IN: Rochas e Minerais Industriais no Brasil: usos e especificações. 2.ed, parte I. Rio de Janeiro: CETEM/MCTI, 2008.

CONSTANTINO, V. R. L.; ARAKI, K.; OLIVEIRA SILVA, D. OLIVEIRA, W. Preparação de compostos de alumínio a partir da bauxita: Considerações sobre alguns aspectos envolvidos em um experimento didático. Quimica Nova, 25(3): 490-498, 2002.

DIDÁTICA SP, disponível em: <https://www.didaticasp.com.br/forno-muflatemperatura-1200c-dimensoes-internas-200x400x200mm>

EZUGWU, E. O.; WANG, Z. M. Titanium alloys and their machinability - a review. Journal of Materials Processing Technology, 68: 262-274, 1997. 
GOLDSTEIN, J. I.; NEWBURY, D. E.; MICHAEL, J. R.; RITCHIE, N. W. M.; SCOTT, J. H. J.; JOY, D. C. Scanning Electron Microscopy and X-Ray Analysis, 4 ed. Springer, New York, 2018.

GREGORY, N. W. Evidence for volatile compounds in the Fe2O3-HCl-H, O-FeCl3 system. Inorganic Chemistry 22: 3750-3754, 1983.

HABASHI, F. Handbook of Extractive Metallurgy. Vol. II. Wiley-VCH, Weinham, 1997

HABASHI, F. Handbook of Extractive Metallurgy. Vol. III. Wiley-VCH, Weinham, 1997

HANSON, B. H. Present and future uses of titanium in engineering. Materials \& Design, 7(6): 301-307, 1986.

HEIDER, M. Vanádio: a nova fronteira da mineração no Brasil. 2015. Disponível em < https://inthemine.com.br/site/vanadio-a-nova-fronteira-damineracao-no-brasil/>

JENA, B. C.; DRESLER, W.; REILLY, I. G. Extraction of titanium, vanadium and iron from titanomagnetite deposits at Pipestone Lake, Manitoba, Canada. Minerals Engineering, 8(1/2): 159-168, 1995.

LARGO RESOURCES, disponível em: <http://www.largoresources.com/ operations/maracas-menchen-mine/default.aspx>, acessado em 16/04/2018.

LASHEEN, T. A. Soda ash roasting of titania slag product from Rosetta ilmenite. Hydrometallurgy, 93: 124-128, 2008.

LUZ, A. B.; LINS, F. A. F. Tratamento de Minérios. 5 ed, cap 1. Rio de Janeiro, CETEM/COPM, 2010.

MANUAL DA QUÍMICA, disponível em: <https://manualdaquimica.uol.com.br/quimica-geral/filtracao.htm>

MIDAT.ORG, disponível em <https://www.mindat.org/element/Vanadium>.

Mineral Commodity Summaries 2018. U.S. Department of Interior. U.S. Geological Survey, January 2018.

MITCHELL, P. S. The use of vanadium. Vanitec, 2011.

MME (Brasil); Beneficiamento de Minérios, Brasília, 2006. Ministério de Minas e Energia - MME.

MONTERO, L. M. C. Obtenção de TiO2 a partir de cloração de uma ilmenita e caracterização sequencial dos materiais envolvidos. Tese de doutorado, Pontifícia Universidade Católica do Rio de Janeiro, 2016.

MOSKALYK, R. R.; ALFANTAZI, A. M. Processing of vanadium a review. Minerals Engineering, 16: 793-805, 2003. 
PARIRENYATWA, S.; ESCUDERO-CASTEJON, L; SANCHEZ-SEGADO, S.; HARA, Y.; JHA, A. Comparative study of alkali roasting and leaching of chromite ores and titaniferous minerals. Elsevier. Hydrometallurgy, 165: 213226, 2016.

Periodic Table - Vanadium, Royal Society of Chemistry, disponível em: <http://www.rsc.org/periodic-table/element/23/vanadium>

ROINE, A. Outokumpu HSC-Chemistry for Windows, 06120-ORC-T, Versão 6.0, Outokumpu Research Oy, Information Service, Pori (Finlândia), 2006.

SIDRAK, Y. L. Dynamic Simulation and Control of the Bayer Process. A Review. Ind. Eng. Chem. Res., 40: 1146-1156, 2001.

Sumário Mineral Brasileiro, vol. 36. Departamento Nacional de Produção Mineral, 2016.

TATHAVADKAR, V.; JHA, A. The effect of moltem sodium titanate and carbonate salt mixture on the alkali roasting of ilmenite and rutile minerals. VII International Conference on Molten Slags Fluxes and Salts, 2004.

TAYLOR, P.R.; SHUEY, S.A.; VIDAL, E.E.; GOMEZ, J.C. Extractive metallurgy of vanadium containing titaniferous magnetite ores: a review, Miner. Metall. Process, 23(2): 80, 2006.

WESP, E. F.; BRODE, W. R. The absorption spectra of ferric compounds. I. The ferric chloride-phenol reaction. J. Am. Chem. Soc. 56:1037-1042.

ZAKI, S. A. Alkali roasting of titania slag for preparation of high grade $\mathbf{T i O}_{2}$. Inorganic Chemistry - An Indian Journal, 12(1), 2017.

ZHANG, W.; ZHU, Z.; CHENG, C. Y. A literature review of titanium metallurgical process. Hydrometallurgy, 108: 177-188, 2011.

ZHU, J.; CAO, L.; WU, Y.; GONG, Y.; LIU, Z.; HOSTER, H. E.; ZHANG, Y.; ZHANG, S.; YANG, S.; YAN, Q.; AJAYAN, P. M.; VAJTAI, R. Building 3D structures of vanadium pentoxide nanosheets and application as electrodes in supercapacitors. Nano Letters, 13: 5408-5413, 2013.

ZIEMNIAK, S. E.; OPALKA, E. P. Titanium(IV) oxide phase stability in alkaline sodium phosphate solutions at elevated temperatures. Chemical Materials, 5: 690-694, 1993. 